\title{
LATIN AMERICAN APPAREL: RECOMMENDATIONS FOR SUCCESSFULLY ENTERING THE TORONTO FASHION MARKET
}

\author{
by \\ Isabel C. Fernandez \\ B.A. Social Media Communication, Universidad Monteavila, 2011
}

\author{
A Major Research Project \\ presented to Ryerson University \\ in partial fulfillment of the \\ requirements for the degree of \\ Master of Arts \\ in the Program of \\ Fashion \\ Toronto, Ontario, Canada, 2015 \\ (C) Isabel C. Fernandez 2015
}




\section{AUTHOR'S DECLARATION FOR ELECTRONIC SUBMISSION OF A MRP}

I hereby declare that I am the sole author of this MRP. This is a true copy of the MRP, including any required final revisions.

I authorize Ryerson University to lend this MRP to other institutions or individuals for the purpose of scholarly research.

I further authorize Ryerson University to reproduce this MRP by photocopying or by other means, in total or in part, at the request of other institutions or individuals for the purpose of scholarly research.

I understand that my MRP may be made electronically available to the public. 


\title{
Abstract \\ LATIN AMERICAN APPAREL: RECOMMENDATIONS FOR SUCCESSFULLY ENTERING THE TORONTO FASHION MARKET
}

\author{
Isabel C. Fernandez \\ Masters of Arts in Fashion, 2015 \\ Ryerson University
}

Dress has played a vital role as a form of expression for different ethnic groups in the diverse city of Toronto. This is a means by which communities have maintained their relationships to their homelands and preserved memories (Brown, 2012). Latin American fashion's recent rise in popularity can be seen most obviously in mass-markets throughout the industrialized West (Root, 2005); however, there are only a few Latin American fashion brands available in Toronto. Hence the researcher investigated and established the process for a Latin American fashion apparel brand to successfully enter the Toronto fashion market. The secondary purpose of this major research project is to provide Canadian residents with the opportunity to experience Latin American cultures through fashion. Even though the countries that make up Latin America have their own characteristic cultural traits, this study had hoped to create a framework of recommendations that will serve as a guideline for entrepreneurs and designers (regardless of their Latin Americancountry of origin) on the successful introduction of Latin American fashion apparel brands into the Toronto fashion market. The approach for this project consisted of the implementation of a mix of a qualitative and quantitative methodology. The conclusions and lessons learned can be applied to any Latin American fashion brand entering the Toronto marketplace. 


\section{Acknowledgements}

It is a pleasure to thank those who made this thesis possible. This major research project would not have been possible without ConstanzaOquendo, whose talent, friendship, and trust was my inspiration to do this research.

I would like to express my deepest gratitude to my thesis advisor, Lucia Dell'Agnese,whose encouragement, patience, advice, guidance, and support, from the initial to the final stages of this MRP, enabled me to develop an understanding of the subject.

The excellent advice and support of my second supervisor, Henry Navarro, has been invaluable on an academic and creative level, for which I am extremely grateful.

I would also like to thank other members of the program's staff like Bernie Murraifor her guidance and direction with issues concerning the Ryerson Ethics Board Protocol. Alison Matthews David whose experience and professionalism encouraged me to do my best along these 2 years, and Mauro Chiera for his patience and guidance before I started my studies at Ryerson, all the way to my last days in the school. These 3 people have my highest respect.

It is an honor for me to have received the Ontario Graduate Scholarship Program (OGS), so I want to thank the committee for giving me their support by believing in my research topic and in myself as the researcher.

I would also like to thank my parents, Maria Isabel Rincon (Mom), Eduardo Fernandez (Dad), Marisabel Fernandez (sister), and Eduardo Fernandez (brother), who have always given me their unequivocal moral and emotional support, for which my mere expression of thanks does not suffice.

I am indebted to many of my colleagues who supported and accompanied me along the Master of Arts in Fashion Program: Darina Granik, Maggie Jonk, Lauren Watson, 
MyriamCouturier, FilomenaGasparro, Mary Dal Cin, Natasha Lamoureux, Kate Bialowas, and Ariana Ho.

I must thank all the interviewees and some of the Canadian fashion industry's top experts, who participated in my research; without their valuable input this would have not been possible:Bob Kirke, Hailey Coleman, Lu Ann Lafrenz, Osmud Rahman, Robert Ott, Wayne Clark, Stephan Caras, and Sebastian Guarin.

I would like to thank my friends Johanny Lopez and Luis Torres for their support and encouragement on every event I attended with the case study.

Last, but by no means least,Nick Hultink, who has been there to encourage me and remains by my side through my stressful and happy times.

Finally, I offer my regards and blessings to all of those who supported me in any respect during the completion of the project. 


\section{Table of Contents}

Page

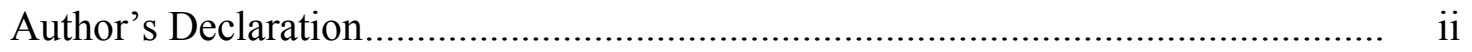

Abstract ......................................................................................... ii

Acknowledgements....................................................................................... iv

List of Tables ........................................................................................ vii

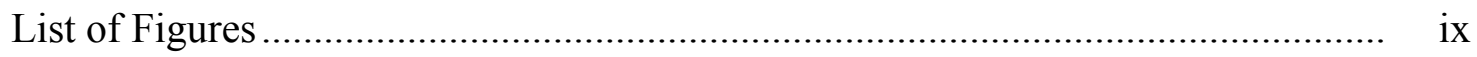

List of Appendices .....................................................................................

CHAPTER ONE: INTRODUCTION .............................................................. 1

Research Question and Goals....................................................................... 3

CHAPTER TWO: LITERATURE REVIEW .................................................... 5

2.1 The Latin American Community in Toronto ................................................ 5

2.2 Latin American Dress ........................................................................... 6

2.2.1 Dress and Identity .......................................................................... 7

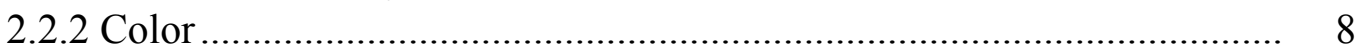

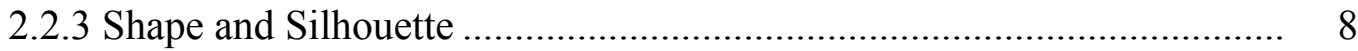

2.2.4 Latin-Inspired Clothing ....................................................................... 9

2.3 Latin American Business Practices............................................................... 10

2.4 Fashion Marketing ………………........................................................ 11

2.5 Importing Into Canada ……………………………............................... 12

CHAPTER THREE: METHODOLOGY AND PROCEDURES …....................... 15

3.1 Design: Strategy and Framework ……………………................................. 15

3.2 Significance of the Chosen Methodology …………………………............. 16

3.3 Advantages and Disadvantages of the Methodology ..................................... 17

3.4 Anticipated Outcomes and Project Significance ........................................... 17

3.5 Ethical Considerations and Dissemination Plan ........................................... 18

CHAPTER FOUR: DISCUSSION, ANALYSIS, AND RESULTS ………........... 20

4.1 Case Study Brands ............................................................................ 20

4.1.1 Luisa Nicholls............................................................................. 20

4.1.2 ConstanzaOquendo Caracas ............................................................... 20

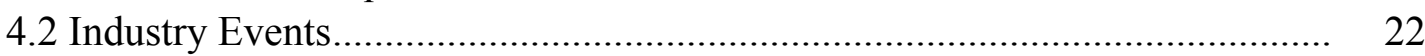

4.2.1. Event Selection........................................................................ 22

4.2.2 Creation of Branding Material.............................................................. 23

4.2.3 Sample Selection ……................................................................ 24

4.2.4 Price Definition ................................................................................ 24

4.2.5 XPosed Tradeshow and Auction ...................................................... 24

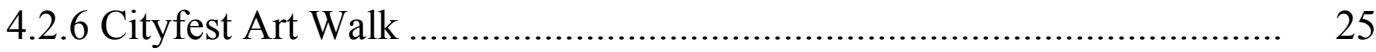

4.2.7 Latin Fashion Week Canada.................................................................... 26

4.2.8 Lessons Learned From Industry Events ............................................... 27 


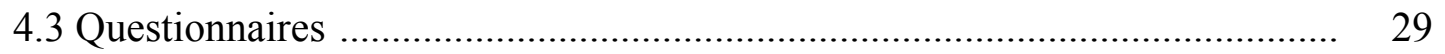

4.3.1 Questionnaire Problems Encountered .................................................. 29

4.3.2 Questionnaire Analysis and Results ................................................... $\quad 30$

4.4 Interviews and Results ............................................................................ 34

4.4.1 The Latin American Community in Toronto / Latin American Dress .... 34

4.4.2 Business and Latin American Business Practices .................................. 37

4.4.3 The Toronto Fashion Industry ……………....................................... $\quad 39$

4.4.3.1 Toronto Fashion Calendar and Seasons......................................... 40

4.4.3.2 What the Toronto Fashion Consumer Seeks .................................. 42

4.4.3.3 Sales Representatives, Show Rooms, and Retailers in Toronto ...... 42

4.4.3.4 Representing and Importing International Brands......................... 43

4.4.3.5 Latin American Designers in Canada ............................................. 44

4.4.4 Fashion Marketing ……………….................................................. 45

4.4.4.1 The Product............................................................................. 46

4.4.4.1.1 Manufacturing in Toronto .................................................... 46

4.4.4.1.2 Product Design................................................................... 48

4.4.4.1.3 Sizing System in Canada ......................................................... 49

4.4.4.1.4 Garment Tags................................................................... 51

4.4.4.1.5 Collection Samples and Orders............................................. 52

4.4.4.1.6 Pricing ............................................................................ 54

4.4.4.1.7 LookBook ………………………………................... 54

4.4.5 Being an Entrepreneur in the Fashion Industry ..................................... 55

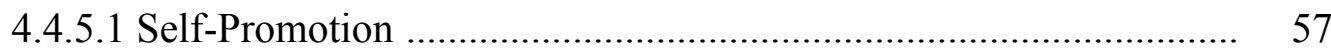

4.4.5.2 Resources for New Designers in Toronto..................................... 58

4.4.5.3 Marketing a Latin American Brand in Toronto .............................. 59

4.4.5.4 Potential Stores and Retailers to target........................................... 61

4.4.5.5 Working with a Show Room and Sales Representative .................. 64

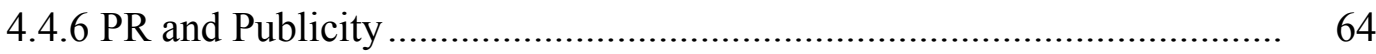

4.4.6.1 Trade Shows and Events to Attend............................................... 64

4.4.6.2 Networking .............................................................................. 66

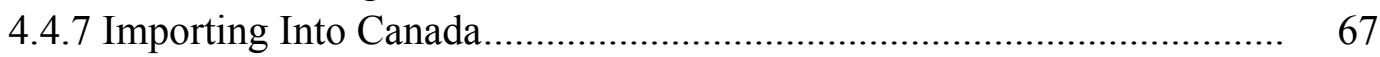

4.4.8 ConstanzaOquendo......................................................................... 68

4.5 Summary of Key Findings: Recommendations for Latin American

Apparel to Successfully Enter the Toronto Fashion Market ........................... $\quad 70$

4.6 Recommendations for the Brand ConstanzaOquendo ................................... $\quad 72$

4.7 Limitations and Recommendations for Future Research ............................... 75

CHAPTER FIVE: CONCLUSION ...............................................................

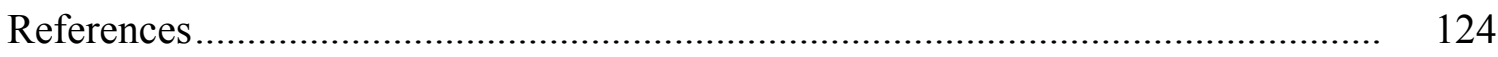




\section{List of Tables}

$\begin{array}{lll}\text { Table } & \text { Page }\end{array}$

1.Countries in the FTA With Canada ..................................................................... 13 


\section{List of Figures}

Figure

Page

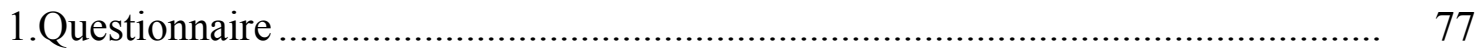

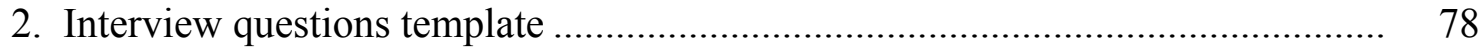

3. Look Book ........................................................................................... 79

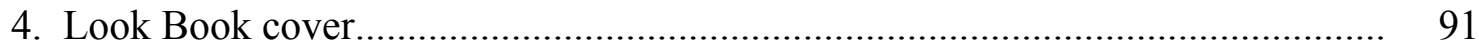

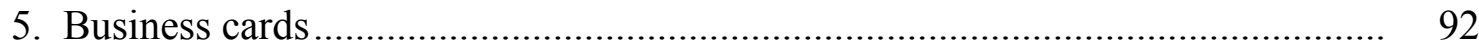

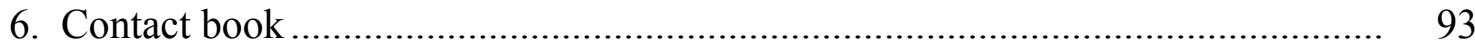

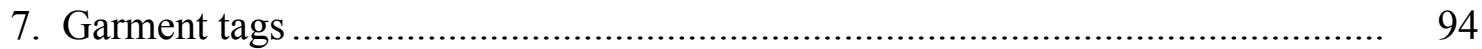

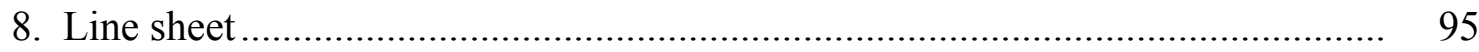

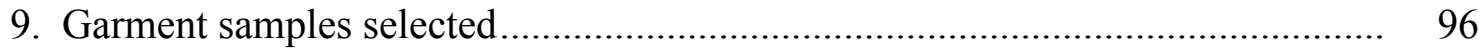

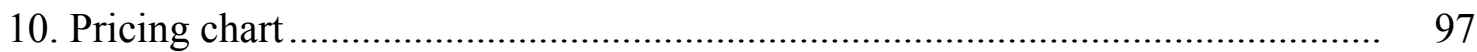

11.XPosed pictures of ConstanzaOquendo's stand .............................................. 98

12. C.O.'s "thank you" email sent after the XPosed event ..................................... 99

13.Cityfest Art Walk pictures of C.O.'s stand ...................................................... 100

14. Latin fashion week pre-launch party........................................................... 101

15. Latin fashion runway show .................................................................... 102

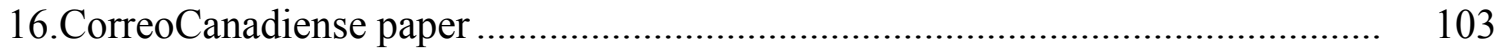

17. Fashion Studio Magazine.............................................................................. 104

18. The Lady-Like-Leopard.............................................................................. 105

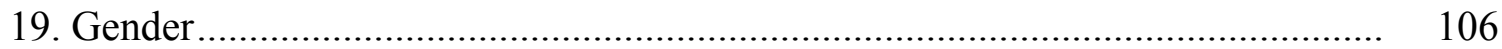

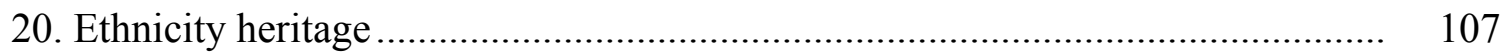

21.Culture identity ................................................................................. 108

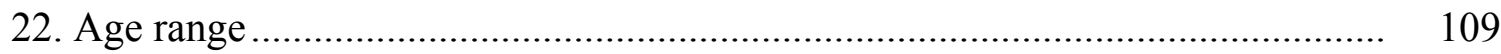

23. Education qualification ........................................................................... 110

24. Clothing expenditure............................................................................. 111

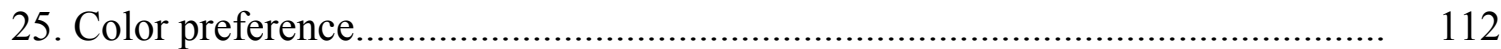

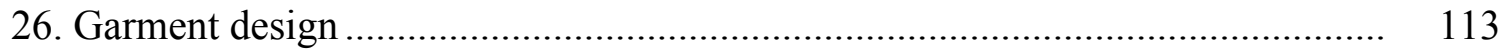

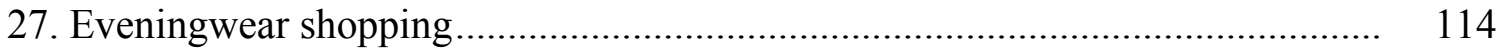

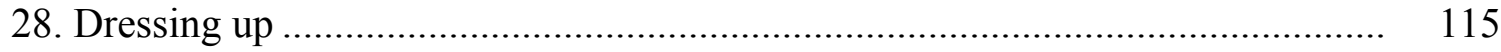

29. Buying eveningwear ................................................................................... 116

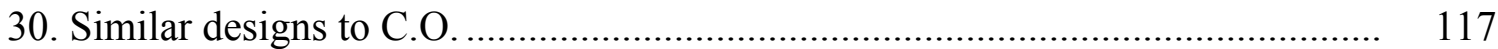

31. To wear C.O........................................................................................ 117

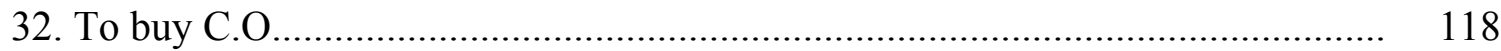

33. Reasons to buy C.O.................................................................................. 119

34. Reasons for not buying C.O.................................................................. 120

35. ConstanzaOquendo's customer description................................................. 120

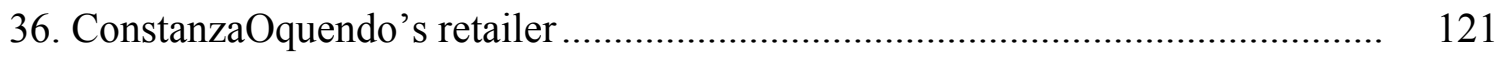

37. ConstanzaOquendo's boutique location in Toronto ....................................... 122

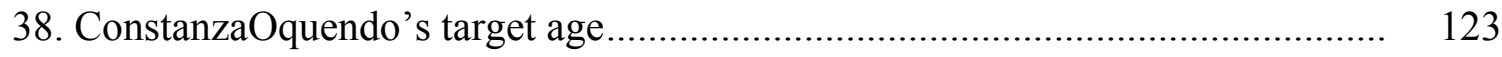




\section{List of Appendices}

$\begin{array}{ll}\text { Appendix } & \text { Page }\end{array}$

1. Questionnaire Template ................................................................................ 77

2. Interview Questions Template ............................................................... 78

3. ConstanzaOquendo's Look Book …………………...................................... 79

4. ConstanzaOquendo'sPrinted Look Book......................................................... 91

5. ConstanzaOquendo Business Cards................................................................. 92

6. ConstanzaOquendo's Contact Book ………………........................................... 93

7. ConstanzaOquendo's Garment Tags............................................................ 94

8. ConstanzaOquendo's Line Sheet ..................................................................... 95

9. ConstanzaOquendo's Samples Selected .......................................................... 96

10. ConstanzaOquendo's Pricing Chart ................................................................ 97

11. XPosed pictures of ConstanzaOquendo's Stand ................................................ 98

12. ConstanzaOquendo's "Thank You" Email …………........................................ 99

13. ConstanzaOquendo'sStand at Cityfest Art Walk .............................................. 100

14. Latin Fashion Week Pre-launch Party …………........................................... 101

15. Latin Fashion Runway Show …………………....................................... 102

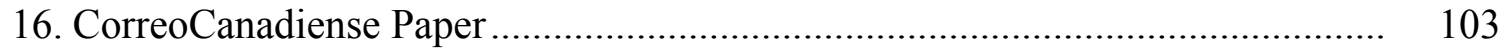

17. Questionnaire Results .................................................................................. 106 


\section{CHAPTER ONE: INTRODUCTION}

Cultural diversity has become a defining feature of the city of Toronto and a fundamental part of its identity. People from all over the world have made this city their home and have contributed greatly to its growth and development (Miedema\&Brown, 2012). The Latin American community constitutes one of the top five visible minority groups in the city (City of Toronto, 2015). For the purpose of this research, as indicated in the Encyclopædia Britannica, Latin America is understood to consist of the "entire continent of South America in addition to Mexico, Central America, and the islands of the Caribbean, whose inhabitants speak a Romance language" (as cited in Lockhart, 2014, para. 2).

Along with artistic expressions, fashion has enabled these immigrants to find common bonds during their initial experience of settling in a new city (Brown, 2012). These creative expressions have had a profound effect on Toronto, awakening the interest of citizens who are not of Latin American origin.

It is interesting to understand how Latin Americans express their origins throughmultiple creative mediums and how dress plays a vital role in the process of identity construction for different ethnic groups. "Latin American fashion's popularity can be seen mostly in mass-market products throughout the industrialized West" (Root, 2005, p. X). However, despite its growing Latin American population, it is difficult to find stores in Toronto that sell garments that have a Latin American heritage.

The data collected proved that there are only a few Latin American brands available to fashion lovers in Toronto, even though Canadians of Latin American originmake up one of the largest non-European ethnic groups in Canada (Schugurensky\&Ginieniewicz, 2007), representing $2.6 \%$ of the total Toronto population in 2006 (City of Toronto, 2015). 
Veroni's(2010) theory claims that groups who are as internally diverse as this one often face challenges in their host society, particularly with regards to community building and participation:

In this case, the first challenge has been of a practical nature - how to meet the group's diverse needs ... and the second challenge is the complex question of building community, a process which is important for minority groups to be recognized under Canada's official policy of multiculturalism. (p. 188)

After some investigation was conducted, the researcher noticed that there are some gaps in literature represented by the small amount of research conducted on the intercultural analysis of fashion marketing, which includes Latin American countries. In addition, there are few statistics based on the actual population of this ethnic group in Toronto. Conversely, there is now much evidence to support the hypothesis that providing Latin American styled garments is a niche of opportunity in the Canadian fashion industry. This is especially so considering that in 1980sand 1990s, large numbers of immigrants from Central and South America dramatically increased that community in Toronto and "made the Spanish language one of the top 10 'mother tongues' in the city" (Brown, 2012, para. 1). This big wave of immigration was due to a series of military coups in Central and South America which led to intense domestic conflict, making people leave their homelands looking for safety and good opportunities:

Many of those who came to Toronto as a result of political destabilization did not plan to live in the city for the long term, hoping to return home once the problems had subsided. But the situation did not improve and as time passed and children arrived, they became rooted in Canada. (Brown, 2012, para. 8) 
This has provided a considerable target of opportunity for Latin American fashion brands wanting to enter this market. The researcher believes it is very important to satisfy the needs of this diverse group because fashion importers have not fulfilled the style necessities that this specific segment of the Canadian population requires. It is important to satisfy this need because it will represent a great medium of social participation and community building for this group.

With this project the researcher hopes to provide both a business option and a social empowerment opportunity that supports diversity by facilitating participation of Latin American cultures within Toronto's multicultural fabric. Furthermore, the audience of this project is Latin American fashion entrepreneurs, importers and designers, which want to enter the Canadian fashion market for the first time.

\section{Research Question and Goals}

The study sought to answer the following research question: What does a Latin American fashion apparel brand need to consider, in order to successfully enter the Toronto fashion market?The primary goal of this project was to identify a set of recommendations for a Latin American fashion apparel brand to take into consideration in order to be successful in entering the Toronto fashion market. Even though all Latin American countries have their own characteristic cultural traits, this study hoped to serve as a general guideline for entrepreneurs and designers, independently of which country in Latin America they come from.

The secondary goal was to provide the Latin American population of Toronto with the possibility to maintain their own culture through fashion.

The tertiary goal was to provide the rest of the Torontonians with an option to be exposed to Latin American cultures in a way other than food and music, which is something they can already experience in Toronto. 
In order to reach the aforementioned goals, a mix of a qualitative and quantitative methodology was implemented for this project. The above-mentioned goals were achieved by:

- Investigating the reception of a Latin American fashion brand by the Toronto fashion industry through a case study.

- Obtaining direct feedback on the brand's style, design, and price through questionnaires distributed at local fashion industry events.

- Learning from the experiences of the Canadian fashion industry's experts through interviews, where they shared insights on what is currently happening locally, hence future importers are prevented from making related mistakes in the future.

- Analyzing the important legal and logistical aspects to take into consideration when planning to export a Latin American fashion brand into the Toronto fashion market. 


\section{CHAPTER TWO: LITERATURE REVIEW}

For the purpose of this study, the researcher identified five major topics that were important to investigate. These topics include: the Latin American Community in Toronto; Latin American dress;importing into Canada; Latin American business practices; and fashion marketing.

\subsection{The Latin American Community in Toronto}

For the purpose of this research, and as previously indicated in the Encyclopædia Britannica, "Latin America is understood to consist of the entire continent of South America in addition to Mexico, Central America, and the islands of the Caribbean whose inhabitants speak a Romance language" (as cited in Lockhart, 2014, para. X). The City of Toronto's (2015) web page states that this city is heralded as one of the most multicultural cities in the world, where "half of its population $(1,237,720)$ was born outside of Canada, up from 48\% in 1996" (para. X). As Fernando Valladares stated, today "we don't need to leave Toronto to visit the world" (as cited in Kaitlin, 2012, para. X). Statistics Canada (2003) shows that between 1996 and 2001, the number of Canadians of Latin American origin rose by 32\%, reaching 520,000 habitants, with $29 \%$ of them concentrated in the city of Toronto" (para. X). Girard and Smith (2013) used the 2006 Census of Canada to conclude that the number of Canadians of Latin American origin grew to over 527,000 , representing $3.49 \%$ of the total Canadian population (p. 226). Schugurensky and Ginieniewicz’s (2007) article titled “The Latin American Community in Canada: Some Challenges Ahead" estimates that the Canadian population of Latin American origin would soon reach one million. These studies prove that there has been previous research done on the scale of the Latin American community in Canada, but as the most recent information is from 2007, there is a great gap of current statistics. 
While it is not known what the real figure is today, data gathered by the magazine Factor Hispano states that Latin Americans are now the third largest ethnic minority in Canada, where more than half of these immigrants reside in Toronto and Montreal. (Schugurensky\&Ginieniewicz, 2007, para. X)

The exponential growth of this immigrant community in the Toronto area can only mean a market expansion opportunity for Latin American fashion brands. This data contributes to the understanding of the importance of this project in terms of promoting cultural diversity in Toronto.

\subsection{Latin American Dress}

Given the rising prevalence of Latin American culture in Canada, it is important to obtain a general idea of what is considered Latin American fashion. Renee White (2002) comments on how "Latin fashion could call to mind such stereotypes as black lace and colorful ruffles, but Latin American fashion today draws from Latin American culture in a variety of subtle and sophisticated ways" (p. 19).As Samantha Critchell (2002) reports in the Los Angeles Times, It takes more than a map to understand Latin American fashion. It is about geography, culture and even deeply held religious beliefs. And if it is a commercial success, it is also about capturing the attention of New York, Milan and Paris fashion insiders who are literally a world away from where the design was born. (para. X)

From the tango-inspired dress of Argentina and guerrilla chic in downtown Buenos Aires, to swimwear on Copacabana Beach in Brazil, and the rainbows that adorn indigenous women in Peru, Regina Root explores Latin American fashion as a source of inspiration for designers throughout the world. This book was very useful for the purpose of this research, as Renne White (2002) mentions that the influence of these cultures has been significant throughout the 20th 
century: "Though Latin (American) culture has risen in popularity in recent years, little attention has been paid to the contribution of Latin (American) fashion designers" (para. X). White writes an article for the NewYork Amsterdam News on how Latin American designers began to gain prominence in the 1950 s and 1960s and comments on an exhibition that took place on March 5, 2002, at the Museum at the Fashion Institute of Technology (FIT), titled "Latin American Fashion: Exploring Identities on the New York Runway," curated by Kimberly Randall, which according to White was the first to highlight the role of Latin American fashion designers in the North American fashion industry. This exhibition featured more than 80 garments by 24 designers, including Oscar de la Renta, Carolina Herrera, Adolfo, and Mark Montano.

\subsubsection{Dress and Identity}

Dress has played a vital role in the process of identity construction of the different ethnic and cultural Latin American groups (Melendez, 1995), hence it is very important for this ethnic group to keep their traditions alive even when they are abroad. According to Project Runway judge Nina Garcia, Latin (American) women spend a lot of money in beauty and in fashion because it is in their culture (Valladares, 2013).

In the book The Latin American Fashion Reader, Root (2005) explores the use of dress as "part of a "social experience' to communicate specific ethnicity, values, beliefs, practices, and economic status of many groups that form the Latin America's cultural map" (p. X). The designer and writer Mercedes Valladares(2013) states that Penelope Cruz, Shakira, Jennifer Lopez, and Sofia Vergara are just a few Latin (American) celebrities projecting an exotic style, fashion sense, and sex appeal. These prominent women have successfully merged their Latin American roots with their fashion identity. Though Latin American cultures vary in tradition, religious beliefs, and dialects, Latin American women continue to merge their natural femininity and sense of fashion with their cultural roots. These Latin American actresses are part of the norm on television, film, and commercials; their exotic features have influenced a host of designers worldwide (Valladares, 2013). 
Root (2005) mentioned that a unifying characteristic of inspiration of Latin American dress is "Dance" where "the vast array of dances associated with Latin America, from the samba to the Paso Doble, are equally connected to traditional Latin costume" (p. X). There seems to be a direct correlation of how the body moves and how the garments move with it (Root, 2005). Root (2005) concludes by describing Latin American fashion as a distinct indicator of their cultural identity, mentioning that their garments have a unique style with elaborate fabrics.

\subsubsection{Color}

Latin women's skin tones vary, influencing fashion colors and patterns. Since stereotypes exist, carnival ruffles and brightly colored tropical prints, appropriate for festival settings, do not translate very well into the everyday wardrobe of the Latin American woman. According to Randall, 'there's a myth that everything Latin is in hot tropical colors, but they don't exist in everyday fashion" (as cited in Critchell, 2002, para. X). Valladares (2013) comments that a great tendency is to pair soft feminine shades with splashes of vivid color accentuating women's exotic features: "For instance, basic background prints made of brown and cream instantly transform with splashes of orange or red" (para. X). Randall notes that although the clothing of Carnaval and celebrations is what is seen most often in the United States, that is not what the woman who is shopping in Mexico City or Sao Paulo is wearing (as cited in Critchell, 2002).

\subsubsection{Shape and Silhouette}

Critchell (2002) comments, "the emphasis is on cut, not printed fabrics" (para. X). "Since Latin women's body shapes are curvaceous in nature, designers have accentuated these features in the drape, cut and silhouette shape" highlighting instead of masking natural curves. "Retailers have also taken notice by styling store mannequins and displays with these trends as part of the visual merchandising story" (Valladares, 2013, para. X). Today we see how designers have 
reinterpreted silhouettes with Latin women's body shapes in mind to appeal to this growing demographic.

White (2002) describes Latin American fashion as stunning and provocative, and mentions that Latin American designers share certain unifying ideas in the "Architecture" of the dress as "an appreciation of the structural properties of fabric" (p. 19). Cathy Maguire, co-curator of the FIT exhibition notes that "Venezuelan designer Angel Sanchez, whose work is included in the exhibit, is a trained architect" (as cited in Critchell, 2002, para. X).

\subsubsection{Latin-Inspired Clothing}

It is possible to conclude that Latin American fashion designers are very influenced by cultural symbolism and their country's history. But Root (DATE) also mentions the ways in which outside forces such as modernization, tourism, and globalization have affected the nature of fashion creation and consumption in Latin America, in both positives and negative ways, stating that "some designers are heavily influenced by their heritage, others by their travels, and others look to their stylish relatives" (Valladares, 2013, para. X).

According to Oscar de la Renta, who was born in the Dominican Republic and has been one of New York's most famous names in fashion, there is at least one consistency in Latin American style - that the Latin American woman is one who has always felt strongly about her femininity — that has influenced his designs (as cited in Critchell, 2002)."Latin American women - they love to be flirtatious in a slinky dress, going dancing" and the first and foremost thing about their shoes is that "they have to be sexy," says shoe designer Edmundo Castillo (as cited in Critchell, 2002, para. X), who was born and raised in Puerto Rico and worked for Donna Karan before launching his own line in 1999. Castillo and de la Renta stated that their childhoods, when they were surrounded by several sisters, gave them insight into what Latin American 
women — aswell as women all over the world — really want in their wardrobes; de la Renta says his collections now are mostly seen through his "international eye," which was trained while he worked in both Spain and Paris, but his Latin American heritage is evident in his use of color and light (as cited in Critchell, 2002).

Collectively these texts demonstrate that while fashion remains a signifier of identity, Latin American fashion is also in a state of constant change in response to the interactions between culture, designers, and consumers, both native and foreign.

\subsection{Latin American Business Practices}

In order to understand how business is done within Latin American countries, it is important to get to know these countries' economy, political background, historical influences, and what their traditions are when it comes to negotiating and finalizing contract agreements. In their book Can Latin American Firms Compete?, Robert Grosse and Luiz F. Mesquita(2007) discuss the unique challenges that Latin American countries face, where the economic development works as a roller-coaster with booms and busts. The book descrines how Latin American firms have survived the underdeveloped and unstable institutional environments. In their research, the authors indicate abundant evidence demonstrating the unique strategies that successful Latin American firms have followed to "cope not only with the broad scope and quickness of economic and political changes in the region but also with the challenges of going global” (Grosse \&Mesquita, 2007, p. X).

When it comes to Latin American countries, it is also important to look at their business ethics, hence two texts were used for this topic: Arruda's (1997) "Business Ethics in Latin America"and Tsalikis, Seaton, and Sheperd's (2014) "Business Ethics Index: Latin America." Both texts mention that corruption and impunity are serious moral diseases in Latin America, 
where low ethical standards in politics have had deep impact on individuals, organizations, and economic systems. Conspicuous consumption, materialism, and selfishness are the words often used by the authors describing the attitudes and principles of the Latin American population. Arruda also states that this can be the result of a long period of dictatorship in most of these countries.

\subsection{Fashion Marketing}

Harriet Posner's (2011) book Marketing Fashion was vital to this research as she offers a contemporary guide to fundamental principles of marketing theory and branding practice. She explains concepts, which are applied to the evolving context of today's global fashion and retail industry. Posner mentions that Fashion can be divided into two overarching levels: (a) Haute Couture and couture, and (b) Ready-to-wear. Ready-to-wear fashion is available at all levels of the market including: high-end fashion; middle market; mass market; and value fashion (Posner, 2011).

Another important text that contributes to the development and understanding of the topic of fashion marketing Ko and Megehee's(2012) research titled "Fashion Marketing of Luxury Brands" which is different from Posner's book because it summarizes 15 articles related to fashion marketing of luxury brands. This research studies luxury consumer behavior in order to understand luxury brand management and highlights the idea that luxury brand managers need to develop a coherent and integrated long-term global strategy, which takes into account countryspecific requirements. Ko and Megehee conclude that

consumers in different countries have different perceptions of what constitutes a luxury product and use different criteria (i.e., price, guarantee, design, and/or advertising) in making purchase decisions. The impact of country-of-origin on purchase decisions 
appears to be weaker than the influence of a Brand. (p. X)

This research is relevant to this study because every entrepreneur in the fashion industry should be able to differentiate a luxury brand from the rest and it highlights key things that entrepreneurs, in this specific segment of the market (luxury brands), need to consider.

Upon completion of this literature review, it was possible to conclude that further study is necessary in the area of intercultural analysis of fashion marketing including data from Latin American countries. The other areas covered in this literaturereview provided enough information for the purpose of this study.

\subsection{Importing Into Canada}

Because this research was based on the importation of Latin-American fashion apparel brands into Canada it was necessary to get to know the Toronto fashion industry. Conservative MPP Christine Elliott notes that fashion is big business and is also a cultural industry: "There are over 50,000 people employed by the fashion industry in Ontario, and that number is growing"(as cited in Maddeaux, 2014, para. X). But Canadian designers face a unique challenge when it comes to securing funding, in that there is practically none available to support local manufacturers. "The few fashion competitions that take place here offer laughably small cash prizes or none at all” (Maddeaux, 2014, para. X). According to Sabrina Maddeaux, fashion designers in Ontario do not qualify for grant money from the Ontario Arts Council because the area of fashion is not considered a cultural industry by either the federal or provincial government. FAT (Toronto's other long-standing fashion week, Arts \& Fashion Week) founder VanjaVasic considers strange that in Toronto fashion isn't considered a cultural industry "when it is such a huge part of contemporary culture"; she mentions that the designers, who attend FAT, 
think about fashion as an art form exploring issues of "sexuality, politics and the environment through clothing” (as cited in Maddeaux, 2014, para. X).

After taking a look at Toronto's fashion industry it was also of great importance to become familiar with the Canadian importation and exportation policies that apply to Latin American countries. Table 1 lists the Latin American countries that participate in free trade agreement (FTA) with Canada.

Table 1

Countries in the FTA With Canada

\begin{tabular}{lc}
\hline Country & Date in which the FTA was brought into force \\
\hline Honduras & 01 -Oct-14 \\
Panama & 01 -Apr-13 \\
Colombia & 15-Aug-11 \\
Peru & 01 -Aug-09 \\
Costa Rica & $01-$ Nov-02 \\
Chile & 05-Jul-97 \\
\hline
\end{tabular}

Source: Foreign Affairs, Trade and Development Canada (2013).

All this data is provided on the Foreign Affairs, Trade and Development Canada (FATDC) website and was of great use for this research because inclusion in the FTA enables a firm to compete on a more even playing field with local firms in the FTA partner country (FATDC, 2013). Under the FTA, a range of Canadian goods, as well as goods being imported, benefit from the reduction or elimination of tariff and non-tariff barriers to trade, such as quotas or technical barriers (FATDC, 2013). This was very important for this research because the fashion industry 
is influenced by the FTAs, and this can affect the competitiveness of any brand that wants to enter the Canadian fashion industry. 


\section{CHAPTER THREE: METHODOLOGY AND PROCEDURES}

\subsection{Design: Strategy and Framework}

The methodology best suited for this project was a qualitative method, as the phenomenon under investigation was not quantifiable and little investigation has been done in this area. The qualitative research was accompanied by a literature review, which provided a background to conduct this study (Klopper, 2008).

\section{Data collection: instruments and procedures}

Four instruments were chosen to collect data for this study:

1. Twocase studies pertaining to fashion brands imported into Canada: the Venezuelan highend fashion brand "Constanza Oquendo" and the Colombian fashion brand "Luisa Nicholls.'The goal was for these brands to serve as an example of the different steps a brand should go through in order to enter the Toronto fashion market.

2. Participation inindustry events,such as: a trade show, a sample sale, and a runway presentation, where the case study brands would be showcased. The three events in Toronto that were selected to participate in were:

- The "Fashion's Future XPosed" show on June 24-25, 2014 at the Brunswick House in Toronto.

- The "Cityfest Art Walk" on August 23, 2014, at Canoe Landing Park at ConCord City Place in Toronto.

- The "Latin Fashion Week"on October 25-27, 2014 at the Spoke Club, in Toronto.

3. A questionnaire thatwas handed out during the above-mentioned events(see Figure 1).

4. Interviews (see Figure 2) with some of the Canadian fashion industry's top experts who had different backgrounds, and could provide knowledge to the research. The selected 
interviewees were: Bob Kirke (Exec. Dir., Canadian Apparel Federation); Hailey

Coleman (Importer at TTBLUES); Lu Ann Lafrenz (Fashion Entrepreneurship professor, Ryerson University);Osmud Rahman (Consumer Behavior, Cross-Cultural Marketing professor, Ryerson University); Robert Ott(Vice President Product Development, Jones NY, and Chair, School of Fashion, Ryerson University); Wayne Clark (Canadianfashion designer); Stephan Caras (Greek fashion designer established in Toronto); Sebastian Guarin (Colombianfashiondesigner established in Toronto); Lucia Dell'Agnese (Sizing expert, professor Ryerson University); Eduardo Fernandez (International Business expert, professor at University of Toronto).

\subsection{Significance of the Chosen Methodology}

In order to truly understand what Latin American apparel brands need to successfully enter the Toronto fashion market, the researcher believed that there was no better way to do this than to experience it herself through a case study. According to Robert Yin (2013), case studies are the preferred strategy when the focus is on a real life, contemporary context. However while the case study method is very useful to define causal inferences, validity and generalization are challenging aspects when designing a case study evaluation, "especially when the number of cases being studied is highly limited (even limited to a single case)" (Yin, 2013, p. X).

Questionnaires are extremely helpful for collecting quantitative information from a large number of people attending a big event (Posner, 2011), hence along with the interviews, they were chosen to expand the data and complement the case studies with up-to-date information. Questions were prepared beforehandto conduct semi-structured interviewsin which respondents were able to share their opinions and views, leaving room for further discussion and reflection. 


\subsection{Advantages and Disadvantages of the Methodology}

Some of the disadvantages of the designed methodology were:

- Some trade shows requiredan application and a high monetary participation fee.

- The demographic that attended the trade shows did not buy any samples from the brand.

- One of the selected fashion brands(Luisa Nicholls)did not collaborate with the research. This represented a risk from the beginning of the study.

- Not all industry professionals were available for an interview.

On the other hand, the advantages of this research method were:

- The attendance of sample sales and trade shows offeredimmediate feedback in respect to the acceptance of the case study brandConstanzaOquendoby the fashion consumers in Toronto, through the questionnaire.

- Interviews provided first-hand input from professionals in the Toronto's fashion industry.

\subsection{Anticipated Outcomes and Project Significance}

It was anticipated that the results obtained would be applicable to other brands from Latin American countries, even though the case studies selected came from only two countries in Latin America.

At the outset of this study, it was thought that the case study brands, among others, would provide some Latin American fashion options to Toronto citizens, with the hope that in the future, those same brands would be introduced to additional Canadian provinces that have a significant Latin American population such as Quebec, British Columbia, and Alberta, contributing to the growth in diversity of the Toronto fashion market (Statistics Canada, 2007). This project was worthy of academic inquiry because fashion plays a big role in cultural identity and "the challenge for groups that are internally diverse is to achieve adequate levels of representation" 
(Veronis, 2010, p. 188). Hence, this project symbolized both a business opportunity and a social empowerment opportunity that supported diversity by facilitating participation of Latin American Cultures within Toronto's multicultural fabric, fulfilling the fashion preferences of many Torontonians by offering a different option of clothing style, unique textiles, and cultural value.

Since most studies of fashion marketing have focused on brands in general, this researchconcentrated specifically on factors influencing the marketing of Latin American fashion brands in Toronto. This project filled a research void andisa starting point for future studies since little has been published on this particular topic. Furthermore, the sub-topics that were addressed in this research, such as the Toronto fashion consumer and being a fashion entrepreneur in Toronto, are also of significance to the fashion industry.

This project is interdisciplinary in nature because it contributed to a variety of fields and disciplines such as: Cultural Studies, Latin American Studies, Identity Studies, Fashion Studies, Fashion Marketing, and Branding.The goal of this project was feasible within a year, the period of time provided by the Yeates School of Graduate Studies at Ryerson University to complete this MRP.

\subsection{Ethical Considerations and Dissemination Plan}

For the protection of the participants' rights, it was necessary to contact Ryerson University's Research Ethics Board (REB) for review and approval. Informed consent was obtained from all the participants, as well as from the relevant authorities in Ryerson University to use the information gathered for the purpose of this project.

This project included multiple dissemination channels such as:

- The case studies showcased at local fashion trade shows and runway events in Toronto 
such as the XPosedFashion Show andLatin Fashion Week, where different audiences learned about the brandConstanzaOquendo.

- The sample sale at Cityfest Art Walk in Toronto, where samples of the case study brand were on sale.

- The final research paper with an analysis of the results and a framework of recommendations for entrepreneurs in the Toronto fashion industry. This document will be accessible through the Ryerson University Library,

- A presentation of the research findingsat an international conference.

All these channels influenced what the outcomes of the study were and will continue to do so in the future as the information keeps being disseminated. 


\section{CHAPTER FOUR: DISCUSSION, ANALYSIS, AND RESULTS}

\subsection{Case Study Brands}

\subsubsection{Luisa Nicholls}

As mentioned in the Advantages and Disadvantages of the Methodology section of this research paper, one disadvantage of the designed methodology was the possibility that one or both of the selected fashion brands for the case study would not be available for collaboration. After many attempts (phone calls, emails, and personal communication) to contact the Colombiandesigner Luisa Nicholls, the brand did not express interest in participating in this study. From the early planning stages of this project the researcherwas aware that this represented a risk.

\subsubsection{ConstanzaOquendo Caracas}

The high-end eveningwear brand from Venezuela "ConstanzaOquendo Caracas" selected as a case study for this project did express her great interest in participating in the study; hence in this chapter, you will find the results obtained through her collaboration. As stated on the web page, the main goal of the brand's founder, owner, and creative director ConstanzaOquendo is to enhance the elegance of women by giving a hint of sensuality to their everyday life through clothing (Biography, n.d.). This designer ConstanzaOquendo first appeared on the fashion scene in Caracas, Venezuela in July 2012 with a show launching the company’s first collection, “Spring 2013 Constanza Ready-to-wear." At this event Constanza received much media attention where the famous Venezuelan newspaper "E1 Universal”commented:“'Oquendo is envisioned as one of our designers that will internationalize the label "Made in Venezuela"' (CITATION). AUNO, a Venezuelan Fashion Magazine mentioned that the designer "is the new girl of the 
moment" (CITATION) while the popular publication Complot Magazine reported that Constanza is setting "a new way of dressing" (CITATION).

The year 2012 was a great success for this emerging fashion house, culminating inConstanzaOquendo'sparticipation in major charity events benefiting important Venezuelan foundations. In one eventConstanza collaborated with the well-known Colombian accessory brand Mario Hernandez and they created a handbag that was auctioned to benefit the NonprofitOrganization, Angeles del Corazon. This event was sponsored by EPK, an international brand for children's clothing, featuring many ofConstanzaOquendo'spieces that Venezuelan celebrity moms modeled on the catwalk with their sons and daughters. During November of the same year, the Fall 2013 capsule collection "Plancton" was launched, presenting symmetrical cuts and futuristic silhouettes combined with touches of sensuality. This collection was introduced through Constanza's website, as well as through her social media accounts. The launch had the televised support of E! Entertainment Television Latam in a special Designers program. E! obtained the exclusivity of the first public appearance of the collection by going inside the workshop (Biography, n.d.).

The following year her success continued. In May 2013, the Resort 2014 Collection "Britannia Bay" was presented at a fashion show that benefited thenonprofitorganization called Andrea. On this occasion floral prints and bright colors transported the audience to the summer season. In July CNN Spanish renowned anchor Ismael Cala interviewed Constanza, consideringher one of the 20 most influential Venezuelan designers of 2014. Later in October, Harper's Bazaar Latin America named Constanza one of the top 10 designers in the world to be followed closely.

The Fête Galantein Spring 2014 was presented at a fashion show at the Galpones Art 
Center in Caracas. The designer described this collection on her web page as "evidence of maturity, elaborate detail and luxury" (CITATION). One of the pieces in the collection was auctioned off to benefit the Venezuelan American Endowment for the Arts, at a gala in New York City (Biography, n.d.).

Today, the designer is very optimistic about the potential growth for her brand and aims to expand beyond Venezuelan borders. For this reason, Constanzashowed interest in participating in this project and agreed to collaborate with the researcher.

\subsection{Industry Events}

In order to obtain meaningful information and before data collection could begin, critical decisions in respect to: event selection, creation of branding material (Look Book, business cards, contact book, garment tags) sample selection and price definition were necessary.

\subsubsection{Event Selection}

After researching trade shows, fashion shows, and art events that take place around Toronto, the following list was compiled:

- Xposed

- Art \& Fashion Week

- Latin Fashion Week

- StartUp Fashion Week

- World MasterCard Fashion Week
- Mercedes-Benz StartUp

- City Fest Art Walk

- Art Fest Toronto

- Toronto Fashion Week
- The One of a Kind

Show

- Distillery District

Christmas Market

- Cabbagetown Festival

Having reviewed the requirements for each event listed, a selection criteria was determined based on: those who supported new designers (no matter from what country they came), those 
that took place in downtown Toronto (where traveling costs were very moderate), and those that did not have high fees or had no participating fees.

As a new designercoming from a country like Venezuela, where there is currency exchange control,the country does not have a FTA with Canada;it is very difficult for a designer to afford participating fees. For all these reasons it was determined that the following events would be suitable for this research: Xposed, Cityfest Art Walk, and Latin Fashion Week.

\subsubsection{Creation of Branding Material}

In order to work with ConstanzaOquendo, it was necessaryfor the brand to have information available in English for the Canadian Market, as her website and social media accounts were all in Spanish. Thereforeit was importantto translate the brand'sLook Book and modify its designtotarget aCanadian audience.

ConstanzaOquendo's modified lookbook contains 56 pages with images of all hercollections created since her launch in 2012 until Spring 2014(see Figures 3, 4).

For the representation ofConstanzaOquendo in Canada, it was important to have business cards (see Figure 5). This provided the possibility for interested parties to obtain more information on the brand, procure feedback to the researcher for networking purposes.

In order to build a contact list from attendants at the selected events, a contact book (see Figure 6) was designed providing a space to write the contact information of those who wished to acquire news on future events where Oquendowas to be showcased. This provided the researcher with a networking opportunity resulting in potential industry contacts.

For branding purposes it is always important that samples are identified with a designer. Hence garment tags with Oquendo's logo and prices were created (see Figure 7). This provided the possibility for viewer to remember the brand and get to know the garment prices. 


\subsubsection{Sample Selection}

The selection of which samples to ship to Canada was taken into consideration. Oquendo provided images of the samples from all her collectionsand a chart was created separating them into: tops, blazers, skirts, long skirts, pants, short dresses, long dresses.Part of the criteria used for the selection of the different pieces was that the garments could be combined to create complete outfits(see Figure 8) and that a sufficient number of outfits were needed to participate in fashion shows.

After reviewing the samples a selection was made based on uniqueness, providing the best possible representation of ConstanzaOquendo's style, differentiating her from other designers in Toronto. A total of 19interchangeableoutfits were created from the 28 pieces selected(see Figure 9).

\subsubsection{Price Definition}

The designer ConstanzaOquendo, taking into consideration production and shipping, established the initial prices for the garments. Oquendo provideda wholesale price in US\$ and a conversion into Canadian dollars took place. Later the retail percentage was calculated by multiplying the wholesale price (in Canadian \$) by 2.5 and it was possible to finalize with a final retail price. This is a practice commonly used in the retail industry(see Figure 10).

\subsubsection{XPosed Tradeshow and Auction}

As is stated on their webpage, "Fashion's Future XPosed" is an event solely dedicated to providing up-and-coming designers and artists a rare opportunity to showcase their talent on the biggest stage of their young careers!” (XPosed Fashion Show, n.d., para. X). As Rebecca King, owner and operator of Visionary events and creator of XPosedstated, the Toronto fashion scene is in continual growth and evolution. She envisionsXPosed as a vital component of this evolution 
and she believes in helping designers; models, stylists and photographers have the chance to exhibit their talents while the eyes of the top industry professionals are upon them(XPosed Fashion Show, n.d.). "There is no entry fee for students to showcase, we believe that every student deserves a chance to show what they're made of!" (XPosed Fashion Show, n.d., para. X), the only requirement for the event is that participants sell tickets to the event.

Designers that wanted to participate in this event went through an application process. This event took place on June 24 and 25, 2014 at the Brunswick House in Toronto, where 11 designers showcased their collections to over 600 industry and local fashion scene supporters. During the event, participant designers where given the opportunity to auction some of their pieces during the event. ConstanzaOquendodecided to auctiona dress and a skirt. The silent auction concluded with noone bidding on these garments.

In this event ConstanzaOquendo was assigned a space where she could display her pieces and network (see Figure 11). The ConstanzaOquendo stand was created with two mannequins, a garment rack where the sample garments were hung, a table that displayed the Look Book, a computer showing a brand video, and a model wearing a full ConstanzaOquendo outfit and greeting the event attendants, while the researcher handed out a questionnaireregarding the brand for participants to complete. The event was animportant opportunity for networking and promotion.After the eventa "thank you" email was sent to the contactsmade(see fFgure 12) and provided an opportunity for them to respond back and to stay in touch.

\subsubsection{Cityfest Art Walk}

Cityfest is a cultural festival that promotes art in any form to bring the community together. This festival took place on August 23, 2014 at Concord City Place, in Toronto and attracted 770 people, "folks of all ages at zero cost to attendees where they were treated to food, 
drink, and live music in the 20-acre Canoe Landing Park (Cityfest Toronto, 2014). In this event ConstanzaOquendo was assigned a space where she could showcase her collection, sell, and network. The ConstanzaOquendo stand was created with two garment racks where the sample garments were hung, and a table that displayed the Look Book (see Figure 13). The event provided an excellent opportunity for networking and promotion.

\subsubsection{Latin Fashion Week Canada}

As stated on the Networking Worldwide (n.d.) webpage, Latin American Fashion Week Canada (LAFWC)is the largest Latin Fashion Week in Canada. Established in 2012, it showcases local and international designers from Latin America by providing an environment for them to promote their work. Through this event they also create opportunities for models, stylists, makeup and hair artists, photographers, and other creative industry professionals to promote themselves and collaborate with them.

This event is focused on the international market, where all designers participate in a selection process before being invited to present their collections (Networking Worldwide, n.d.). The main objectiveof this eventwas to support Latin American fashion brands, connect and position them withwholesale buyersfrom Canada.

Latin Fashion Week had a prelaunch party on September 3, 2015 at the House of Moments, in Toronto. The purpose of this private event was done to promote Latin Fashion Week, find sponsors and showcase the participating brands. At this event ConstanzaOquendo was presented with a runway show (see Figure 14).

Later on from October 24 to 29, 2014, Latin Fashion Week took place at the Spokes Club in Toronto, where ConstanzaOquendo participated at the runway show (see Figure 15) and had a booth which consisted of a table and a garment rack displaying her samples. At this event 
attendees had the opportunity to shop and place orders forConstanzaOquendo. Although no saleswere placed, good media attention resulted from participating at these events(see Figures 16-18).

\subsubsection{Lessons Learned From Industry Events}

After participating in these events it is possible to conclude that one of the main things to consider during the planning stages are the following:

\section{The Event}

- As a start-up designer in Toronto, there are various inexpensive options to promote a designer's collection in a runway show. Hence it is important to learn about all the events that are taking place, choose the ones that are most appealing, and research about them. It is very useful to meet with participants of past years and ask for their opinion and recommendation. Some key things to determine are how they benefitted from the event and if it was well produced and organized.

- During the event, attendees tend to ask the designer where he/she sells the garments and if it is possible to visit them and make an order. This is the reason why some might consider that participating in these types of events should be done when they are already selling garments in a retailer or if they have a studio that people can visit.

- Investigate if thechosen event is dedicated to one or multiple sectors of the fashion market, promoting brands that carry the same product type (denim, lingerie, sportswear, formal wear, or contemporary fashion). Also consider the market level of the participating brands (as mentioned in the literature review the levels are: high-end fashion, middle market, mass market, or value fashion) (Posner, 2011). All this can affect the successful participation of a brand in an event. For example, a high-endeveningwearbrand 
could be negatively affected if it is exhibited at the same show as a men's mass-market underwear brand.

- Knowthe brand's target market and if the event attendants belong to that group.

- Research the rest of the event participants and compare them to your brand. This can provide you with an idea of how you can prepare for the event, if your brand will stand out among the rest or if there will be some competition.

- Find out whom the media will be and if the press is covering the event so you can plan to talk to them after the show.

- Reach out to key people that you wish to obtain as professional contacts and invite them to attend. This will provide a great networking opportunity. Key contacts could be: retailers, buyers, bloggers, journalists, magazines, stylists, celebrities, and photographers. These key contacts can be of great help to promote the brand.

\section{The Runway Show}

- A rehearsal scheduled days before the show with the models selected, will allow initial fitting and rehearsal.

- The backstage area must be very organized. The use of radios is recommended for clear communication between the front and the backstage. In the backstage the garment racks should be identified with: the designers name, the model's name and the order of the runway.An assistant helping the designer and the models needs to know the order in which the different designers are presenting during the show.

- During the runway show it is important that the music playing reflects the identity of the brand being exhibited and that no elements can take the audience's attention away from 
the model and the garments. For example, videos in the background or the host talking while the model is on the catwalk draws the attention elsewhere.

- If there is not a runway show at the event, having a live model wearing the garments proved to be very positive; this offered the attendants a live example of how the garments fit the body.

\section{Silent Auction and Sales}

- When it comes to silent auctions, people hesitate before biddingon fashion garments without having tried them on first hence there should be an adequate fitting room.

- An important lesson from these events is that by participating in them new opportunities will arise. They are excellent opportunities for publicity and networkinghence the power of networking should not be underestimated.But designers should be aware that media attention and interest in the brand does not always translate into sales.

\subsection{Questionnaires}

A questionnaire was designed to collect data for the study. This questionnaire was handed out at theXPosedfashion event. The questionnaire objective was to analyze the performance of the case study brand ConstanzaOquendoduring its showcase. This questionnaire gathered quantitative data that was used to analyze the degree of preferences in style of the attendants to this event and to obtain feedback on the showcased brand. This survey had a verbal recruitment process, where ascript was designed to recruit participants to complete the questionnaire during the event. The Ryerson REB approved both the script and the questionnaire.

\subsubsection{Questionnaire Problems Encountered}

There were three problems identified;First, in eightout of the 20 questions, some participants selected more than one answer, even though the questions specified that only one of 
the options provided should have been selected. Second, some people didn't respond at all to some of the questions that were asked, and third, a problem in the wording of question 3.8 was detected; Holt Renfrew and The Bay, were considered geographical areas, when in reality they are department stores that have boutiques within them, hence the word "area" is used incorrectly in the statement of the question.

Percentage graphs were created for each question to illustrate the results. To address the above-mentioned problems, two result charts were created for the eight questions for which participants selected more than one answer. It is interesting to know that in comparing the two charts from the eight questions, the results obtained were almost identical. The questions that some participants left unanswered, were notadded in the results.

\subsubsection{Questionnaire Analysis and Results}

\section{Demographic Results}

Thirty-fourpeople answered the questionnaire, of which $82 \%$ were female, $14 \%$ male, and $2 \%$ preferred not to answer(see Figure 19). The population of participants was very multicultural. The three largest population groups were Non-Hispanic White or Euro-American making up $47 \%$ of the population, followed by Latino or Hispanic American (20\%) and East Asian or Asian American (17\%)(seeFigure 20). The majority of the participants were 23-27 years old (50\%) and the second biggest group was 43 years old or older(see Figure 22). All the participants had some type of education except for $2.9 \%$ who preferred not to answer.Thirtyeight percentindicated that they had "a first degree or graduate level profession" and the second biggest group, whichrepresented $35 \%$ of the population, had a postgraduate qualification (diploma or certificate) (see Figure 23).

In terms of monthly spending, it is interesting to note that $46 \%$ of this population 
spendsbetween $\$ 100$ to $\$ 200$ on clothes, $17 \%$ spends between $\$ 50$ to $\$ 100$, and $14.7 \%$

spends $\$ 300$ or moreeach month (see Figure 24).With this last statistic in mind, it is possible to say that $14.7 \%$ of this population would purchase a C.O. garment if it cost $\$ 300$ or more, indicating a potential customer.

\section{Personal Preferences}

When it comes color preferences of garments the first choice was neutral colors as this was picked by almost half of the population;the second choice was bright colors and the third choice was primary colors. Something very interesting is that no one selected acid tone garments. With or without the votes of those who picked more than one option, the results remain the same(see Figure 25).

With references to garment design, there wasa tie between modernist (41\%) and classic designs (41\%), with the majority of answers but no matter the type of garment design selected, most people were looking for uniqueness (35\%) and elegance (26\%) in a garment design (see Figure 26).

No one selectedfuturist style garments and a small percentage selected either historic (2\%) or ethnic inspired designs (5\%). This is something that ConstanzaOquendo and other international designers need to consider when creating their collections.

The favorite place to buy garments for special evening events is the shopping mall (38\%), as a second choice $26 \%$ selected boutiques, and the third favorite option is stand-alone stores $(14 \%)$. It is interesting to note that the online option for buying eveningwear is the least popular (2\%)(seeFigure 27).

People claim that what makes them buy an evening garment is the style (47\%) and quality (23\%). Only a very small percentage (2\%)indicated that they buy evening garments based 
on trends and aspiration (2\%) (seeFigure 29).

\section{Product Opinion}

When people were asked to list designers that they felt were similar to ConstanzaOquendo, only 36\% responded, however 63\% said they did not know any designers similar to ConstanzaOquendo(see Figure 30). Also, when they were asked if they would buy and wear ConstanzaOquendo's garments, 91\% responded yes and 8\% said no(see Figure 32). The main reasons why they see themselves wearing these pieces is because of the uniqueness $(50 \%)$ of the designs and their style (17\%)(seeFigure 33). These results coincide with "style" as one of the main qualities they look for when buying special evening garments, as stated in the previous question 2.5 (see Figure 29).Hence it is possible to conclude that this population would buy ConstanzaOquendo garment's to wear for a special evening.

It is curious to note that respondents would buy ConstanzaOquendo for her uniqueness of designs and style but the majority would not buy Constanza for her quality (question 3.4)(see Figure 33), even though the majority of the population picked quality as the second description they look for when buying evening garments on question 2.5(see Figure 29).It appears that when people look at Constanza's garments quality is not a major consideration.

The people who responded that they would not wear or buy ConstanzaOquendo's garments $(8 \%)$ mentioned that this is due to either its high prices, the designs not fittingtheir style,or the designs were targeted to a younger market(see Figure 34).

People described the ConstanzaOquendo customer asconfident, unique, elegant, and feminine (see Figure 35). The majority of the population (61\%) described the target womanranging between the ages of 25 and 29 years old, while $38 \%$ said between 30 and 34 years old (see Figure 38);2\% see women older than 40 years old as the target market and no one 
selected the option between 15 to 19 years old. This corresponds to the reasons why some women would not wear these garments as stated on the results for question3.5 (see Figure 34).There is no doubt that this target will not be described as conservative or basic, as these options obtained $0 \%$ on question 3.6(see Figure 35).

When asked where in Toronto they consider that these garments could be sold, $61 \%$ choose boutiques, $11 \%$ said stand-alone stores, and 5\% picked online. Boutiques are known for exclusivity and quality therefore they tend to be more expensive than shopping malls. Only $2 \%$ of the population mentioned that they saw this brand selling at shopping malls(see Figure 36), consequently it is safe to say that the population considered ConstanzaOquendo as an exclusive, high-priced brand that should be sold in boutiques. But as stated in a previous question(see Figure 27), shopping malls are the favorite spot to buy special evening wear, and online was selected as a last resource( $2 \%)$, meaning that ConstanzaOquendoneeds to consider selling in boutiques to an exclusive and smaller market or maybe sell in small boutiques located inside shopping malls.The designer should not expect to sell in large quantities in boutiques or online, as these are not the top of mind options for special event garmentshopping.

When asked if they believed they should be sold in boutiques, in what area of Toronto specifically, the favorite options were: Yorkville (23\%)and Queen St. West (20\%). We can say that the third option is somewhere in: Bayview Ave, Bayview Village, Bloor St. West, Avenue Rd., Yorkdale, Holt Renfrew and The Room, located inside The Bay department store (which obtained $14 \%$ of the votes on the table, including the answers where more than one option was selected). Without any doubt Sherway Gardens is not an option as $0 \%$ selected it as an option(see Figure 37). 
The problem encountered in relation to the incorrect use of the word "area" in the statement of the question is not considered to have had a big impact in the results obtained from the questionnaires, since the percentage of votes that The Room at The Bay and Holt Renfrew received did not make a big impact in the overall results.

\subsection{Interviews and Results}

The interviews proved to be valuable in complementing the information collected through the questionnaires. The interviewees were able to share their opinions and views, leaving room for free discussion and more in-depth reflection of the questions asked.

The analysis of the interviews was organized by the same five major topics found in the Literature Review, those topics being: the Latin American Community in Toronto, Latin American Dress, Latin American Business Practices, Fashion Marketing, and Importing into Canada. The researcher believed that conducting the analysis in this manner would present a more logical discussion for this investigation.

\subsubsection{The Latin American Community in Toronto / Latin American Dress}

The answers to the questions related to Latin American women and Latin American fashion indicated that Latin American fashion seems to be growing and countries like Brazil have shown great potential in this industry (O. Rahman, personal communication, January 30, 2015).

In terms of what is Latin American fashion, thereseems to be a stereotype characterized by keywords like: fun, active, exciting, daring, sexy, curves, colorful, beautiful, and elaborate. “I don't know much of Latin American fashion and I don't really follow anybody's trends but I know that the Latin American woman dresses well. They are more sensual, and they are very 
comfortable with this without thinking it's impolite. I like that!" comments the talented designer Stephan Caras (S. Caras, personal communication, February 11, 2015).

Some interviewees compared Latin American and Canadian women, mentioning some differences. Coleman felt that Latin American women are always dressed-up whereas North American women are always dressed casual (H. Coleman, personal communication, January 30, 2015). Lu Ann Lafrenzmentioned: "they would have more style; here in Canada we are plainer in comparison"; she describedLatin Americanfashion as having interesting textures, beading, feathers, ruffles and colors that stimulate the senses, showing of women's curves: "it is less about classics and more about celebrating happiness" (L. Lafrenz, personal communication, February 5, 2015). "South American women love beauty, they love women, they love sexy clothes, high hills, jewelry, spending time on their hair and anything that has to do with fashion. Which you sure don't see much here"(W.Clarck, personal communication, February 12, 2015).

Both Ott andClarckmentioned that Latin American celebrities also influence this stereotype through media and subculture. They gave the example of the Latin American character Gloria Pritchett played by Sofia Vergara in the TV series Modern Family, commenting that Vergara portrays a vicious, loud, sexy woman and this has become a stereotypeof all Latin American women. Ott mentions that politics have alsoinfluenced the perception of Latin America, stating that Latin American countries are known for civil unrest, revolution, drug trade, and corruption and that from a North American perspective this sounds dangerous and almost romantic (R. Ott, personal communication, February 5, 2015).

When asked if they thought that the aesthetic of dress and the presentation of self, that Latin American women have, is an image that could sell in Toronto, the responses varied. Robert Ottcommented that not necessarily because there are challenges like that Latin American 
clothing is much more provocative and sexually suggestive. He believes that their hot climate results in a different beauty ideal and that it is all about the nude and not the clothed body, hence every woman has had some kind of cosmetic surgery.

Ott mentioned that a preferencelike color is very cultural and climate driven, also the bodies are not proportioned the same way and a garment that was designed for a Latin body won't fit a Caucasian or Asian body. He concluded by saying that "Toronto has a very diverse population that might not necessarily relate to this culture. Either they market it towards a curvy body type or you change the fit for the North American market, and these are the 2twostrategies used around the world for any brand" (R. Ott, personal communication, February 5, 2015).

Wayne Clarckresponded negatively stating that he didn't believe that this was possible and that even though they were sellable this wouldn't happen in Canada ("maybe more in the USA and in the international market"); on the other hand, he feels that today there is a revival to a womanly shape and that women want to have curves again: "Today too thin doesn't look healthy anymore" (W.Clarck, personal communication, February 12, 2015).

Hailey Coleman, an apparel importer, mentioned that in order for a Latin American brand to sell in Toronto, it needs to be adjusted. She shared the example of the Mexican brand of jeans that she imported, in which they had to limit the details and change the shape of the jeans by making them a higher raise, before importing them.

On the other hand, Lafrenzresponded positivelybecause she believes that "just like anything, it is going to be for a specific target market" (personal communication, February 5 , 2015). Both Guarin and Lafrenz agree that the diversity of the population in Toronto benefits this and that any women, no matter their background, couldemulate this style.Lafrenz also mentioned that itwould depend on which stores sell these garments and how they are accessorized because 
any outfit could be put together or accessorized with one garment from a Latin American designer and look great.

\subsubsection{Business and Latin American Business Practices}

As stated previously by Ott, often it is better for designers to find a partner that will take care of the business aspect of their company so designers can focus on creating their collections. Clarck gave his experience:

I ran my company for 20 years, I did everything, from the design to the business aspect but it got to be too much. This company I work with now, from 5 years ago, they came to me and offered me this job. They have a factory and told me to come in one day a week, pick the brand and do some sketches. Today they take care of the business aspect for my brand and what is great about this is that they still sell to my same customers in

the U.S. They are my representatives and I use their studio. (Personal communication, February 12, 2015)

Ott mentioned that in terms of funding sometimes it is a good idea for designers to find investors. He gave the example of Armani and Yves Saint Laurent, who built their empire based on partnerships. "A lot of these partners ended being their life partners, who were in the shadows" (R. Ott, personal communication, February 5, 2015). Ott stated that it is important for designers to find a support system around them because, as Caras, Guarin, and Clarck stated, it takes designers many years of experience and hard work for them to be able to sustain themselves from their fashion designed collections.

When asked about their experience working with Latin American brands and thedifficulties they encountered, Kirke mentioned: "I have worked with Colombian designers, but they weren't competitive enough to come to Canada. A lot of people focus on beautiful 
attributes but they are not sellable to this market, that's the problem" (B. Kirke, personal communication, February 5, 2015).

Eduardo Fernandez, who is an advisor on International Business \& Corporate Management for operations in Latin America and The Caribbean, mentioned that when doing business with Latin American countries it is important for entrepreneurs to study the current political and social state of their own country, because this might affect their production, as well as the state of the economy in which they wish to enter. Brands and companies need to make sure they "will be able to produce enough and reach the expectation of those other markets" (E. Fernandez, personal communication, February 1,2015). They need to evaluate and determine if it is a good time to do business and at what scale they should do it. "The choice of which markets to enter should be driven by an assessment of relative long run growth and profit potential for the firm" (E. Fernandez, personal communication, February 1, 2015).

Fernandez also noted that "In the Caribbean and Latin America, the costs and risks associated with doing business are big. These nations are characterized by being less developed and not all of them have great future economic growth projections" (Personal communication, February 1,2015). Another issue that these countries seem to share is political instability, unrest and violence. Fernandez gave the example of the Dutch government which is withdrawing support to Curacao because of the great rise in insecurity and another example is Venezuela, the primary drug doorway for European export.

Some countries are affecting the economy of others. For example, "Venezuela and Argentina affect the rest of the Caribbean countries that depend on them, and all Latin America is being affected by the low prices of commodities like oil (Venezuela, Ecuador), gas (Trinidad and Tobago), and minerals (Colombia, Peru)" (E. Fernandez, personal communication, February 1, 
2015). But each Latin American country should be evaluated individually because they are different and separate entities. The political, economic, and financial situation in Mexico, Chile, and even Colombia is very different than in Venezuela.

When a firm is contemplating foreign expansion it must explore three basic decisions: which markets to enter, when to enter those markets and on what scale. The magnitude of the advantages and disadvantages associated with the entry mode of a firm is determined by a number of factors including transport costs, trade barriers, political risks, economic risks, costs and firm strategy. This will also determine the attractiveness of a country as a potential market for an international business. (E. Fernandez, personal communication, February 1, 2015)

\subsubsection{The Toronto Fashion Industry}

When asked to describe the Toronto fashion market, most interviewees considered it a very challenging one,as Robert Ott mentioned, it is a difficult business to be in anywhere:"I did my thesis on Canadian artisanal fashion designers, and I found out that they spent more time managing their business than creating. The reality is that not everyone is good at both, and ultimately the business suffers" (Personal communication, February 5, 2015).Stephan Caras stated that people get disappointed because " $99 \%$ of the fashion industry is hard work and frustration" (Personal communication, February 11, 2015).He also mentioned that Canada is a difficult market and that he wouldn't have survived if he had depended on the local market, his following abroad, and selling internationally to boutiques in the U.S. and in Europe is what has kept him going. He stated that before coming to Canada he gained experience working with the best and later on he decided to establish himself in Toronto because it was a great place to live and raise a family, even though as a designer he could have had more exposure in a more fashion 
conscious country than in Canada. His agent wanted him to move to New York butCaras is a strong believer that "if you take care of your business it will take care of you"(Personal communication, February 11, 2015).

\subsubsection{Toronto Fashion Calendar and Seasons}

Dell'Agnese mentioned that "the different seasons around the year are a defining element to how Canadian's live and dress" (Personal communication, February 11, 2015). The collection calendar in Toronto is based on the seasons (winter, spring, summer, fall) but depending on the size of the company, the typical Canadian designer would design for approximately sixselling seasons or selling periods: Winter, Spring 1, Spring 2, Fall 1, Fall2, and Holiday/Cruise(Dell'Agnese, personal communication, February 11, 2015). The designer Sebastian Guarin mentioned that the Toronto fashion calendar differs from the European and the American because they have two extra collections: Resort and Pre-Fall which is not often seen in Canada.

Lafrenz comments that the calendar depends on the target market of the brand because there are specialized designers that only do knitwear (and their product is more related to fallwinter) while others do swimwear (and their holiday line will focus in the summer). On the other hand, with so many seasons some designers are starting to create garments that are season-less andcan be worn throughout the entire year. "From a manufacturing and production point of view, this is good news, hence designers can produce garments more spread out throughout the year and they don't have drop deadlines at certain months" (L. Lafrenz, personal communication, February 11, 2015).“Designers might still have a fall and a spring season but there are doing more transitional types of pieces, making combinations of things that can be worn in different 
ways" (L. Lafrenz, personal communication, February 11, 2015). This can also be viewed from a sustainability perspective, which is a trendy topic today.

Contrary to other interviewees, Stephan Caras stated that "in Canada there isn't a collection season" and that there is only spring and winter; he considers that spring/summer is a short season and fall/winter is not like the U.S. winter, it is strictly wool jackets:"This restricts designers to come up with a collection" (Personal communication, February 11, 2015). Carasdiscussed how eveningwear is affected by seasons mentioning that "there aren't a lot of restrictions except what you do with colors" (Personal communication, February 11, 2015) but that even in the summer black is a useful color because there is very little that would look summery in eveningwear. He believes that an evening wear collection can last 9 months. Caras concluded by saying that he is not a designer who focuses on trends and that designer dresses don't define a season:"you can make things that last a lifetime and they could wear it for the next ten years as long as it looks feminine" (Personal communication, February 11, 2015).

When asked about what major issues imported brands need to consider about seasons in Toronto,Coleman talked about her experience working with a Mexican brand and mentioned that because Mexico has seasons as well this didn't represent a problem for them: "In terms of design they knew that dark colors and thick materials were for the winter and the contrary for warm seasons" (Personal communication, January 30, 2015). But there weretiming issuesbecausein Toronto seasons need to arrive 6 months in advance and countries like Mexico don't work that much ahead of time (H. Coleman, personal communication, January 30, 2015). Alexia Lewis (personal communication, February 5,2015) stated that the delivery times in Canada are as follows:

- Spring: delivered by the first week of February 
- Summer: delivered in May

- Fall: delivered in August

- Holiday: delivered by the end of October

\subsubsection{What the Toronto Fashion Consumer Seeks}

Bob Kirke commented that Colombian swimwear might be something attractive to Torontonians because that is what Colombians specialize in, but that people do not look for Latin American suppliers, they just look for the best product no matter where it comes from. Stephan Caras comments that when he designs he doesn't think of what Canadian women looks for; rather he thinks of what women in general want and that they have a need to feel ultra feminine. He states that fashion is more than a trend for them because it is how they expresses themselves. He remarks that when a boyfriend or a husband tells him that they have never seen their women so beautiful, he feels that he accomplished something.

Lucia Dell'Agnese compares the Canadian to the American consumer and believes that they are very different. She gave the example of the big department store Target, who didn't make it in Canada and had to close all its stores recently; they underestimated the Canadian customer and this was a hard lesson for them. "This has really brought to the forefront the importance of knowing your customer. You can't transfer knowledge of the American consumer into Canada"; there might be similarities but it is necessary to study the Canadian consumer on its own (L. Dell'Agnese, personal communication, February 11, 2015).

\subsubsection{Sales Representatives, Show Rooms, and Retailers in Toronto}

Lafrenz mentioned that for the retailers the most important aspect is the price-points (because they can't sell something that is out of their price ranges) and how the new brand's style fits within what the store already carries. For example if the store sells eveningwear and 
they also carry accessories, maybe they won't pull the whole line but they will select some pieces that could work for them.

Kirke mentions that "sales representatives are looking for things that can sell and that can get to Canada on time. They want to feel supported in a way that they can actually sell the product” (Personal communication, February 5, 2015).And Rahman talked about his experience working with a show room and how they selected the brands they wanted to represent. He mentioned that it is not simply as liking the design, they had to believe that the brand had potential. He commented that the brandneeded to grab their attention and this could have been done through media. Before they approached it theywould evaluate the brand by doing an extensiveresearch, visittheir store, and follow their performance with other retailers who sold it. "When we got to the trade show we had already studied these brands, but wekept our eyes open for new things that cached our attention and then we would do research" (O. Rahman, personal communication, January 30, 2015). He also emphasized that the financial team attended the trade showswith them to negotiate and help make decisions and this was why the prices also had an impact. He commented that from a show room perspective the private labelsrepresent the real business because representatives are constantly looking for brands and competing for theirlicenses, whichneed to be acquired before the brand becomes well knownotherwise it becomes very difficult and expensive. On the other hand, these licenses do not last very long( 5 years or less) because the brands want to evaluatethe representative's performance (O. Rahman, personal communication, January 30, 2015).

\subsubsection{Representing and Importing International Brands}

Rahman revealed his experience working with a license of a North American Street wear brand in Canada while it was being produced in China and India. He mentionedthat due to the 
long distance,he encountered many barriers with delivery times andthe overlooking of thequality from so far away but on the other hand the labor cost and custom duties were verylow. He mentioned that the styling for the Canadian market did not represent a problem because they designed it and it was approved by New York.Sometimes they asked for adjustments to make it consistent with the U.S. brand but this didn't represent a major problem:

Finding customers wasn't an issue either because we hired sales men. We had also selling agents who took care of the east coast, another one of the west coast and we had in house selling people also. We were under a big corporation that was publicly owned so we had a lot of support. (O. Rahman, personal communication, January 30, 2015)

Coleman talked about work speed and language barriers as a problem thatrepresentatives might encounter when working with brands that come specifically from Latin America but might be something to consider when working with other countries. Coleman mentioned that in her case working with a Mexican brand the language was not a problem because even though all documents were in English, they had people in Mexico who spoke both languages. "Also, we provided them with all the documents they needed to export so they wouldn't have problems. The documents are: the invoice, the country of origin and the packing slips" (H. Coleman, personal communication, January 30 , 2014).But "I would say that in working with a Latin American brand the speed is an issue, Latin Americans work slower, we are very precise with timing and they wouldn't respect the deadlines" (H. Coleman, personal communication, January 30, 2014); hence this caused a problem for her as her clients here could not make the orders 6 months in advance.

\subsubsection{Latin American Designers in Canada}


After asking the interviewees if they knew of any Latin American designers that sell in Canada, the majority answered that they did not know of many, mentioningCarolina Herrera and Oscar de la Renta as the few they knew. But both Stephan Caras and Robert Ott argued that these designers are both based in NYC hence their style is veryAmericanized. "I'm going to say that I don't think fashion is a place where Latin Americans are known. But good design transcends the origin of the designer, for example Carolina Herrera, I wouldn't have thought she was Latin American" (R. Ott, personal communication, February 5, 2015).Robert Ott also made an interesting point arguing that "designers don't usually market themselves with a nationality; some even change their names to sound more European and American. Only a few Latin American designers have made the transition" (Personal communication, February 5, 2015).He gave the analogy of how Latin singers become famous when they start singing in English and that it is like they have two identities: one is Latin American and the other one isNorth American; "even their songs sound different in both languages" (Personal communication, February 5, 2015).

Sebastian Guarin noted that the Latin Designers who are famousare all really high fashion (Personal communication, February 6, 2015). As a native-born Colombian who grew up in Canada, Guarincomments that Latin designers are very creative, they"like sexiness and sometimes that doesn't fit in the Canadian culture. Because I grew up here I feel my Latin taste is veryAmericanized"(Personal communication, February 6, 2015). Guarin states that if designers want to be successful in a different culture they need to modify their designs because they need to adapt to the market.Stephan Caras supported this idea by commenting that "Latin designers load their dresses, they over do things, and I tend to do this too sometimes but this doesn't work in North America; people here shy away from it" (Personal communication, February 11, 2015). 


\subsubsection{Fashion Marketing}

Bob Kirke emphasizes that for brands to market themselves it is very important for them to be able to communicate what makes them unique.

\subsubsection{The Product}

Ott commented that when it comes to designing a product to sell in Toronto, it is important to ask the question: "Is this filling a niche in the Canadian Market that nobody is providing?" because it is important to meeta need that is not already met and to create the demand for it (R. Ott, personal communication, February 5, 2011).As Bob Kirke mentioned, "you can't have a good sales agent if you don't have a good product that can be sold"(Personal communication, February 5, 2011.

\subsection{Manufacturing in Toronto}

Dell'Agnese notes that "Canadian designers such as Joe Fresh have their head office located in Toronto, developing everything here but manufacturing offshore in other countries" (Personal communication, February 11, 2015). The Canadian designer Wayne Clarckalso produces his collections in Canada ever since the 1990s and now the company that he works for has their own factory. "You can produce here but there are only a few manufactures and contractors left and everyone struggles. It isn't easy for these companies to find good sample makers" (W. Clarck, personal communication, February 12, 2015).On the other hand, it seems thatthe customer does not want to pay a lot for a garment, hence designers have to find less costly labor and less expensive fabric in order to produce a less expensive product (Dell'Agnese, personal communication, February 11, 2015). Dell'Agnese also stated thatthe North American Free Trade Agreement (NAFTA) was established and thiseliminated the tariff and the duties, helping emergent economies but affecting negatively the Canadian manufacturing industry by 
shrinking this job sector. "This is why large manufacturing facilities closed in Toronto and in other parts of the world as well because manufacturing labor costs were inexpensive in countries such as India and Bangladesh”(Dell'Agnese, personal communication, February 11, 2015).

From his experience Guarin says:"I was lucky that my family has been able to help me here and there, because fashion is an expensive industry to start in, especially in Toronto, where the fabrics aren't good and you have to import" (Personal communication, February 6, 2015).Coleman comments that thesmall production done in Canada is very costly. "Those who do produce here have a big fund to do it”(Personal communication, January 30, 2015). She gave the example of Canada Goose(a Canadian brand who produces their garments in Canada) whose product she considers to bevery expensive. Coleman mentioned that one reason why TT Blues (the Mexican jeans brand she represented in Canada) produced in Mexico is because minimum wage there is less than $\$ 5$, less costly in comparison to Canada's.

Caras agrees with Coleman by stating that hedoesn't consider that Canada has a big manufacturing industry and so his fabrics come from Italy or France even though he considers that they are expensive. He believes that NYC has a lot of eastern and European fabrics in their show rooms but he prefers to buy directly from the producer in Europe. (S. Caras, personal communication, February 11, 2015).On the contrary, Sebastian Guarindoes order his fabrics from NYC, and he commented how this represents a big cost for him because "you either have to ship them or go get them yourself" (Personal communication, February 11, 2015). He mentioned that he has thought of producing in Colombia instead of going to China because they have good quality knitwear:

I don't think the labor in Colombia is cheaper than in China, but at least I am giving my home country jobs. I have family there that could help in the production and I speak 
Spanish so the language won't be a problem. I don't speak Chinese for example so that is

a problem.(S. Guarin, personal communication, February 11, 2015)

Some challenges and barriermentioned by the intervieweesthat designers from abroad encounter when producing their designs in Canada are based on transportation and the sizing system in Canada. When it comes to transportation "shipping around Canada is a huge deal, because the cities are scattered apart. Canada is a big country in comparison to the states" (L. Dell'Agnese, personal communication, February 11, 2015). In terms of the sizing system "each country has its range of body types and sizing. With a brand like C.O. there might be certain styles that might not work for all body types, hence there might be some considerations to take" (Dell'Agnese, personal communication, February 11, 2015).For those designers who still want to produce in Canada, Rahman comments that "if the design team is out of Canada this could be challenging for any designer," and recommends "to have a partner in Canada or to hire someone and do a joint venture: 50-50 and 50-40. Someone who also takes a financial risk and that knows the market enough to indicate the changes that have to be made in the designs and style" (Personal communication, January 30, 2015).

\subsection{Product Design}

As mentioned before, the design of the product is a very important aspect of the production process that has to take into consideration the target market's needs and its culture. Hence when it comes to designing garments for exportation, designers should change their designs to fit the new target and be able to sell them in that new country, even if this means having two different identities, as stated by Ott.Coleman agreed with this and talked from her experience working with a Latin American brand, stating that: "everything had to cater towards the Canadian market. We wanted to keep some Latin American details in the design of the jeans 
because we thought that it would be cute but people here just didn't understand it" (Personal communication, January 30, 2015). It seems that "we are creatures of habit and change throws people off” (H. Coleman, personal communication, January 30, 2015).

Another good point, as stated by both the literature review and by Ott, is thateach culture has its history expressed through pattern and color, hence by taking details out of a designed garment you take the essence and the authenticity out of it also. This is why this job should be left in sensitive hands so it's not done inappropriately (R. Ott, personal communication, February 5, 2015).Ott recommends that rather than adapting the Latin American design to the American target, "it is better to start from scratch, design for a Canadian consumer and then add Latin American references by attribution, as opposed to authenticity"(Personal communication, February 5, 2015).Ott also mentioned craftsmanship in garment design as something that is reemerging today and that designers are implementing as a way to differentiate themselves. Ott defined craftsmanship as the process and the love for making something really beautiful and handmade, with a sense of imperfection (Personal communication, February 5, 2015).

\subsection{Sizing System in Canada}

Dell'Agnese, Apparel Design and production professor at Ryerson University,mentioned that the manufacturing of garments with measurements started when men's military uniforms first appeared, as they needed to distinguish themselves from the enemy. Women on the other hand stayed at home and made their own clothes; nobody knew their measurements until mass production started and it became necessary. Before that, women did not purchase garments in stores until around the early 1900s, during the Industrial Revolution (Dell'Agnese, personal communication, February 11, 2015). 
Dell'Agnese stated that today the sizing systems in both Canada and the U.S.are based on body measurements collected in the early 1940s. This was a massive project where over10,000 women were measured by hand (over their undergarments using a tape measurement), from coast to coast.But the compositions of the population and the respecting body shapes have changed since then;the American and the Canadianpopulations were not as mixed as they are now. Today many different ethnic groups make up the population,such as Asian and Hispanic, who have different body shapes and proportions.Dell'Agenesegave the example that when she did her research: "in comparison to the American Whites, the American Black had a shorter torso and longer legs while Hispanics had a longer torso and shorter legs" (Personal communication, February 11, 2015).

Also a lot of these cultures assimilate other customs when they move to other countries, hence it would be interesting to see how different ethnic groups have now become close to the American white population through generations and environmental factors (L. Dell'Agnese, personal communication, February 11, 2015). People's lifestyles have changed today, a big part of the population is much more active now than they used to be because there is more awareness of the importance of a healthy lifestyle, but in contrast there is still a part of the population that does not participate in this lifestyle (L. Dell'Agnese, personal communication, February 11, 2015). Consequently, the measurements collected by hand in the early 1940s are not matching the population anymore."To do this type of measurement survey again todaywould cost millions of dollars and while it is important, I do not think the government thinks this is a critical area"(L. Dell'Agnese, personal communication, February 11, 2015).As a resultthe sizing system is avoluntary sizing standard used as a guide by designers, it is not mandatory for them to follow it. Dell'Ageneseconsiders this to be one of the frustrating things about the fashion industry because 
"a customer can walk into a store today, try on three different dresses which arelabeled to be the same size and they will all fit differently" (L. Dell'Agnese, personal communication, February $11,2015)$. She considers that thiswon't change unless the customer forces itby deciding that it is enough. From a positive perspective, sizes have become a differentiator factor for brands today. Dell'Agnese concluded by stating that these sizing issues are only present in women's

fashion and that it is not the case for menswear. When a man wants to buy a pair of pants and he asks the retailer for a size 32/34 everyone knows that means: 32 waist and 34 length; this is not the case for women because they don't want to reveal their measurements hence there is a type of mystery attached to it.Dell'Agnese recommends new designers to be aware of the inconsistency in the measuring system and that "they should try and design garments that can accommodate as many different sizes and diversity as possible" (Personal communication, February 11, 2015).

\subsection{Garment Tags}

According to Colemanand the Canadian Government's Competition Bureau Regulations for consumer textiles, the consumer textilelabels on the products need to describe the following:

- Care Information: it is not mandatory to outline the care information in the form of either written words or symbols on the garment tags. However, where care information is provided, the information must appear in a manner, which is neither false nor misleading and mustcommunicatethe appropriate method of care for the article to which it applies (Competition Bureau, 2011). Written care instructions may be provided in English or French for Ontario (Competition Bureau, 2011).

- It is difficult to know the fullmaterial content of a textile but if this is unknown designers must check with the fabric mills or have the fabric tested for accurate composition (L. 
Dell'Agnese, personal communication, February 11, 2015).The Competition Bureau (2000) states that ageneric name of each fibre present, in an amount of $5 \%$ or more, must be stated as a percentage of the total fibre mass of the article. Generally, the fibres must be shown in order of predominance. For example, for an article made from fabric of blended polyester and cotton fibres (each of which is present in an amount of 5\% or more by mass), an appropriate fibre content disclosure is: $65 \%$ polyester, $35 \%$ cotton/cotton. (para. X)

- Dealer Identity or CA Identification Number:

Identification may be disclosed by identifying the name and full postal address under which the dealer normally carries out his business, or for a dealer in Canada, an identification number obtained by applying to a Competition Bureau office of Industry Canada. Obtaining this number is not a requirement but it may be used in place of their name and address on the labels. (Competition Bureau, 2012, para. X) Coleman stated that in the U.S. this is called RN (Registration Numbers).

- Size (in both English and French): as mentioned before, the determination of garment dimensions and designation of sizes is left to the discretion of the dealer (Competition Bureau, 2000).

\subsection{Collection Samples and Orders}

Coleman and Lewis recommend that when designers meet with sales representatives they should have everything ready: the samples, a fabric book (indicating all the colors), price sheets, a Look Book and order forms (for retailers to make additional orders after the first one). Look Books should indicate the minimum order for each style and the delivery dates (all styles should 
have an early delivery and a late delivery date which are usually 2 weeks off). Coleman mentioned that sales representatives and retailers don't like to waste time and they want everything ready for them to order if they are interested in doing so.

When it comes to samples, Lewis recommended designers to create three for each style: one to send to boutiques in Montreal, another one for boutiques in Toronto, and one to give to sale representatives for selling purposes. Designers usually make the samples in a size 4 but this can often vary to a size 6 (H. Coleman, personal communication, January 30, 2015).

In terms of timing, Lewis commented that representatives need the samples 6 months before the start of the season because retailers make the orders 6 months in advance. When starting in the business, Lewis recommends representatives and designers to start by shopping the samples for 3 months and when they reach an order of 800 pieces for each style then the designer should go into production. She considered that when this number is reached it is a good time to start production, reducing the costs of materials (A. Lewis, personal communication, February 5, 2015).

When retailers make an order, Coleman believes they will usually order one style on each size $(0,2,4,6,8)$ or more (Personal communication, January 30, 2015). But on the other hand Lewis stated that stores usually order: one in XS (Extra-Small), two in S (Small), two in M (medium), and one in L (Large).She also mentioned that brands usually have an order policy of a minimum of four to six pieces of one style on each color (A. Lewis, personal communication, February 5, 2015).

Order payment methods vary; according to Lewis the first order a store makes is COD (CashOn Delivery, meaning the store will pay at the arrival of the garments). Some retailersalways use this payment method(the brand makes that call). Lewis recommends 
entrepreneurs to be flexible with retailers who make big orders to maintain a client.For the second order the stores usually pay 30 days after the delivery. When the order is delivered the designer should give the retailerthree branded bags with the garments to go into the boutique (A. Lewis, personal communication, February 5, 2015).

\subsection{Pricing}

Stephan Caras mentioned that it all depends on which retailer willsell the brand, who the client is, and the price. He mentioned that when he startedas a designer he had to take into consideration the prices of his garments but today, as he has become a known designer, he doesn't think of the price anymore. He stated that because his fabrics are expensive the garments become expensive."If the consumer doesn't want it then that's it but I don't want this to stop my creativity" (S.Caras, personal communication, February 11, 2015).Carasfeels that Canadais not a price-conscious place and that its citizens don't recognize quality. He feels that women are easily influenced by ads and brand names, not giving credit to the quality of the garments:")eople don't recognize quality. They run to the sales to buy things because it is from a known designer" (S. Caras, personal communication, February 11, 2015).

\subsection{Look Book}

Lewis commented that designers need to have two catalogues: (a) A catalogue in which the images are all in a white background and the models are standing in similar poses (this is what you use to sell to boutiques, and this Look Book needs to be clean); and (b) aLookBook with which you can get creative.Lewis also recommends using models that are not too thin and who look healthy like the model from ConstanzaOquendo'sBrittania Bay Collection (see Figure 3) (A. Lewis, personal communication, February 5, 2015). Robert Ott also commented "this is not what the real customer looks like" (Personal communication, February 5, 2015). 


\subsubsection{Being an Entrepreneur in the Fashion Industry}

Lafrenzrecommendsnew fashion graduates to start by utilizing connections made at university. "For example, they should make connections with somebody that can produce their line and somebody that produces fashion shows. They should also connect with a photographer that can take pictures for them and get their name out there" (L. Lafrenz, personal communication, February 5, 2015).

Caras comments that "it is different with every designer. It is all about what they want in life, and what they expect in fashion" (Personal communication, February 11, 2015).He feels that passion is what should drive them. Caras recommends young designers to obtain experience: "When I started I used to beg to work for free, so I could show people what I could do. Until you actually do it, people don't see it" (Personal communication, February 11, 2015).He also stated that when he became an independent designer he could master any position in the industry and that has been a key to his success: “If you don't know how to make clothes you won't know if someone else is making them good for you" (Personal communication, February 11, 2015). He said that still today he makes his own patterns because he has not found anyone that can do it.

In terms of production, Caras stated that the first thing designers need to do is to negotiate with the fabric producer: "For example, I negotiated with them: if I buy 100 meters from you which ones can I get?'(Personal communication, February 11, 2015). Then when the design period came he started a relationship with the fabrics: "I connect with them and feel chemistry. Once I connect, it takes me from there. I don't plan, I have the fabrics and I see what they want from me" (Personal communication, February 11, 2015).

Ott comments on how entrepreneurs often have to face art versus business when they start: "thisis a very difficult business to be in, I did my thesis on Canadian artisanal fashion 
designers and I found out that they spent more time managing their business than creating. The reality is that not everyone is good at both, and ultimately the business suffers" (Personal communication, February 5, 2015).Caras also spoke about how in the fashion industry "you have to make a business out of your art, and it is not enough to sell one piece" (Personal communication, February 11, 2015). He compared fashion designers to singersstating that they might create a song and sell it for 10 years but fashion does not work the same way; "you are only as good as your last collection" (Personal communication, February 11, 2015).

Caras mentioned that many students go into fashion for the wrong reasons because the majority of them believe that they are going to graduate being designers and they want to have a great salary right away:

You need to be attached to another designer who went to school for at least 3 years and did 3 years apprenticeship. By the time you become a designer it's around 8 to 11 years and you still might not make money. Who is going to support you? You can become a doctor in 11 years, are you sure you want to do this? (Personal communication, February 11, 2015).

On the other hand Ott comments that creative people are usually in it for the art and satisfaction, not necessarily to become rich and that is how it should start. They need to find a niche that the business needs day in and day out, develop a reputation that their work is exceptional and that they are reliable. That is the secret to success! (Personal communication, February 5, 2015).

He recommends not to say,

"I am going to be a fashion designer," because that sets up unrealistic expectations. And don't say "I am going to put out a collection"; I would rather say: "I want to work in the 
fashion business and I want to save and earn money that enables me to make a collection in the future" (Personal communication, February 5, 2015).

Clarck recommends that young designers should work where they want to live for the rest of their life. "I had the opportunity to move to LA when I was young and today I regret that I didn't.You need a crazy reason why you think this world needs more dresses, because it doesn't" (Personal communication, February 12, 2015).

\subsubsection{Self-Promotion}

When asked to identify successful ways for self-promotion as a new designer,some strategies that the interviewees mentioned were: doingdirect sales, going into stores, and meeting with the buyers. Also it will depend on the brand's budget but maybe they can consider posting an addin a magazine(O. Rahman, personal communication, January 30,2015). As a new designer in Toronto, it wasGuarin's focus last year to get the brand showcased in magazines and editorials. He felt that heneeded to get to know the city of Toronto, introduce the brand, make a good impression by showing his best pieces, and to network with key people in the industry:

Nobody is going to buy from you if they don't know you. You need to create a buzz around you. For me it was better to get people to know me a little bit before selling. Whatever works for you do it, there really is no manual on how to do it. (Personal communication, February 6, 2015)

Another way to showcase the collection is by organizing your own fashion show or participating in one. Lafrenz believes in "going to universities and finding out about their shows to connect with them. Another strategy could be to talk to newspapers and TV channels as a special interest story" (Personal communication, February 5, 2015). Another strategy mentioned 
by both Lafrenz and Rahman is to considersponsoring celebrities who attend important events (which are relevant to your target).

Lafrenz, Rahman, Coleman, and Guarin all agreed on the importance of marketing through the Internet and participating in social media today. "If media has promoted your brand this will draw attention. It is good to have your name out there" (O. Rahman, personal communication, January 30, 2015)."Right now I sell on e-commerce, and I am going into Shopify, which has good commerce with good prices" (S. Guarin, personal communication, February 6, 2015).Stephan Caras commented that Canada is a difficult market and that he is also considering the use of Internet as a medium to expand his market:

I wouldn't have survived if I had depended on the local market. I sell internationality to boutiques in the states and Europe. I have created a following and that is what has kept me going. Now that there is online shopping we are trying to get on it, people from different continents have expressed that they want to buy my things, so I think this is a great idea. (Personal communication, February 11, 2015)

Caras mentioned that today people are not afraid to spend a lot of money online on clothes:"You would feel they need to touch it, but no! There is a customer and you need to find him/her!'(Personal communication, February 11, 2015).

Lafrenz concluded by stating that "it takes someone with a marketing heart to build up his or her own business, if you don't have it in you then partner with someone that does. People with a marketing background could give great advice" (Personal communication, February 5, 2015).

\subsubsection{Resources for New Designers in Toronto}

Kirke believes that there are not many resources or support available for new designers in 
Toronto because "like any other business, it is not art, it is commerce" (Personal communication, February 5, 2015). As also stated in the Literature Review, the City of Toronto does not consider fashion as an art form hence it does notoffer much financial support to local fashion designers and manufacturers. Some of the few resources that do exist are the incubators.Lafrenz believed that becoming a member of the TFI (Toronto Fashion Incubator) orthe Fashion Zone at Ryerson University "can be a great start"; she believes that they create great opportunities,provide support, networking possibilities and exposure for new designers (Personal communication, February 5, 2015).

Coleman also recommended the TFI and the FGI (Fashion Group International) for networking opportunities. She was herself a member of the Ryerson Fashion Zone and recommended designers to participate in an incubator that is run by professionals who have experience and connections that can help the business grow (H. Coleman, personal communication, January 30, 2015).

\subsubsection{Marketing a Latin American Brand in Toronto}

After researching how to market a brand in general, it was interesting to understand the interviewees' perspective on how to market a Latin American brand to the Toronto Fashion market specifically. Bob Kirke, the Executive Director at the Canadian Apparel Federation, stated that in his opinion, "there is nothing to distinguish Latin American designers and Canadian designers" (Personal communication, February 5, 2015). He poses the question: "Why would they care about Latin Americans more or less? Overall people don't care where garments come from. $95 \%$ of our market is imported, in general people don't buy because of where it is made; I would say that only $10 \%$ does" (B. Kirke, personal communication, February 5, 2015). He believes that this is good news for Latin American designers because they won't be 
discriminated based on where it is made, but they also won't be given extra credit for it (B. Kirke, personal communication, February 5, 2015). Kirke also shared some of his experience: "I met 12 Colombian designers in the States, six of them had excellent products but their most important attributes were invisible; because they didn't talk about them" and "they missed the point" (Personal communication, February 5, 2015). Kirke believes that in order for designers to promote their brand they need to tell the story behind it and explain what they are doing. Even though this is no different for a Canadian or any other brand,it seems that this could be a challenge for Latin American brands maybe due to a language, cultural, or social barrier.

Kirke mentioned that he noticed a lack of marketing in the Colombian brands because they were not thinking about the new market place or"looking around figuring out where their product fitted" (Personal communication, February 5, 2015). He considered it was important for these brands to ask themselves the questions: To whom am I going to sell? Who is the consumer? Who is the retailer that will sell to them and where is it located?Kirke considers that "everything is about marketing!" and thatthe product is what will givedesigners access to the market, not the free trade agreement" (Personal communication, February 5, 2015).Rahman agreed that the product and its marketingare key elements to making a connection with the consumer, no matter where it comes from.

Rahmansuggested that word of mouth is important to promote a brand, helping the community get to know it. He referred to the case study brand ConstanzaOquendo, mentioning that because it comes from a country that is not in the NAFTA with Canada, the duty costs are very high and this becomes a challenge. C.O. would benefit from key people in the industry talking about it because the perception of the consumer is important; it is not just the design of the product. "You need a lot of things to change people's mind set" (O. Rahman, personal 
communication, January 30, 2015).Ottrecommends Latin American brands to create the demand:"you have to get consumers to talk to the retailers and say that they want to buy from C.O." (Personal communication, February 5, 2015). Ottbelieves that when brands come from abroad it is important to ask the question: are they filling a niche in the Canadian Market that nobody is providing? Because they need to identify a niche andmeet a need that is not already meet.Guarinmentioned:

Even though I was born in Colombia and came here when I was 10. I never mention that I am Colombian as a strategy to brand, I leave that out. If they ask I would say it, but it really doesn't matter unless you are producing everything there. (Personal communication, February 6, 2015)

It seems that there aren't many differences in the marketing of a Canadian brand to one that comes from abroad, but challenges will always be present. Just like Lafrenzrecommendedall designers to partner with someone who has a marketing background, according to Rahman international brands should have a partner in Canada who can help them overcome language, cultural, social, and financial obstacles.

\subsubsection{Potential Stores and Retailers to Target}

When asked about stores and retailers that brands should target, Coleman recommended entrepreneurs to walk the streets of Toronto, especially the areas mentioned in the questionnaire, known to have vast options of fashion retailers (Queen St. West, Bayview Ave., Bloor St. West, Avenue Rd., Yorkville, Yorkdale, Ossington\& Dundas, Sherway Gardens, the Danforth) and to get to know the stores and boutiques around there. "They need to connect with people in the business" (H. Coleman, personal communication, January 30, 2015). "You have to be able to be versatile and find where your customers are. And if it is not big enough you have to widen your 
market. Narrow down your creativity to widen your audience and if you haven't found it, you need to work harder" (S. Caras, personal communication, February 11, 2015).

Some interviewees talked about enteringbig department stores like Holt Renfrew and The Bay. Lafrenz mentioned that to enter department stores, "the best way is through a connection"; designers need to"get some kind of an introduction with somebody first, or try to set up an appointment with their buyers"(Personal communication, February 5, 2015). For example, the designer "Greta Constantine got into Holt Renfrew because they hired the PR agency owned by Holt Renfrew's owner's son's wife. But today I don't recommend new designers to do this. It takes that kind of a connection to get in there" (W. Clarck, personal communication, February 12 , 2015).

Lewis commented that Holt Renfrew will pick brands up when they see them selling in smaller boutiques. She warns about working with big department stores because very often they ask designers to sign contracts for 2 years, but if the brand doesn't do well the 2-year contract could probably harm them (A. Lewis, personal communication, February 5, 2015).

Stephan Caras advises upcoming designers not to enter big department stores, stating that designers"don't make any money because of the deductions they make from the selling price and the conditions they have where brands have to absorb mark down money. Then the store charges a percentage for warehouse and advertising" (Personal communication, February 11, 2015). The Canadian designer Wayne Clarck agrees that department stores do not represent an opportunity for designers to make big sales:"with department stores you have to guarantee that they will sell $75 \%$ of your garments, if they don't sell you have to take them back" (Personal communication, February 12, 2015). He shared an example of an unfortunate experience he had with a department store: "the week before September 11 happened, I had just finished my new 
collection and was ready to hand it to Sacks but after this tragic event nobody went shopping and so we had to assume all those losses" (Personal communication, February 12, 2015). He stated that the only reason why designers decide to go into these stores is for marketing purposes:"I sell at Sacks but I gave them a number of the maximum orders they could make because I calculated that I could take that amount as losses, but not more than that" (Personal communication, February 12, 2015).

Carasalso commented that after 2 years he was very disappointed with department stores: They might support you for some seasons and then they aren't loyal with you.They can destroy you so easily by canceling an order 2 weeks before and then they call you and say that they don't want to see your business suffer and so they will buy them from you for $50 \%$ of the price. I really feel sorry for young designers that don't have the experience to deal with that. (Personal communication, February 11, 2015)

Caras stated that today it is harder because there are not that many individual stores hence that leaves department stores as one of the few options.

But it will be difficult for those who still wish to enter department stores, for marketing purposes, because it seems that these stores have a policy to not take on new vendors, and only work with the ones they already carry. "The only reason why I am at Holt Renfrew and The Room today is because I have been for 40 years in the industry" (W. Clarck, personal communication, February 12, 2015), and if those stores don't carry Canadian designers the press would crush them.On the other hand, for those who do make it into a department store,Clarckreminds them that "in the industry you only get one chance. If Sacks decides they want to take you on, and you screw up, I can guarantee you are not getting another chance with them in the next 10 years" (Personal communication, February 12, 2015). 


\subsubsection{Working with a Show Room and Sales Representative}

Coleman mentioned that TT Blues decided that theydidn't want to open a showroom because they didn't have the price for the overhead:

We just started contacting sales representatives and got them to promote the brand. To contact them we did two things:we walked into every show room around Tycos Drive and Wingold Ave. (where most of the show rooms are located in Toronto) showing them the brand. And we visited the stores in Torontowhich we thought had a good fit for our brand image, and asked them to recommended sales representatives.(Personal communication, January 30, 2015)

There is a good chance the sales representatives will decide to work with the brand if:theylike the craftsmanship, have clients that would buy it, and if the brand has the capacity to produce the quantities needed. "In our case they knew that we owned a factory in Mexico, that there was a whole company behind the brand and that we were capable of producing and responding to their needs"(H. Coleman, personal communication, January 30, 2015).

\subsubsection{PR and Publicity}

\subsubsection{Trade Shows and Events to Attend}

When participants were asked what tradeshows they recommended for upcoming designers and if it was worth participating in them, Rahman responded positively saying that "trade shows are great to find out if the price is competitive enough with the competition" (Personal communication, January 30, 2015). He pointed out that designers need to consider the participation fees and mentioned that it will depend on the market they are targeting. As mentioned in the Lessons Learned From Industry Events section of this research, not all fashion 
events in Toronto target the same market segment. On the other hand, the shows usually have a selection processes and deadlines that designers need to be aware of when planning for them.

Guarin mentioned several shows that take place in Toronto, such as Start-Up Fashion Week, FAT (Fashion Art Toronto), Latin Fashion Week, and Toronto Fashion Week. He recommended starting with a smaller show, for example Start-Up Fashion Week in Toronto: This show accepts emerging designers, and has reasonable entrance fees. It was well put together and organized. It got me great exposure. I had to pay $\$ 500$, which is not much, and they did everything: models, makeup, etc. FATis not really my style, is more focused on art, but it still is good exposure.Toronto Fashion Week is great, they offer emerging designer feeseven though they are a lot more expensive.(Personal communication, February 6, 2015)

Lafrenz also mentioned Toronto Fashion Week as being one of the few tradeshow optionsfor high-end brands in Toronto and that it can be used as a marketing tool:

The issue with this event is that it takes place really late in the fall and in the spring, by which time boutiques and stores already have their stock for that season. If you talk to designers showcasing in the show, they know that they won't get bookings from participating and this is problematic. (Personal communication, February 5, 2015) Guarin and Lafrenz agree that designers need to know that most of the shows don't represent higher sales but rather participating in them should be done for marketing reasons.Guarinbelieves that once a brand attends one show that will lead to another opportunityand "the more people you know and the more events you go to the better" (Personal communication, February 6, 2015). 
If costs are an issue, Guarin recommends designers to try producing their own show: "when I was in London I did my own shows, and sometimes this is cheaper, I got everything sponsored; you just have to ask around for help" (Personal communication, February 6, 2015). On the other hand, Coleman and Caras prefer to attend international shows because "that's where you get the media and garner attention. I think it is worth to spend the money" (H. Coleman, personal communication, January 30, 2015).Some of the shows that Rahman, Lewis, and Coleman recommended were the "Magic" Trade Show in Las Vegas, as it has a hall for upcoming designers to promote their brands to the world. They also have a section in their catalogue dedicated to upcoming brands (O. Rahman, personal communication, January 30, 2015).Some other shows mentioned were "ENK" and Coterie.To get the most out these shows, Rahman recommended designers toinvite specific buyers to their booth. And Coleman says that designers need to make sure that they have everything set up to be able to sell when they are there, for example, designers will need to get an RN number in the U.S.

\subsubsection{Networking}

When the participants were asked what they would recommend to fashion entrepreneurs, networking was mentioned as something essential. Lafrenz mentioned that "sometimes it is all about the people you meet. Network cannot be undersold" (Personal communication, February 5, 2015). Lafrenzand Rahman both recommended upcoming designers to get experience working for another company first and learn from all the business aspects because this will provide them with the connections they need to start their own. "My most successful students have been those who have made the best contacts in this field" (L. Lafrenz, personal communication, February 5, 2015).

Guarin recommends to "go to the key events, not all of them, and network, always have business cards and introduce yourself. Behave, watch your image, don't talk bad about others 
and do not do things that could damage your reputation (Personal communication, February 6, 2015). He explained that the fashion circle in Toronto is very small; "the main people are always the main people, they don't change and everybody knows everyone" (Personal communication, February 6, 2015). Establishing a network and contacts can be a disadvantage for those brands arriving in a new country because this might take a while to build (L. Lafrenz, personal

communication, February 5, 2015). This "is a lot of work but if you want to make it, work hard!" (S. Guarin, personal communication, February 6, 2015).

\subsubsection{Importing Into Canada}

When discussing importing into Canada, Coleman talked about her experience working with international couriers. As mentioned before "working with a Latin American brand the speed is an issue" (Personal communication, January 30, 2015) because Canadians are very precise with timing, hence as a brand, it was important for her to consider the courier's business module in order for her to be able to trust and rely on them.

One important aspect about the business that importing entrepreneurs need to consider is that"Canada has free trade agreements with some countries but there are no significant differences today in importing from countries that are in the agreement and those that are not. Kirke comments that the NAFTA has not been very effective so far because they have extremely strict rules of origin:

These are old rules built by the U.S. textile industry 20 years ago and they do not work today in the apparel industry.If they work it is only for larger volume;for example the importation of t-shirts that come from Honduras. But if those t-shirts'fabric was made in a country that does not have a free trade agreement with Canada, theywill not qualify. ... This presents a big challenge. (Personal communication, February 5, 2015) 
Lewis also comments that the material content of the product will affect its duties fees. For example, "if a garment tag says cotton the import taxes will be half than for things who's tag says they are made out of silk" (Personal communication, February 5, 2015).

Another important factor to consider is that companies need to have proof of where the garments and materials were created because Canada customs can ask for it:

Even if the importation took place 2 years ago and you don't work with that company anymore, you need to save the proof, otherwise they will charge you and additionally, they will ask you for proof for the rest of the shipments you have made in the last 2 years. (B. Kirke, personal communication, February 5, 2015)

Kirke comments that it is very difficult to qualify but if a brand is eligible for a duty reduction, meeting the origin rule, they get "free duties" and the difference in shipping costs are significant. Kirke concluded that people should not overestimate these agreements and that they are not working for small countries because they do not have a big enough producing industry to create all the materials necessary to construct the end product. He confirms that this is a big issue and that importation from countries in NAFTA has not increased in large numbers dueto this reason (B. Kirke, personal communication, February 5).

\subsubsection{ConstanzaOquendo}

Many of the interviews had very positive comments about the creativity and aesthetic of ConstanzaOquendo's collections. Ott commented that if he did not know that C.O. is a Venezuelan brand, he would not have necessarily described her as a Latin American designer, just like he wouldn’t consider Carolina Herrera as being from South America. Coleman considered that C.O. stands out for her uniqueness, the "craftsmanship, textures, colors, and all the details that she has" are what make her designs interesting, and she does not know a brand 
that could be her competition in Canada (H. Coleman, personal communication, January 30, 2015). Rahman believed that"they are designs to make a statement and to draw attention. Some people might want that but we shouldn't generalize because it won't be the masses" (Personal communication, January 30,2015). Rahman considered that some of C.O.'s designs might be a bit exaggerated and thatthe bright colors might be suitable for summer but not for all seasons in Canada: "Some designs are a bit too much for Canada and this will affect the price points; less embellishment the lower the price" (Personal communication, January 30, 2015).

Both Coleman and Rahman believed that this brand would be attractive to a small percentage of consumers in Torontowho are women with a lot of income power, who are top earners,and "those that go to balls and glamorous events within Toronto" (H. Coleman, personal communication, January 30, 2015). “We don't have many red carpets in Canada. At TIFF [Toronto International Film Festival] it is mostly Americans walking on it. There is little opportunity for big gowns because there are not that many occasions to wear them here" (R. Ott, personal communication, February 5, 2015). Hence C.O. needs "tomake some design adjustments for the Canadian consumer" (H. Coleman, personal communication, January 30, 2015). Also, Ott believes that the "custom made" business model that C.O. currently runs in Venezuela will not be sustainable in Canada: "If she wants to come here she is going to have to do it through retail" (Personal communication, February 5, 2015).

When asked where they thought that C.O. could sell her garments in Canada, Lafrenz answered that she believed Holt Renfrew's "World Design Lab, where people go to get inspiration" would be a great place; "I definitely see it in some boutiques. Some of the pieces could work for Queen St. West, but because of the high prices not all of them could sell there" (Personal communication, February 5, 2015). Clarck mentioned specialty boutiques: "for 
example, I feel that Hugo Nicholson in Hazelton Ave. could have that customer" (Personal communication, February 12, 2015). On the other hand, Coleman believed that the brand could sell in Yorkville. Rahman recommends C.O. have a Canadian partner who will help her overcome some of the challenges that this new market might present for her.

\subsection{Summary of Key Findings: Recommendations for Latin American Apparel to}

\section{Successfully Enter the Toronto Fashion Market}

There were some commonalities and differences found in the analysis of the results obtained from the different research instruments (i.e., the Literature Review, the questionnaires, and the interviews results), hence by their comparison it was possible to establish the following recommendations for entrepreneurs wishing to develop a coherent long-term strategy in the marketing and management of a brand or business in Toronto. These are discussed in detail below.

\section{Branding}

- Branding material such as business cards, garment tags, Look Books, and signage should be used at all times by the sales representative in the show room as well as at trade shows to promote the brand's identity.

\section{Marketing}

- Consider country-specific needs.

- Understand the target market in the brand's country of origin. Study how this target differs from the one you are entering in Toronto - culturally, financially, and socially.

- If the brand in consideration constitutes a luxury product in its country of origin, understand what "luxury" represents to the population you are entering, in this case Toronto.

- The impact of country-of-origin on purchase decisions is weaker than the influence of a brand. Hence country-of-origin should not be utilized for marketing purposes. 


\section{Networking/Events}

- Once the brand is ready to sell and capable of taking orders, attendindustry events which will truly benefit the brand. This is a key strategy of networking.

- Networking is capable of presenting unexpected opportunities. Butdo not waste time and effort on events that do not appear to hold possibilities. Research the reputation of the event; if it is well organized, do other participating brands belong to the same product type and market level? Know the audience who will attend the event.

- Network and media attention will not necessarily translate into sales but could generate good publicity for the brand.

- Prepare ahead of time in order to benefit from these events. The brand needs to be able to offer a physical address or online page where people can see the collections.

\section{Eveningwear}

- There is interest in historic and ethnic inspired design but the country of origin is not a defining aspect for buyers as long as it is good design.

- Many claim that their eveningwear buying decisions are based on style and quality while it seems that most do not know how to recognize quality and just follow trends (an action which seems hard for people to recognize).

- Today the design and style from known Latin American designers is veryAmericanized.

- Some believe that online shopping will bring opportunities for designers while the questionnaires revealed that online shopping is the least popular option for acquiring eveningwear.

- Bloggers and fashionistas will sometimes give feedback on the brand but retailers are the ones who truly know what sells because they deal with the customer directly. 


\subsection{Recommendations for the Brand Constanza Oquendo}

\section{Marketing and Branding}

- C.O. was described as an attractive high-end brand for special occasion eveningwear, whose target in Toronto should be women with high-income power, between the ages of 25 and 29 years old, and who would shop in boutiques around Yorkville.

- Price point, style, and design should define the adequate retailers for Constanza Oquendo in Toronto.

- The use of signage with the brand logo, the catalogue, and business cards (with contact information including social media accounts) are important for clients to understand the identity. These items should not be missing at industry events.

- A great publicity and promotion strategy to obtain media coverage is to loan garments and dress high-profile personalities and celebrities for galas and events like TIFF. This should be done when C.O. has a showroom or store space in Toronto. Exclusive fashion showroom for stylists and celebrities such as "The Stylist Box" can offer space for this purpose in Toronto, if necessary.

\section{Communications}

- If C.O. is targeting new consumers in Toronto, all the brand communications need to happen in English as well as in its original language.

- C.O. needs to be able to communicate the story behind the brand to a North American target, to capture the brand's essence, values, and philosophy. It is important to define her descriptive qualities in order to outline the brand's persona, which will differentiate her from the competitors. 
- Country of origin should not be used as a marketing tool but Canadians associate Venezuela with very feminine, exotic, beautiful women hence they are interested in learning that this brand is inspired by these women, even though the brand must be adapted to an Americanized market. This is part of the brand's story and it should be communicated.

- Some brand touch points with potential consumers which need special attention because they will define the brand C.O. are: website, social media, advertising and PR through editorials and press, packaging and shopping bags, experience with the sales person. A person who does not know the brand will become aware of it by following it or turning against the brand.

\section{Networking/Events}

- The brand should meet with respective store managers, show the samples and obtain feedback on the brand. This should be done when C.O. is ready to take orders.

- Offer retailers a catalogue adapted to the Canadian market in style and language, employing the North American sizing system and taking into consideration the needs and diversity of the Toronto population.

- A fashion show should be put together by the designer or representative to promote the brand's opening in Toronto. This should be done once the brand has a showroom or is already selling in some retailers. It is not necessary to participate in big events like Toronto Fashion Week until the brand has the financial capacity to afford it and this should only be done with the goal of promotion, not sales.

- The industry events and tradeshows that C.O. attends will describe the identity of the brand, hence events should be picked carefully. 


\section{Design, Style, and Sales}

- Because Canadians do not often have galas to attend, the designer should take into consideration the utilitarian value of some of the garments (like the long gowns), the Canadian lifestyle, and the prices.

- Eveningwear collections are wearable year round; hence C.O. only needs to adapt some of her daywear designs in style, design, and color to the Toronto seasons.

- Oquendo's sizing system (XS, S, M, L) is not suitable for Canada. She needs to adapt it according to Canadian industry practices.

- In Canadian industry practices the samples are size 4 or 6 and these should be very clean, new,and with no imperfections because retailers will assume that the samples will represent their delivered order. The shipping package should be attractive and presentable.

\section{Business Strategies}

- For C.O. to export and enter the Toronto Fashion Market it is necessary for her to: adapt to the Toronto fashion calendar, change her business model from custom made to ready to wear, and be capable of taking orders where the same design must be adapted to different sizes, different textiles, and colors chosen by the retailer.

- Venezuela does not belong to NAFTA. Hence in order for C.O. to be able to produce enough to export to Toronto, she needs to consider changing the country of origin of her garments, since the current political and social state of Venezuela is hurting the production capacity and the high Canadian importation duties are affecting the prices.

- Partner with a representative in Canada who will help the brand overcome obstacles.

- It is necessary for C.O. or her representative to familiarize themselves with Toronto, get to know the retailers and to conduct market research. 
By following these recommendations, any designer will improve the possibilities of successfully entering the Toronto fashion market. For a more in-depth explanation of each of the recommendations provided, please refer to the previously mentioned subsections in chapter 4 .

\subsection{Limitations and Recommendations for Future Research}

It is possible to conclude that this research will serve as a starting point for future study, since little has been published on the importation of Latin American brands into Canada. The establishment of a brand in a new country has a broad scope, hence further study is possible to expand this investigation. Some topics that need further exploration are: the intercultural analysis of fashion marketing, legal aspects of the creation of a company in Toronto, importation of goods to Toronto, pricing, fashion styling, channels of distribution, promotions, servicing, and business and brand management. Once these topics are studied in more depth, it will be possible for the researcher to write a process manual for entrepreneurs on how to successfully enter the Toronto fashion market for the first time. 


\section{CHAPTER FIVE: CONCLUSION}

This research makes two broad contributions: (a) it broadens the theoretical (academic) research pertaining to Latin American fashion and the Toronto fashion market, and(b) results provide recommendations for fashion entrepreneurs, designers, brands, importers, representatives, and marketing practitioners in Toronto and Latin America (regardless of the country origin).

The research question- "What does a Latin American fashion apparel brand need to consider in order to successfully enter the Toronto fashion market?- has been answered and the goals outlined were reached. Now that the framework of recommendations has been written, the researcher plans to put everything that was learned into practice by working as a consultant, guiding Latin American brands on the ways to enter the Toronto fashion industry.

This research represented both a business and a social empowerment opportunity that supports diversity by facilitating the participation of Latin American cultures within Toronto's multicultural fabric. It helps Latin Americans maintain their own identity through fashion, and awakens the interest of other Toronto citizens of non-Latin American origin by giving them the possibility to experience other cultures in a new way. 


\section{Appendix 1: Questionnaire Template}

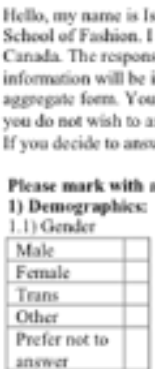

answet

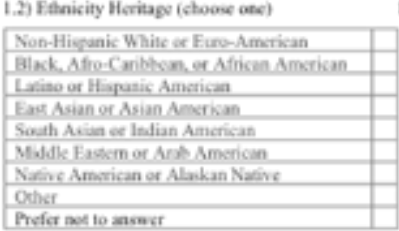

1.5) Highest level ef your edacation qualificatice

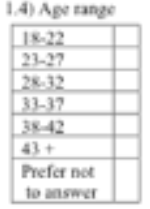
None

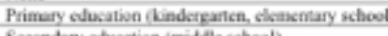
Sosendary efuratien imidde shool High school

Finst descee ef gaduate kevel professional evalification

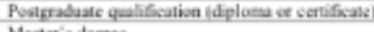
Master s deses

Dextoriac

Prefer not so answer

2) Perwesal Preflereaces

21) What celer gammons
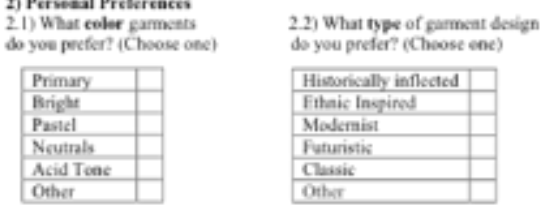

13) which culture do you idcreify yours If with? thoose onet

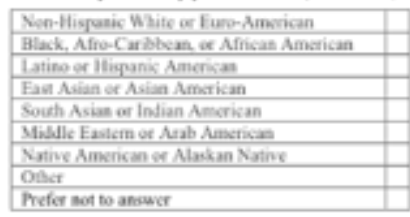

1.6) Menthy slething expenditure (Chose one)

\begin{tabular}{|c|c|}
\hline \multicolumn{2}{|l|}{$50-549$} \\
\hline $550-599$ & \\
\hline $8100-5149$ & \\
\hline $5150-5199$ & \\
\hline$\$ 200-\$ 2290$ & \\
\hline$\$ 290 . \$ 299$ & \\
\hline Ovart 5300 & \\
\hline Prsfer mat to ansect & \\
\hline
\end{tabular}

24) What are you looking for uhen you dress up? (Choose on!

\begin{tabular}{|l|l|}
\hline Uniqueness & \\
\hline Rosikality & \\
\hline Esezance & \\
\hline Sex Appeal & \\
\hline Trendiness \\
\hline
\end{tabular}

\begin{tabular}{l} 
Sex Appoal \\
\hline Trendiness
\end{tabular}

Other

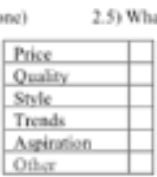

3) Prodect infermation

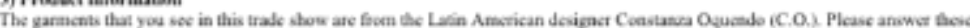
questions with tis is mind.

3.1) List desigacs and brand the are in Totueto and ate similar to Conatunza Oqucndo:
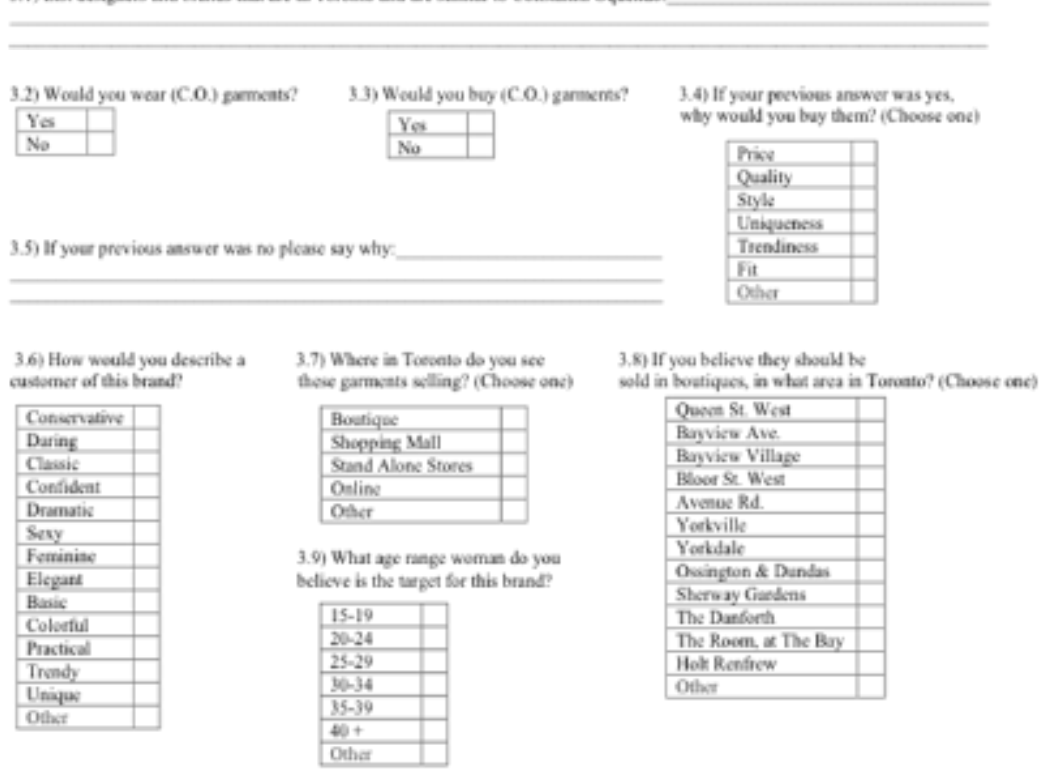

Thenk yeu very much for your time, these results will be used soldy for my Masters thesis and will be shedded in Scpenember 2015

Figure 1. Questionnaire. This figure shows the distributed questionnaire template. 


\section{Appendix 2: Interview Questions Template}

\section{The Toronto / Canadian Fashion Industry}

- Can you describe how the collection calendar is for designers based in Toronto (Seasons, cruise, shows and events)?

- What are the challenges and barriers that designers from abroad encounter when producing their designs in Canada?

- If you are a designer where do you go for products and manufacturing services in Toronto?

\section{Perspective of the Latin American Fashion}

- How would you describe the Latin American fashion?

- How would you describe Latin American Woman in appearance and dress?

- Do you think the aesthetic of dress and presentation of self, that Latin American Women have, is an image that will sell to the retail target market in Toronto?

\section{Questions about the case study brand Constanza Oquendo (C.O.)}

-Where do you see these garments selling?

- Who do you believe is the target market for these garments?

- What makes these designs interesting?

- Do you think C.O. will be an attractive brand to fashion consumers in Canada?

- What does C.O. need to take into consideration in order to successfully sell to boutiques in Toronto?

- What is the competition for C.O. in Toronto?

\section{Based on their knowledge and professional experiences} Latin American Designers

- Do you know of any current Latin American designers that sell in Canada? If you do know any, please mention them.

\section{Upcoming Designers}

- Which do you believe are some good trade shows and fashion events in Toronto to participate in as a new upcoming brand?

- Do you think it is worth for a new brand to participate in a big fashion show like Toronto Fashion Week? Is it financially feasible and beneficial for them?

- What are the best ways of self-promotion as a designer?

- What do Boutique owners require from fashion brands in order for them to make an order?

- What stores do you believe will pick up garments from this brand?

- How do new and upcoming designers enter big department stores like Holt Renfrew and The Bay?

- What do you recommend to a new designer entering the Toronto fashion industry so they become known and established?

\section{Based on your area of expertise} Importer Distributer/REP - Show Room - lawyer

- What should new brands consider in order to open a Show Room in a new country?

- How do you start a showroom? How did you get yours started?

- How do show rooms do business with designers?

- What is the Distributor, importer, representative Margin/Broker Commission?

- What has your experience been with International Curriers and Outsourcing Companies?

- If you have any experience working with Latin American brands, how has that experience been? Do they come from countries that are in the free trade agreement with Canada? What are the difficulties on importing from Latin America?

- Is their anything that Canadians have to be careful of regarding importation taxes?

- What do boutiques in Toronto look for when choosing the brands they will sell?

- What major issues do imported brands need to consider about seasons in Toronto?

\section{For all professions}

- What resources are available in Toronto for new designers?

- What are some great strategies to market a Latin American fashion brand in Toronto?

- What would you recommend to fashion entrepreneurs in Toronto?

Figure 2. Interview questions template. 


\section{Appendix 3: Constanza Oquendo's Look Book}
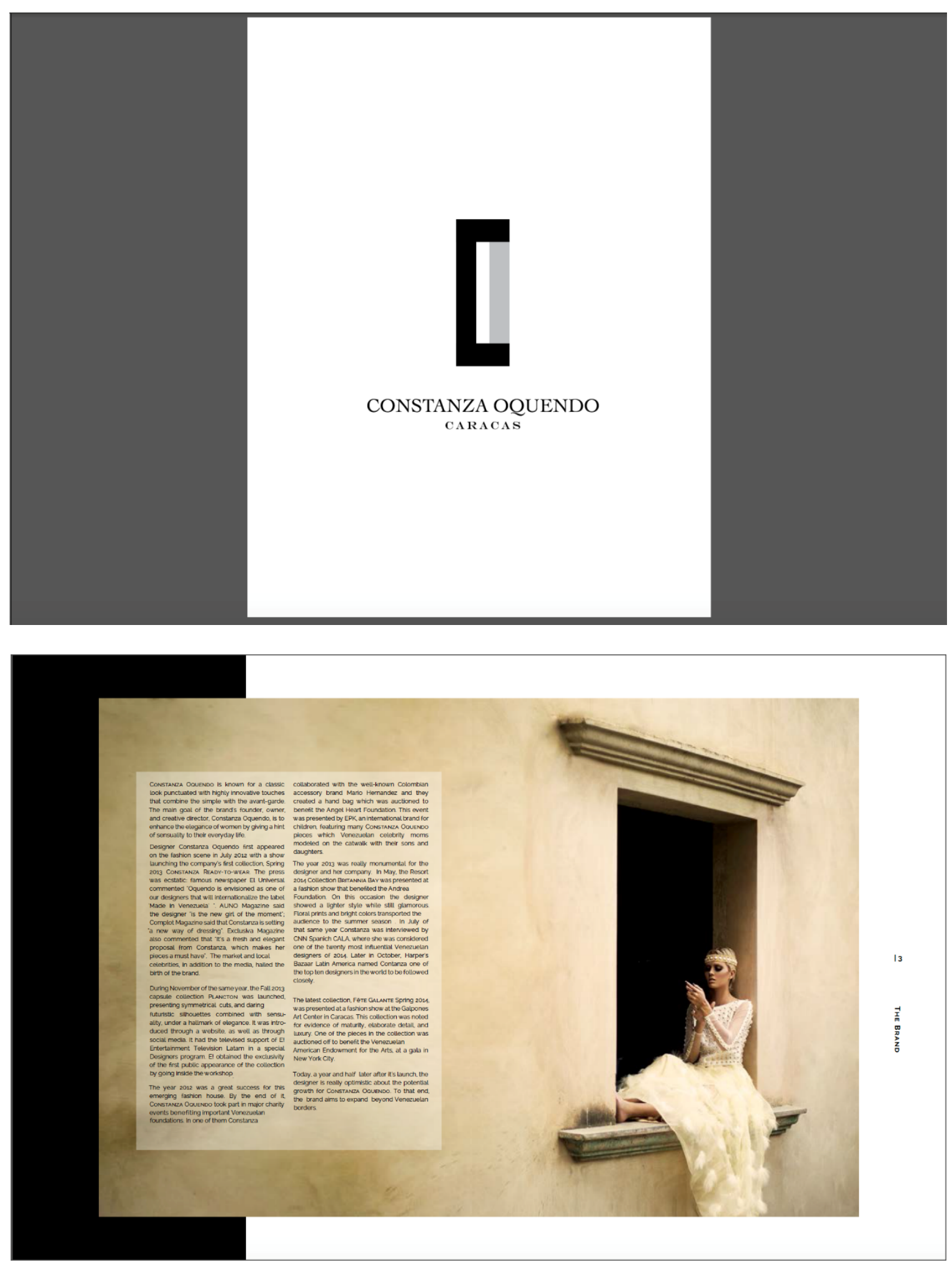

Figure 3. Look Book. This figure details the Look Book translated into English. 

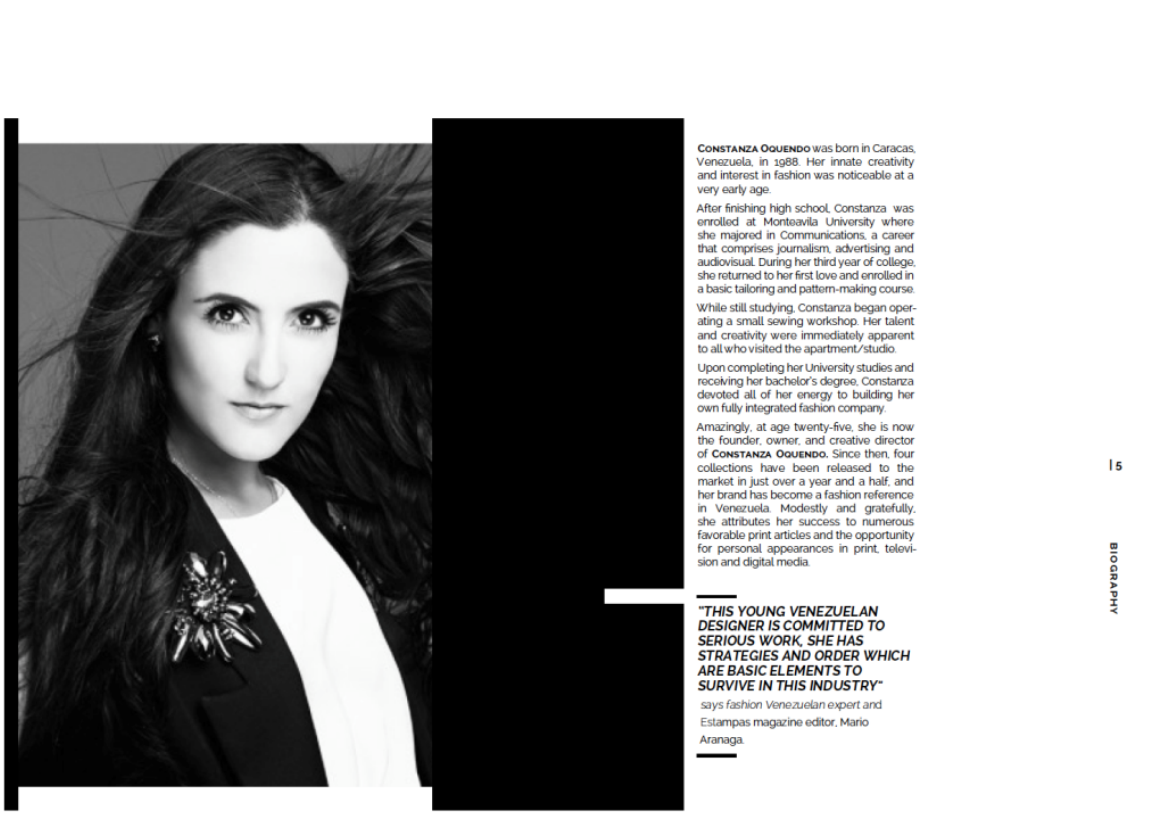

| SPRING 2013

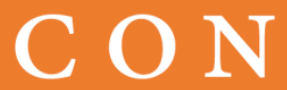

0 ก

N Z A

READY-TO-WEAR

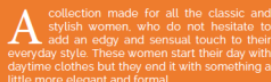

Figure 3. Look Book (cont'd). 

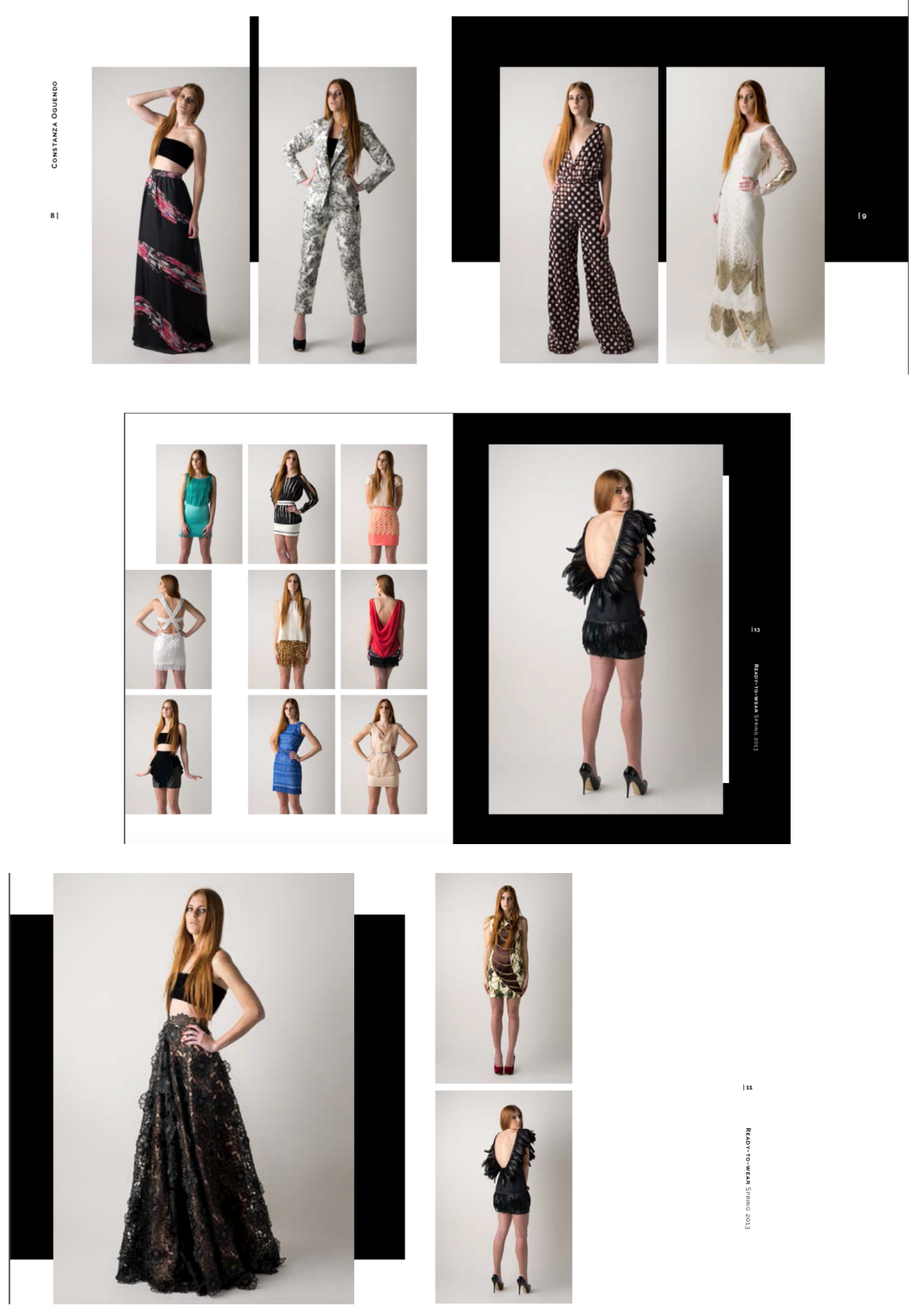

Figure 3. Look Book (cont'd). 

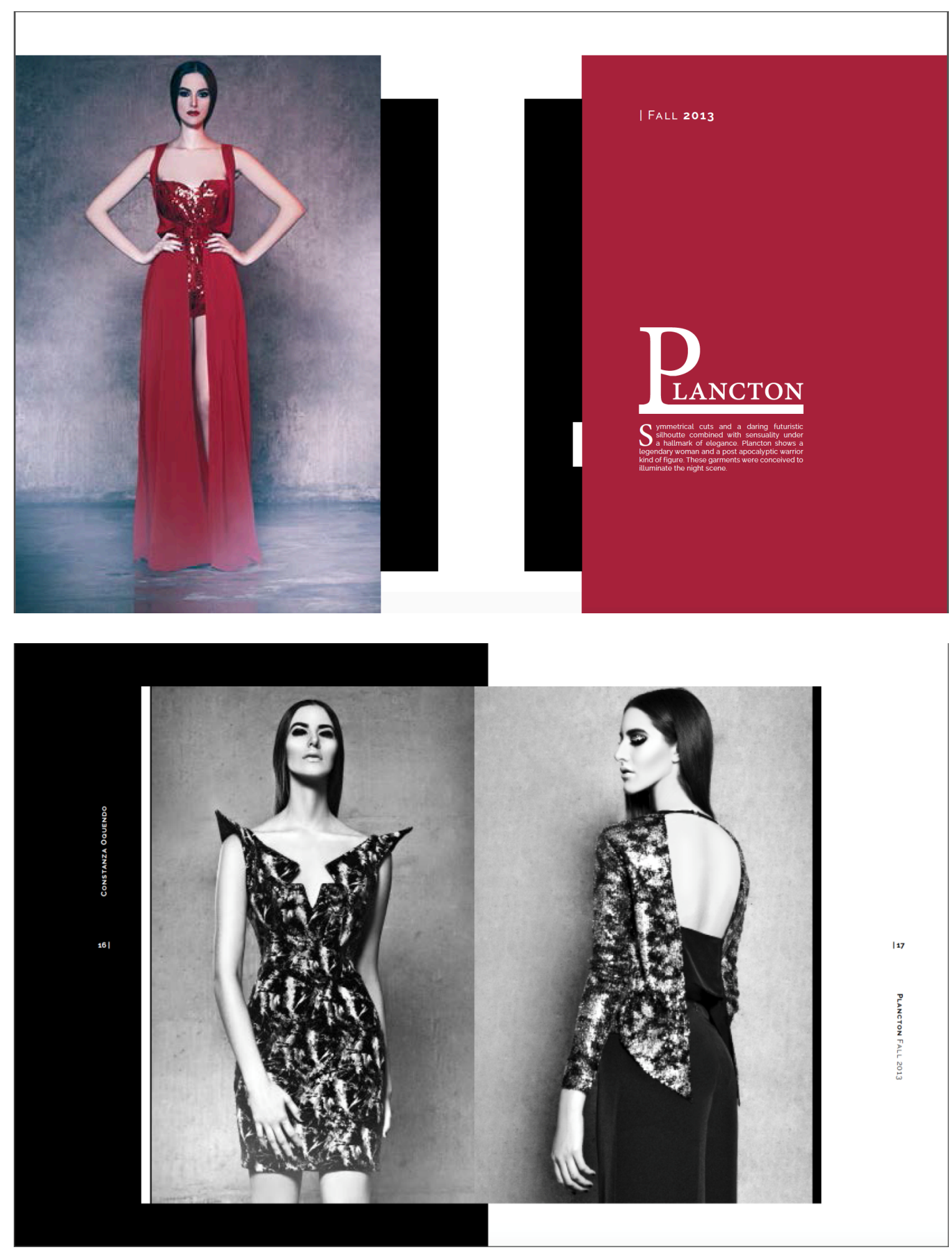

Figure 3. Look Book (cont'd). 

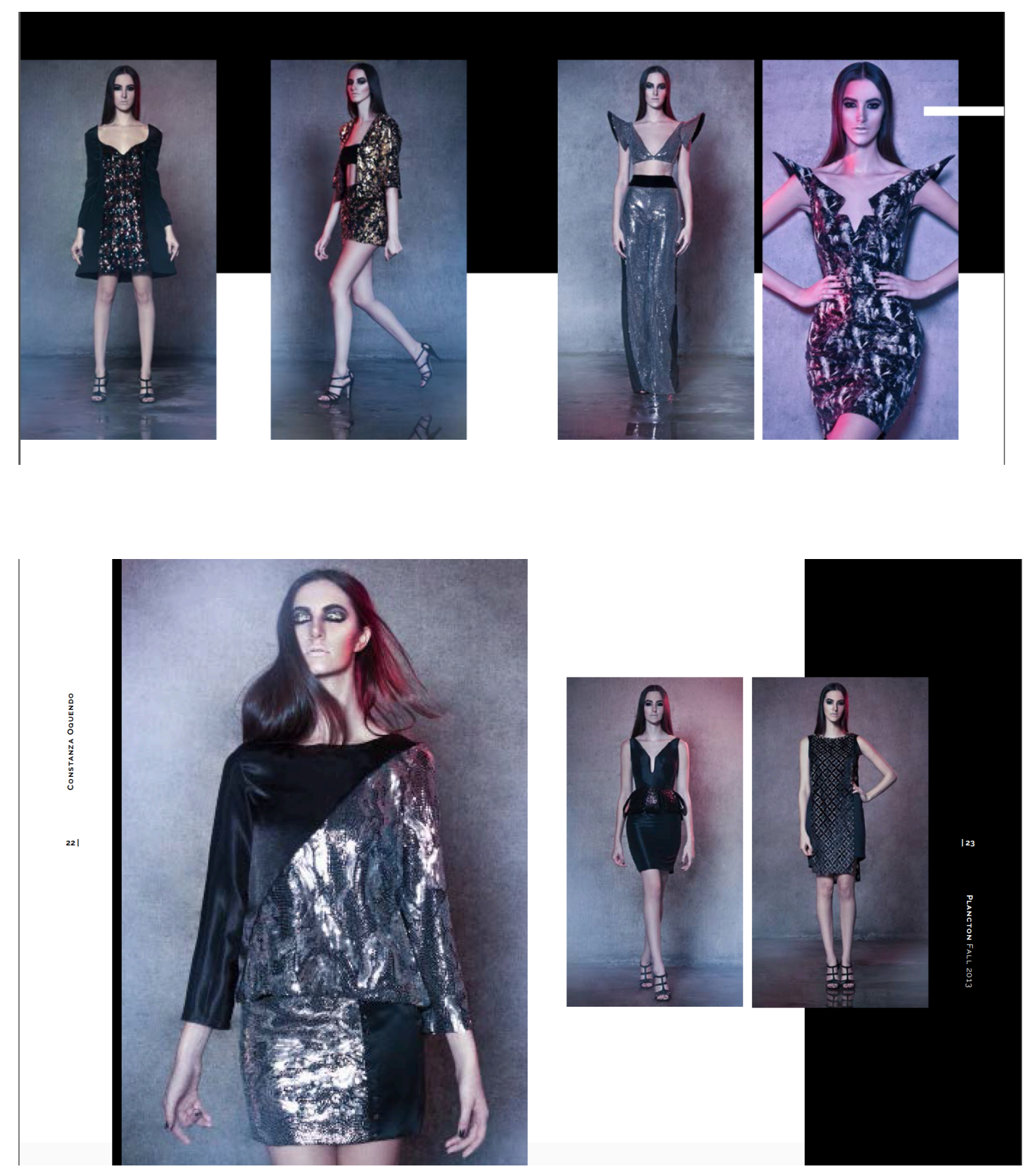

Figure 3.Look Book (cont'd). 

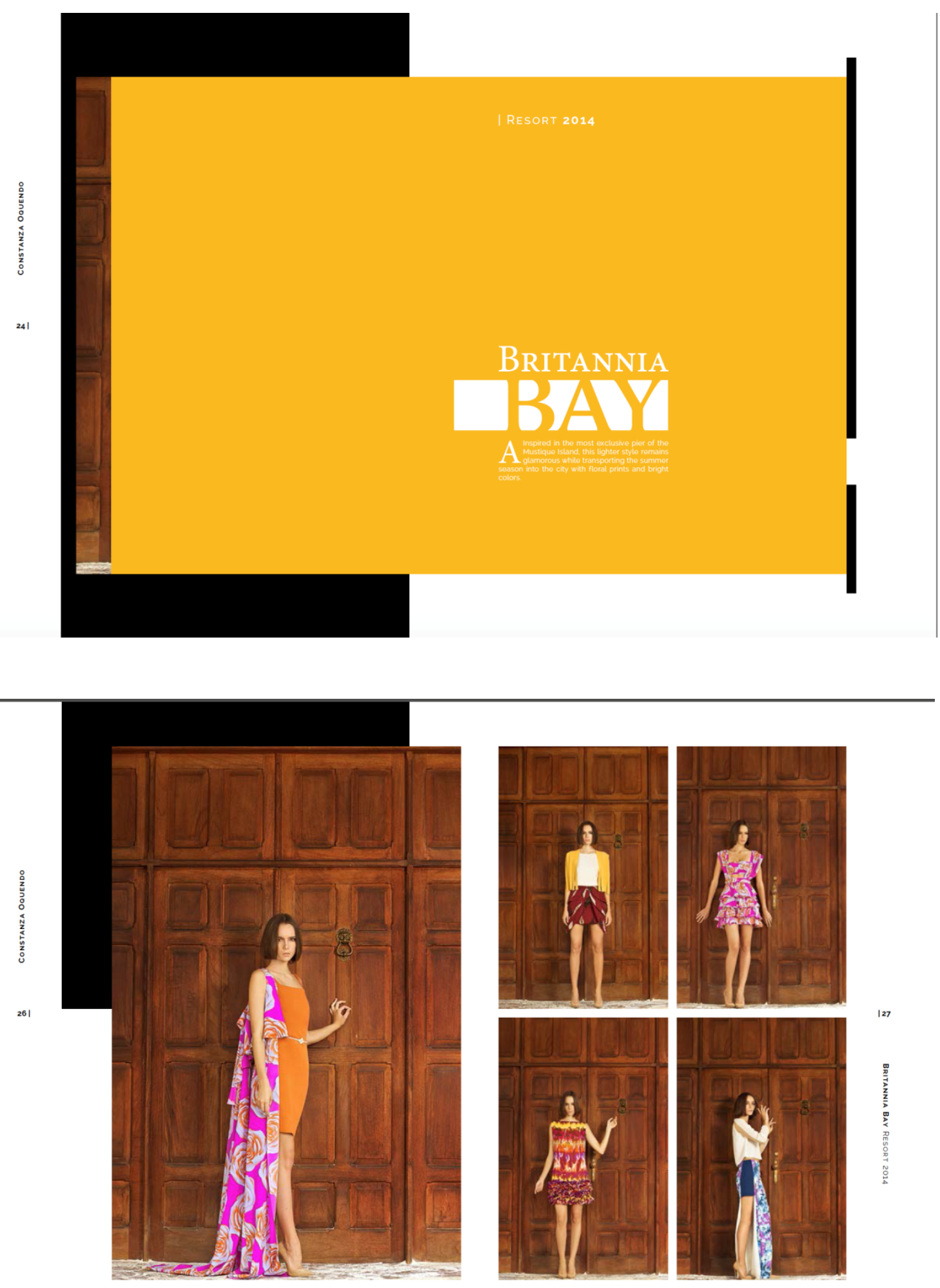

Figure 3. Look Book (cont'd). 

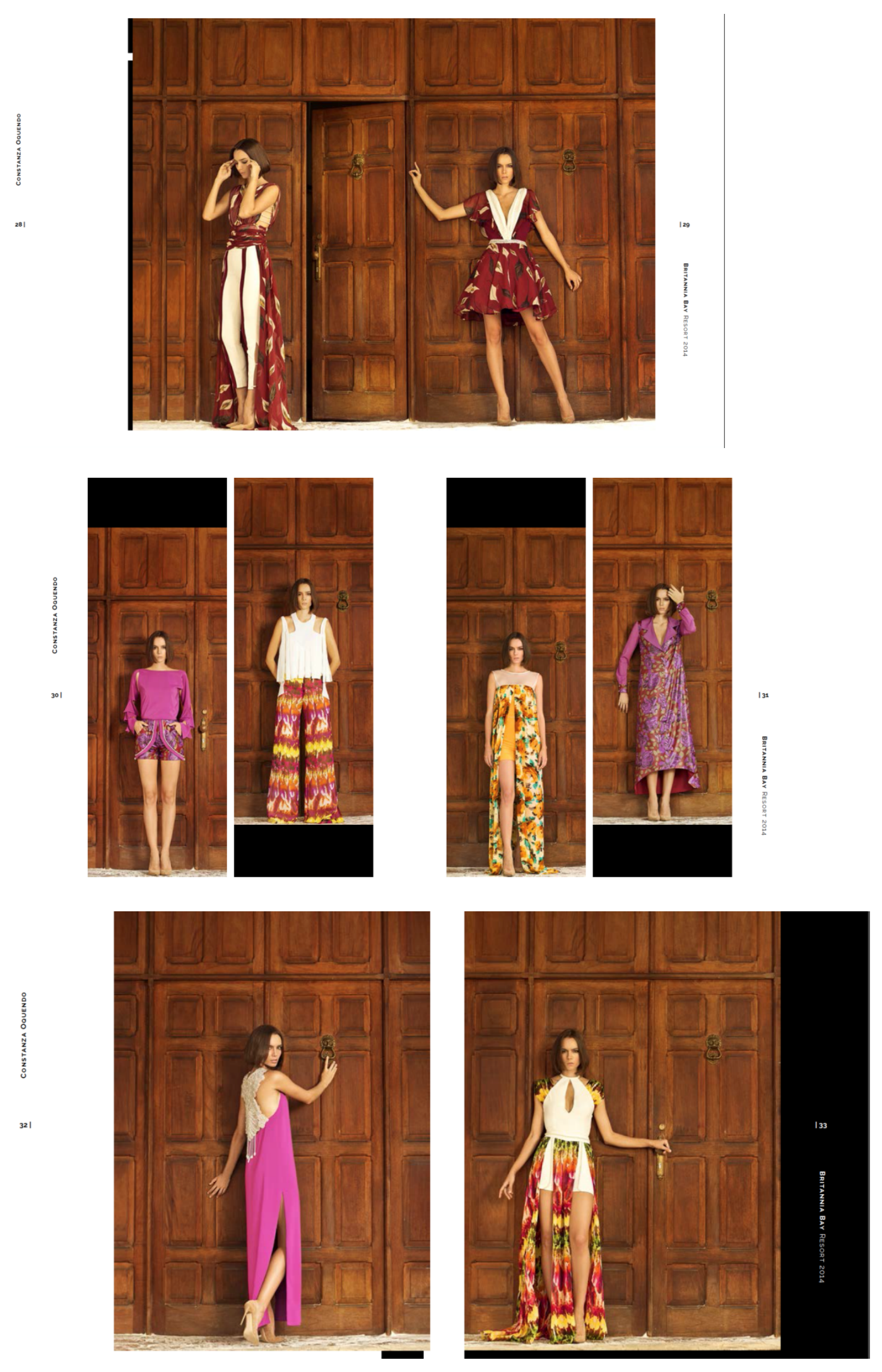

Figure 3.Look Book (cont'd). 

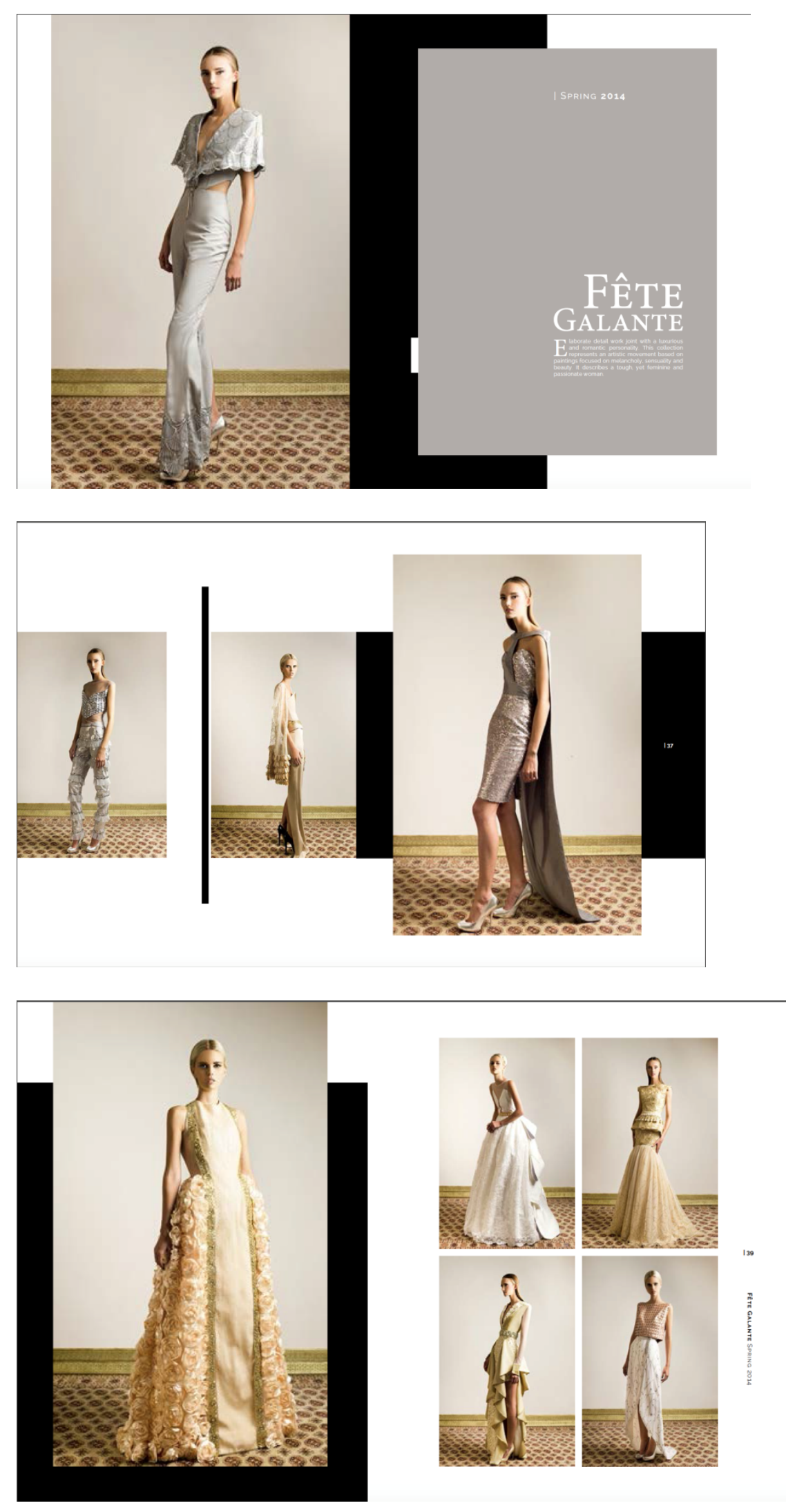

Figure 3. Look Book (cont'd). 

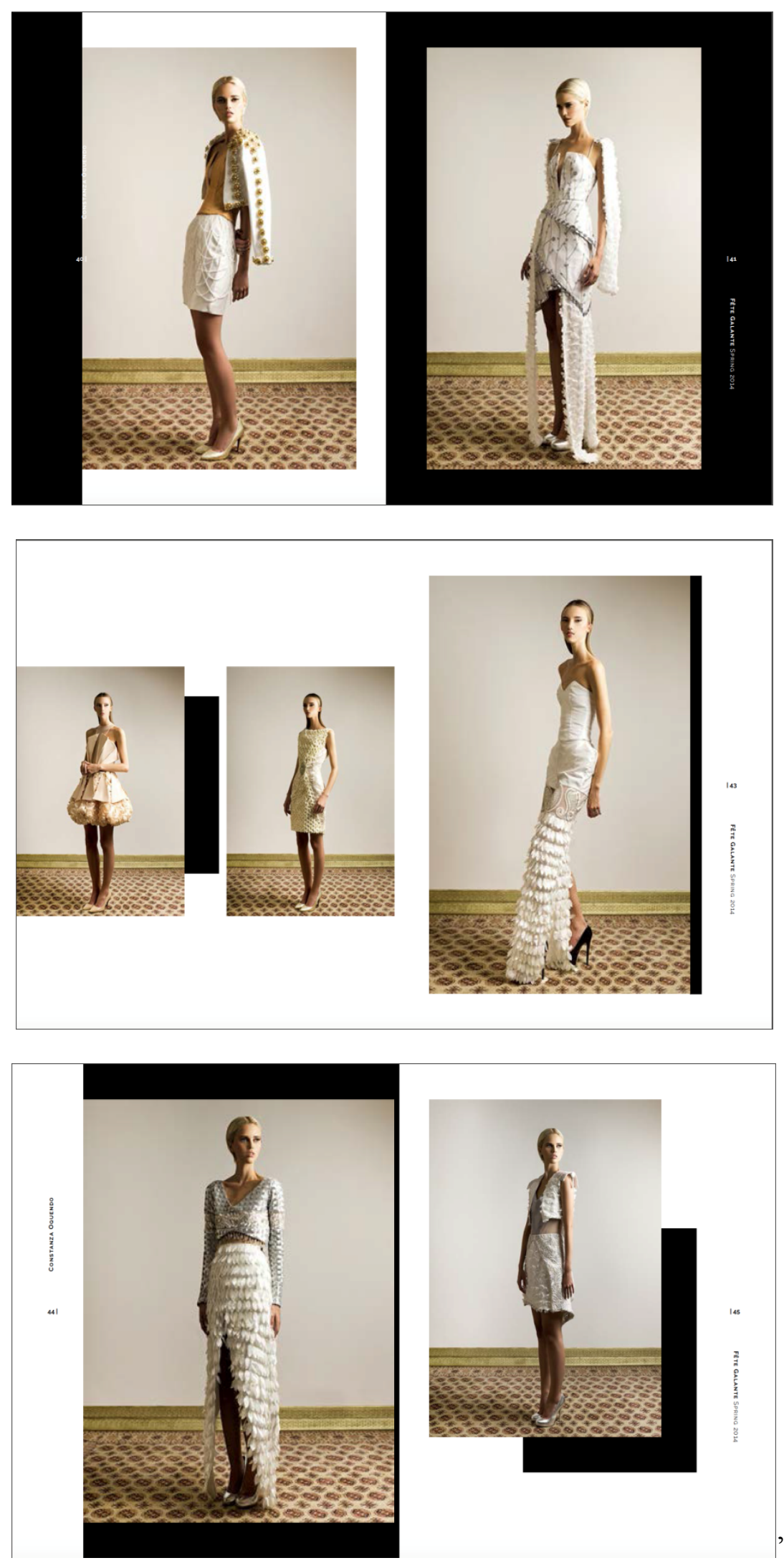

Figure 3. Look Book (cont'd). 

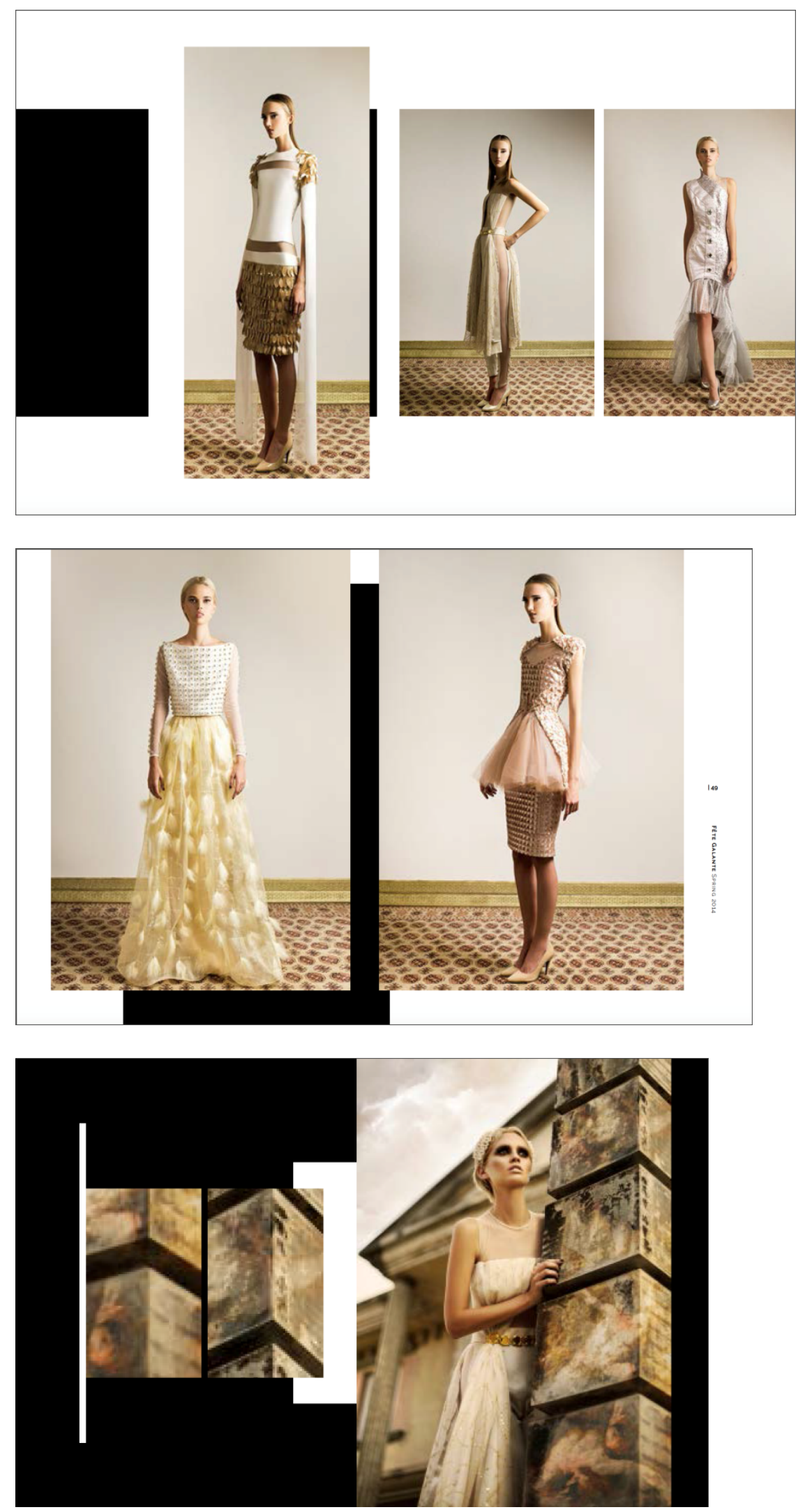

Figure 3.Look Book (cont'd). 

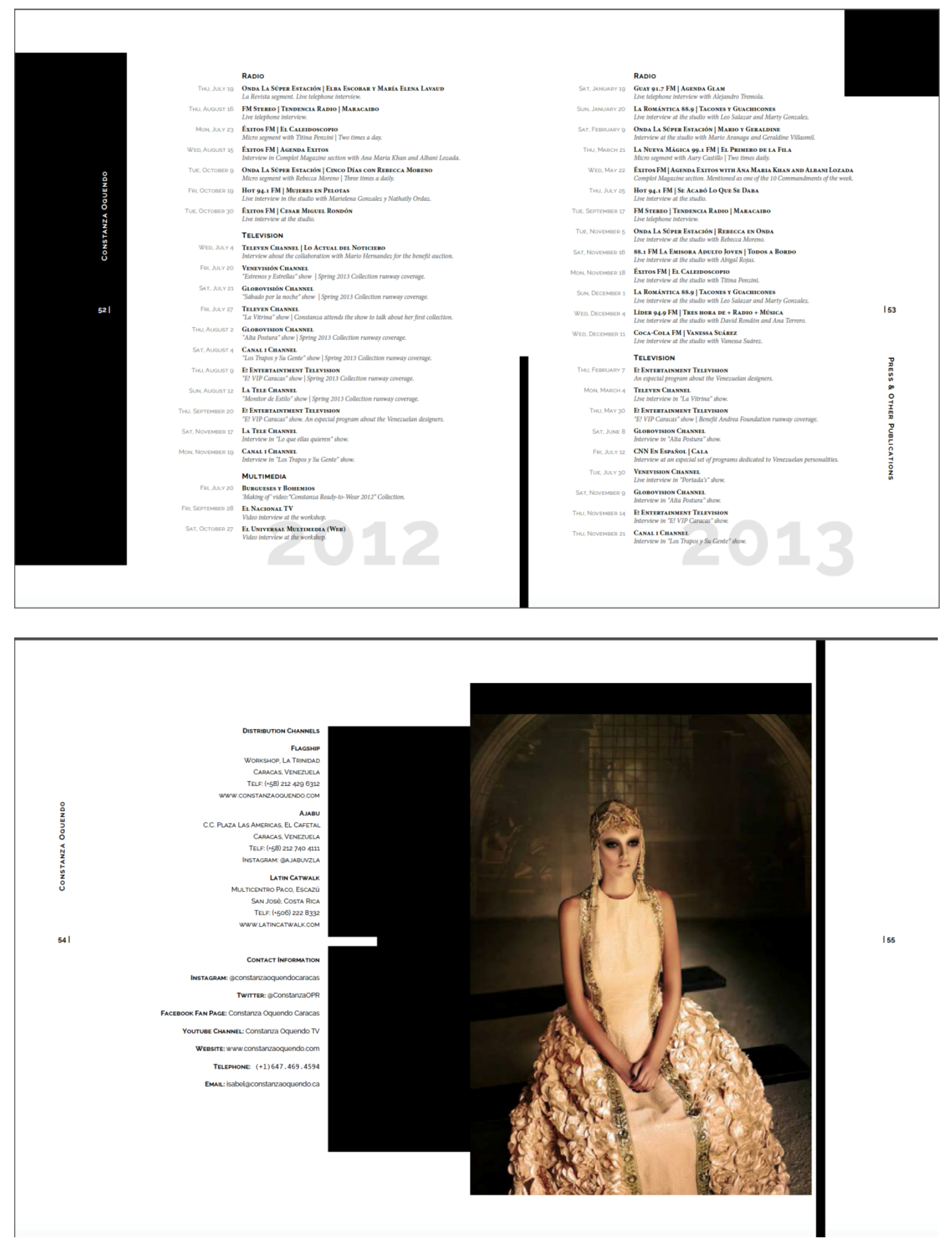

Figure 3. Look Book (cont'd). 

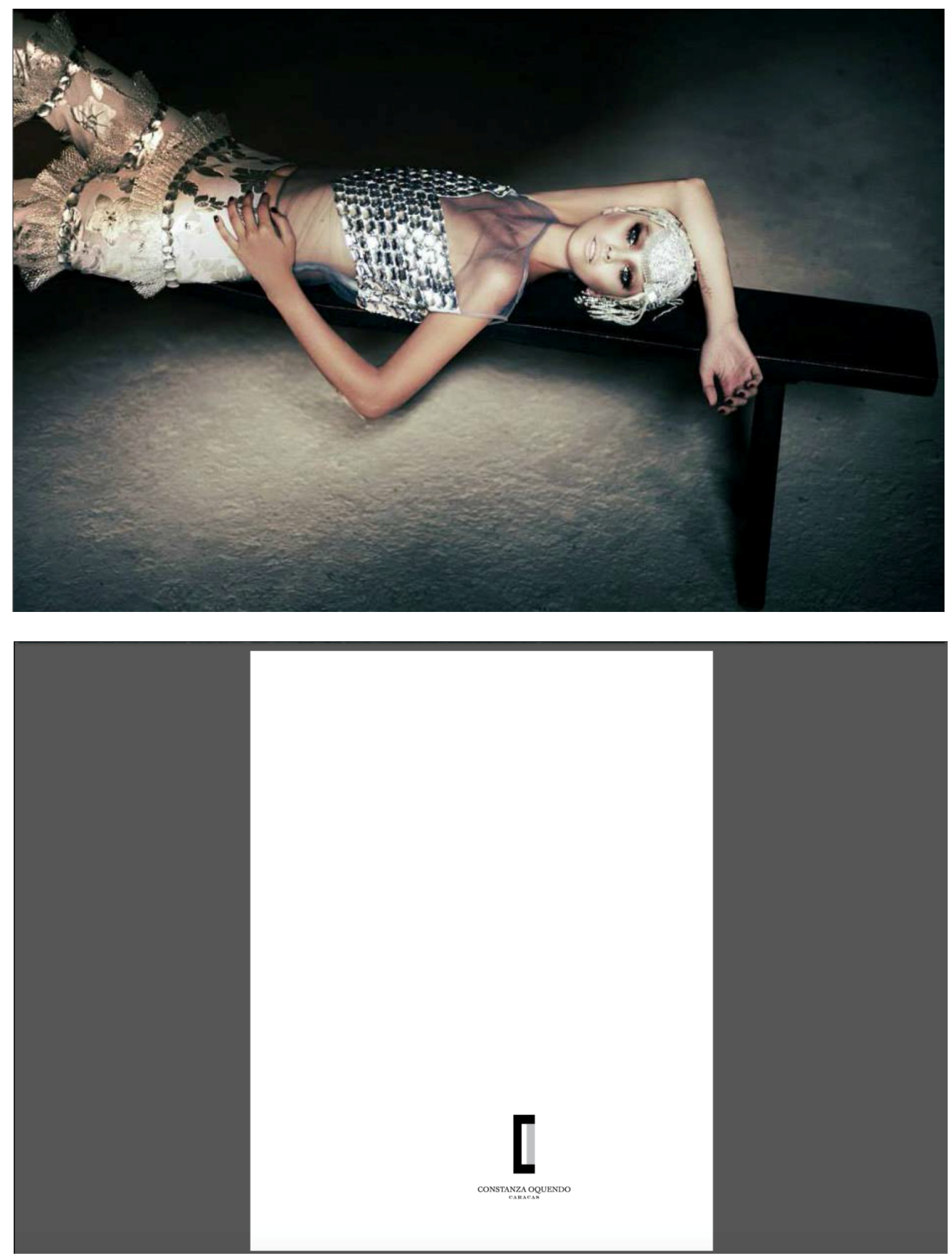

Figure 3. Look Book (cont'd). 
Appendix 4: ConstanzaOquendo'sPrinted Look Book

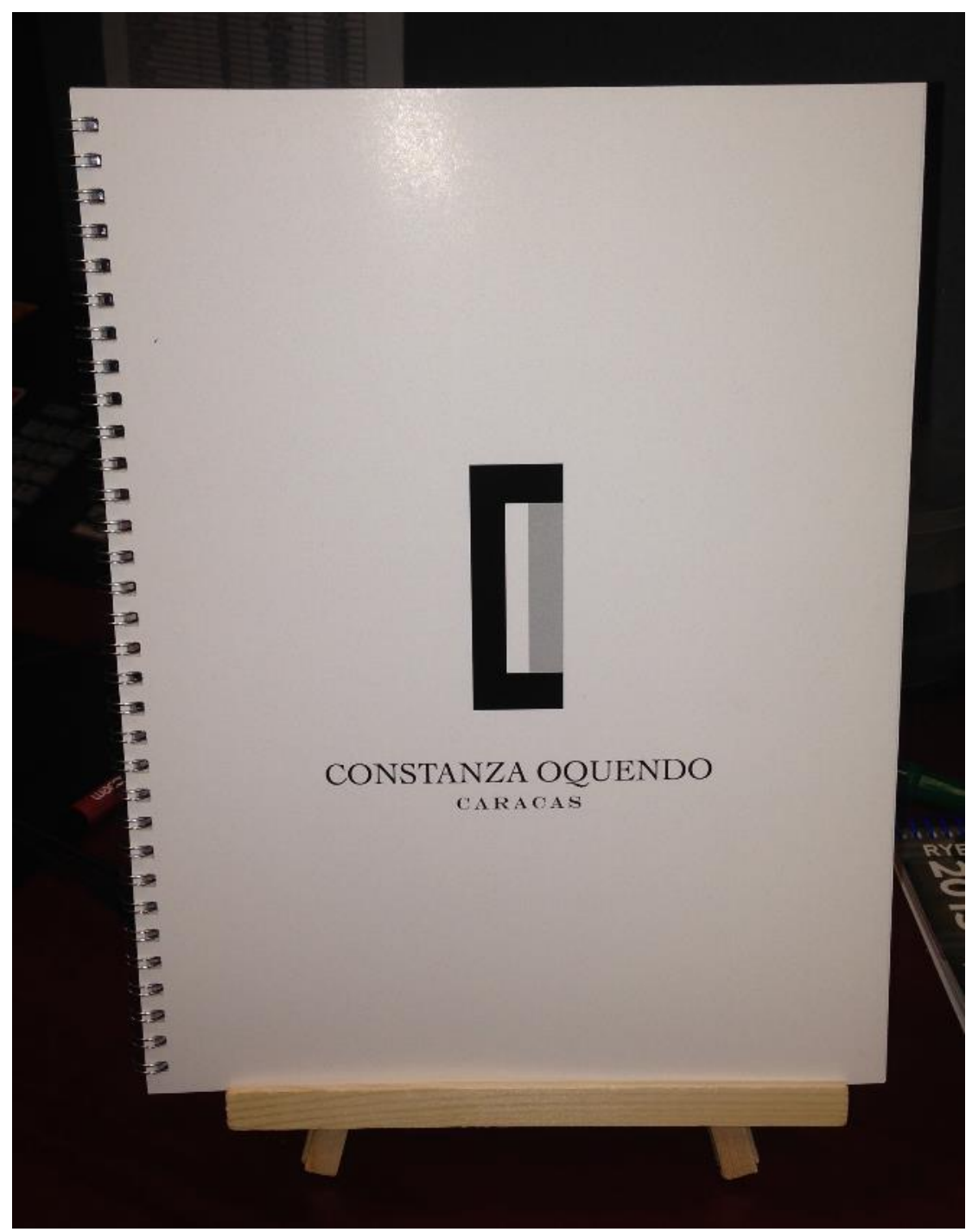

Figure 4. Look Book cover. This figure details the printed Look Book. 
Appendix 5: ConstanzaOquendo Business Card

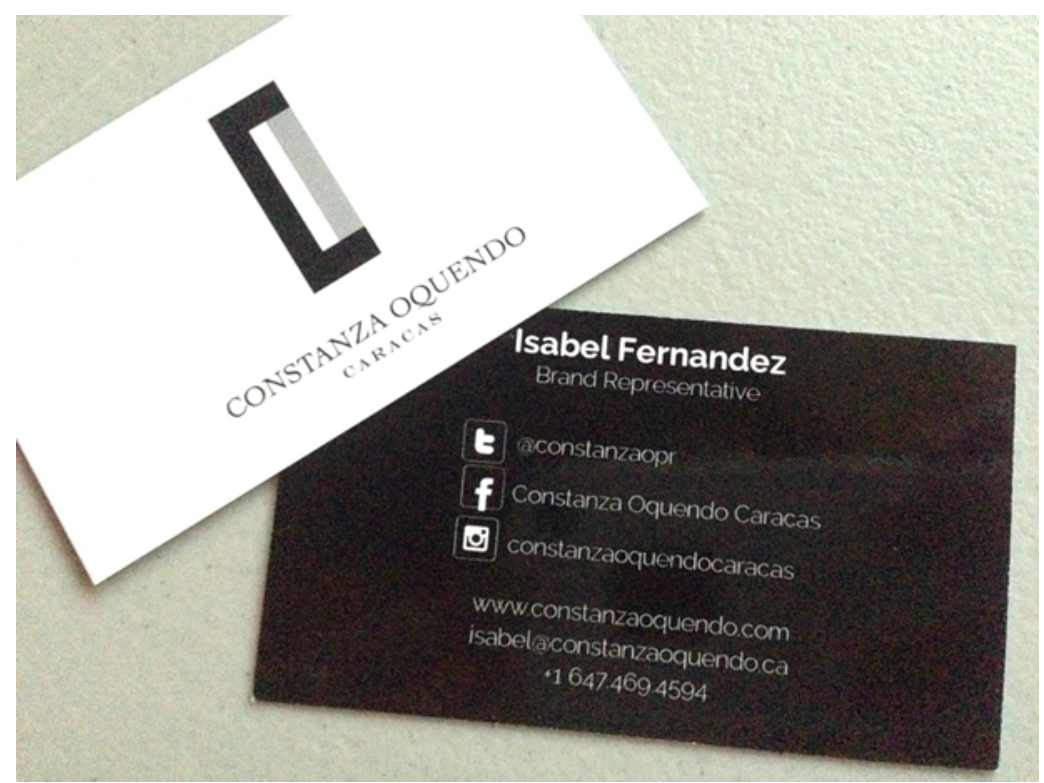

Figure 5. Business cards. This figure shows the contact cards created for the events. 
Appendix 6: Constanza Oquendo's Contact Book

For more information regarding new collections, sales and Constanza Oquendo events please fill the contact information below

\begin{tabular}{|l|l|l|l|l|}
\hline Name & Last Name & Phone Number & E-mail & Comments \\
\hline & & & & \\
\hline & & & & \\
\hline & & & & \\
\hline & & & & \\
\hline & & & & \\
\hline & & & & \\
\hline & & & & \\
\hline & & & & \\
\hline & & & & \\
\hline & & & & \\
\hline & & & & \\
\hline
\end{tabular}

Figure 6. Contact book. This figure shows the design for the sheets of the Contact Book. 
Appendix 7: ConstanzaOquendo's Garment Tags

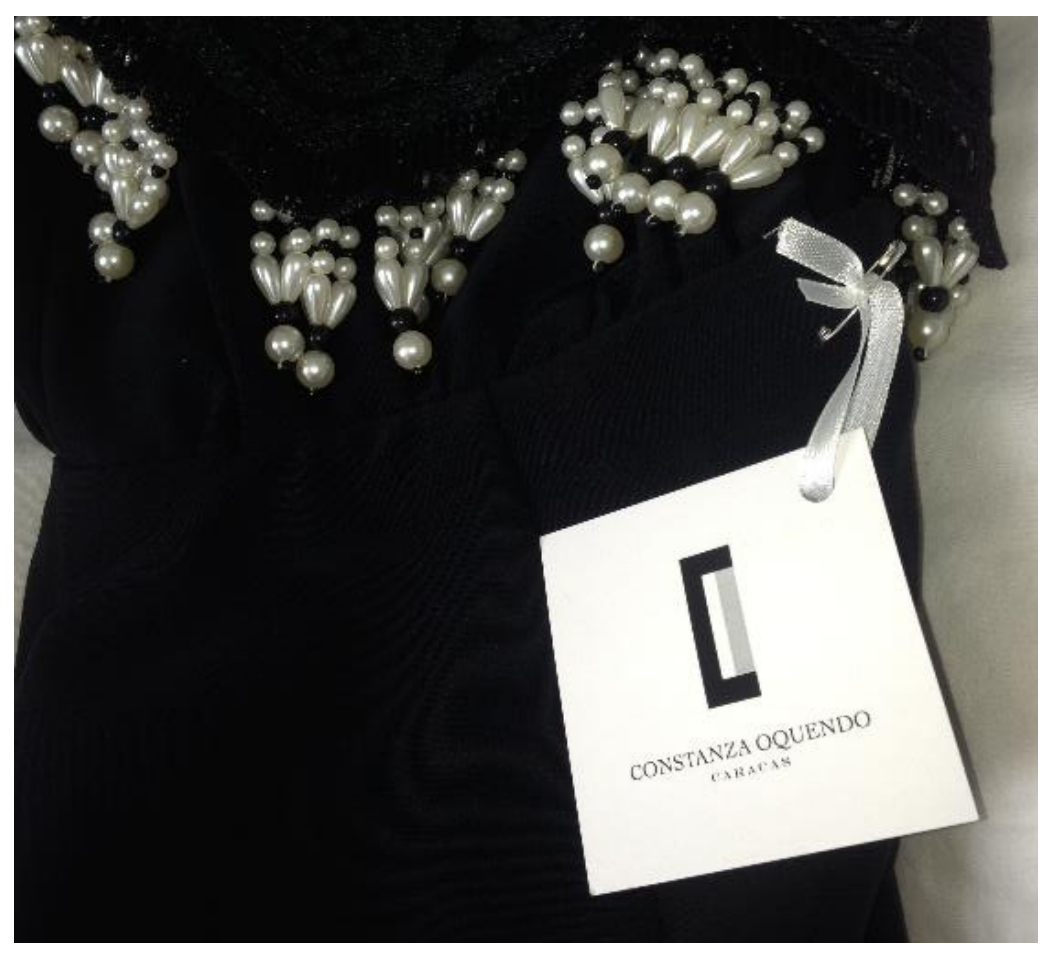

Figure 7. Garment tags. This figure shows the garment tags created for the events. 
Appendix 8: Constanza Oquendo's Line Sheet

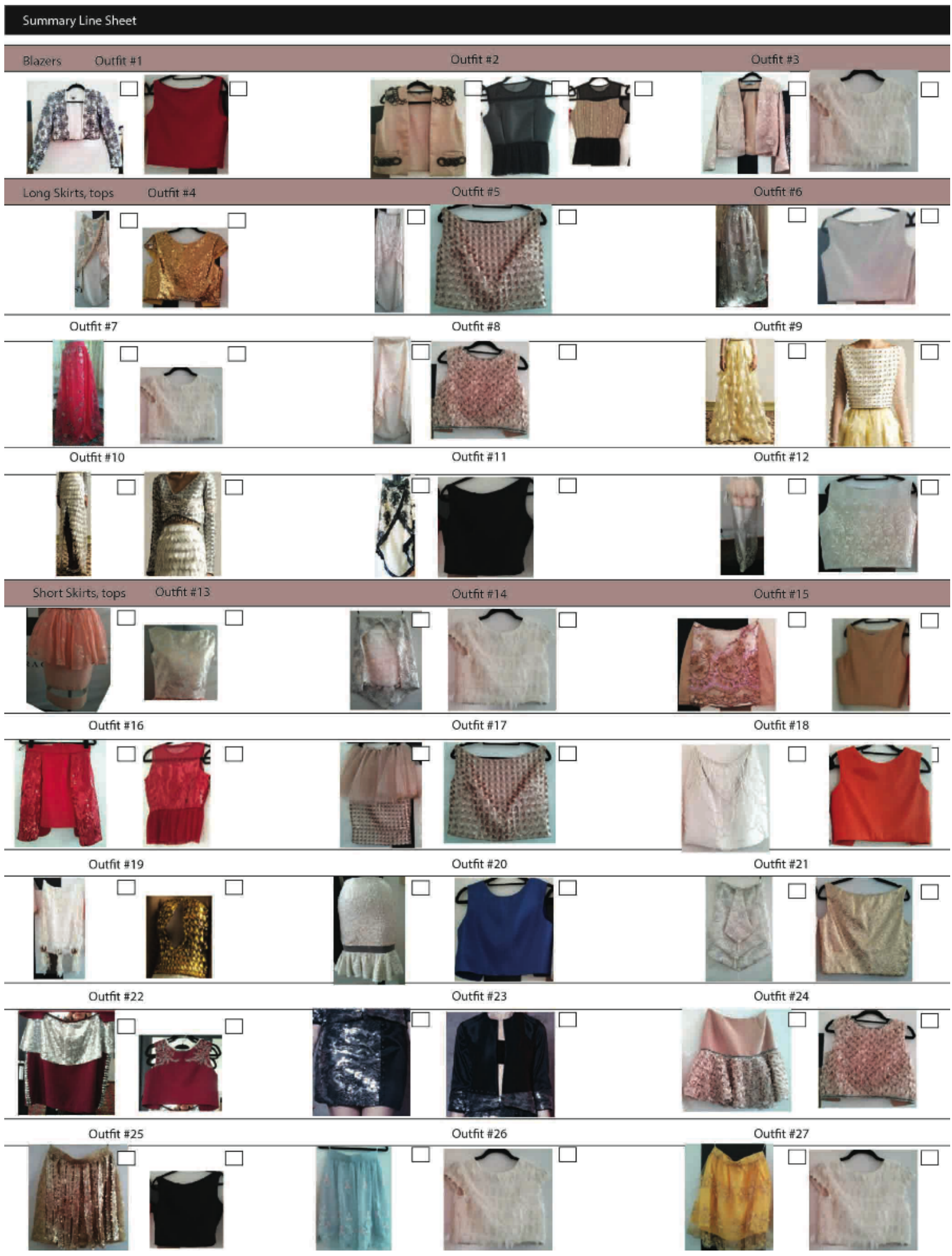

Figure 8. Line sheet. This figure shows the table created with all the samples. 


\section{Appendix 9: Constanza Oquendo's Samples Selected}

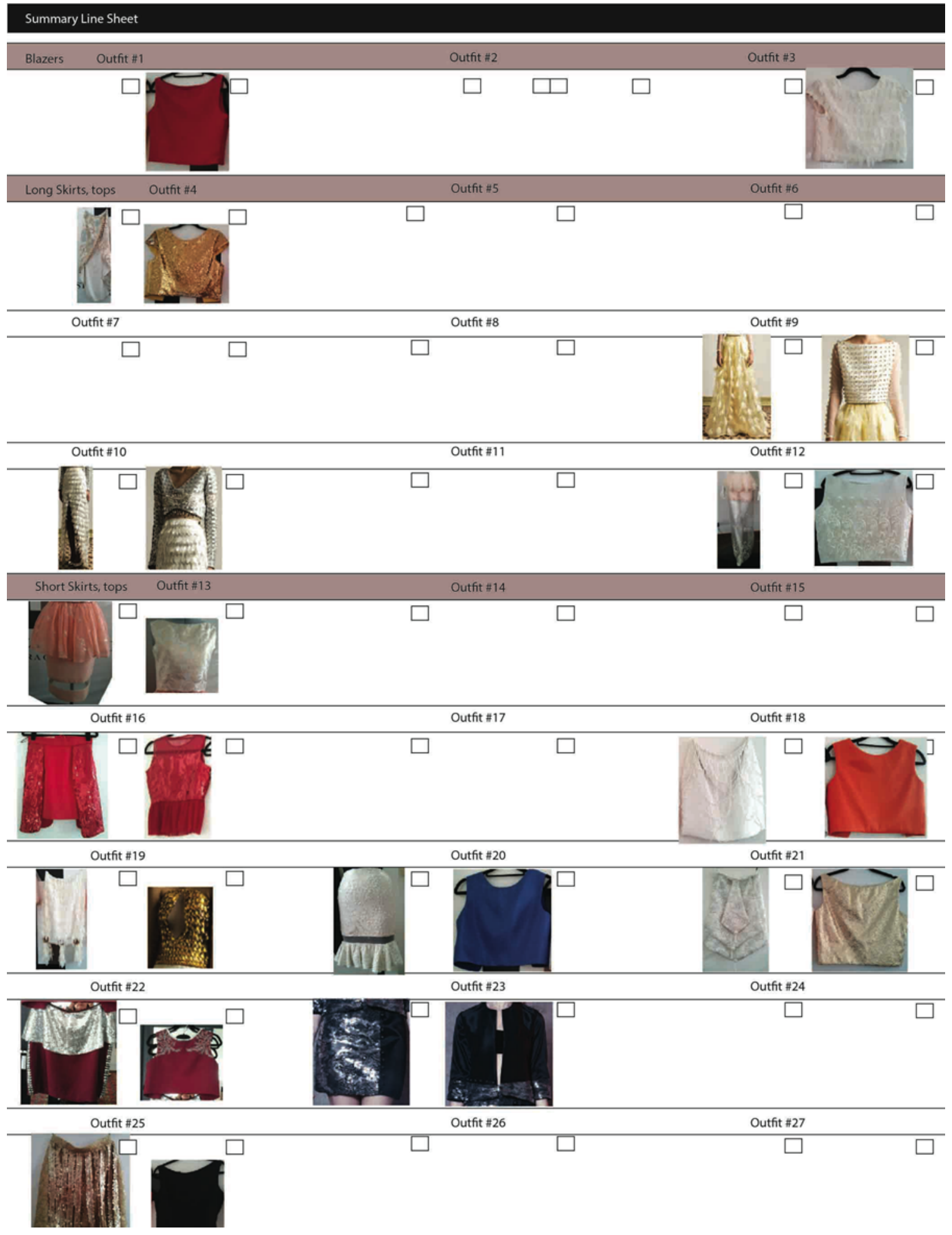

Figure 9. Garment samples selected. This figure shows the garments that were selected to import into Canada. 
Appendix 10: Constanza Oquendo's Pricing Chart

\begin{tabular}{|c|c|c|c|c|c|}
\hline Article & Garment & $\begin{array}{l}\text { Wholesale } \\
\text { price US\$ }\end{array}$ & $\begin{array}{l}\text { Wholesale } \\
\text { price Can\$ }\end{array}$ & (x 2.4) & $\begin{array}{l}\text { Retail price } \\
\text { Can \$ }\end{array}$ \\
\hline 1 & & 92 & 98.92 & 237.41 & 240 \\
\hline 2 & & 443 & 476.32 & $1,150.36$ & 1,150 \\
\hline 3 & & 110 & 118.27 & 283.85 & 285 \\
\hline 4 & & 110 & 118.27 & 283.85 & 285 \\
\hline
\end{tabular}

Figure 10. Garment pricing chart. This figure shows the garments that were selected and their prices. 
Appendix 11: XPosed Pictures of Constanza Oquendo's Stand

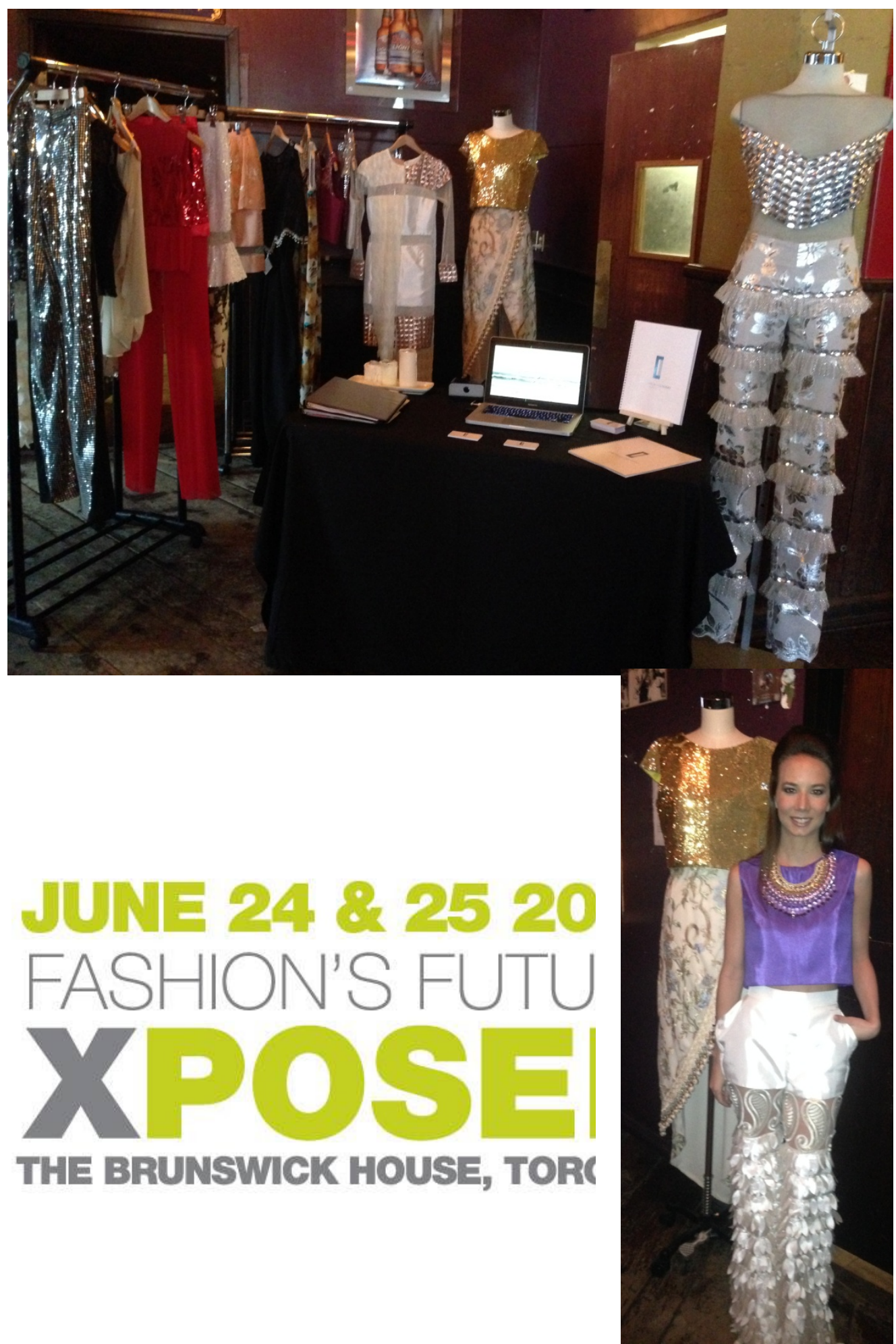

Figure 11. XPosed pictures of Constanza Oquendo's stand. 


\section{Appendix 12: Constanza Oquendo's “Thank You” Email}

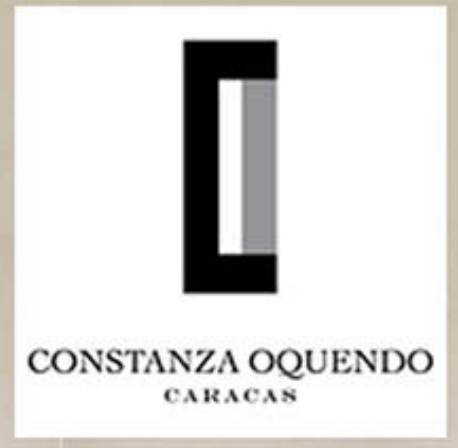

On behalf of Constanza Oquendo we want to thank you for attending the XPosed Fashion Show. This was the first showcase of Constanza Oquendo's designs in Canada and the response was very positive.

I would like to keep in touch with you as Constanza Oquendo will be participating in other upcoming local fashion events. We hope you will honor us with your presence.

Please feel free to contact me in regards to any ideas or events you think are a good opportunity for collaboration.

Thanking you,

\section{Isabel Fernandez}

Brand representative

Constanza Oquendo

$+1647.469 .4594$

www.constanzaoquendo.com

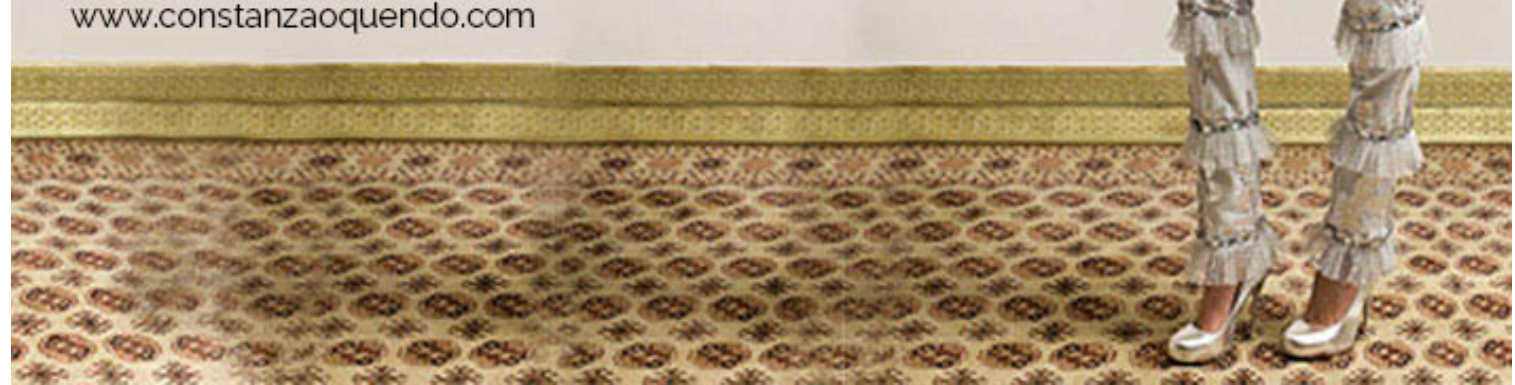

Figure 12. Constanza Oquendo's “thank you” email sent after the XPosed event. 


\section{Appendix 13: Pictures From Constanza Oquendo's Stand at Cityfest Art Walk}
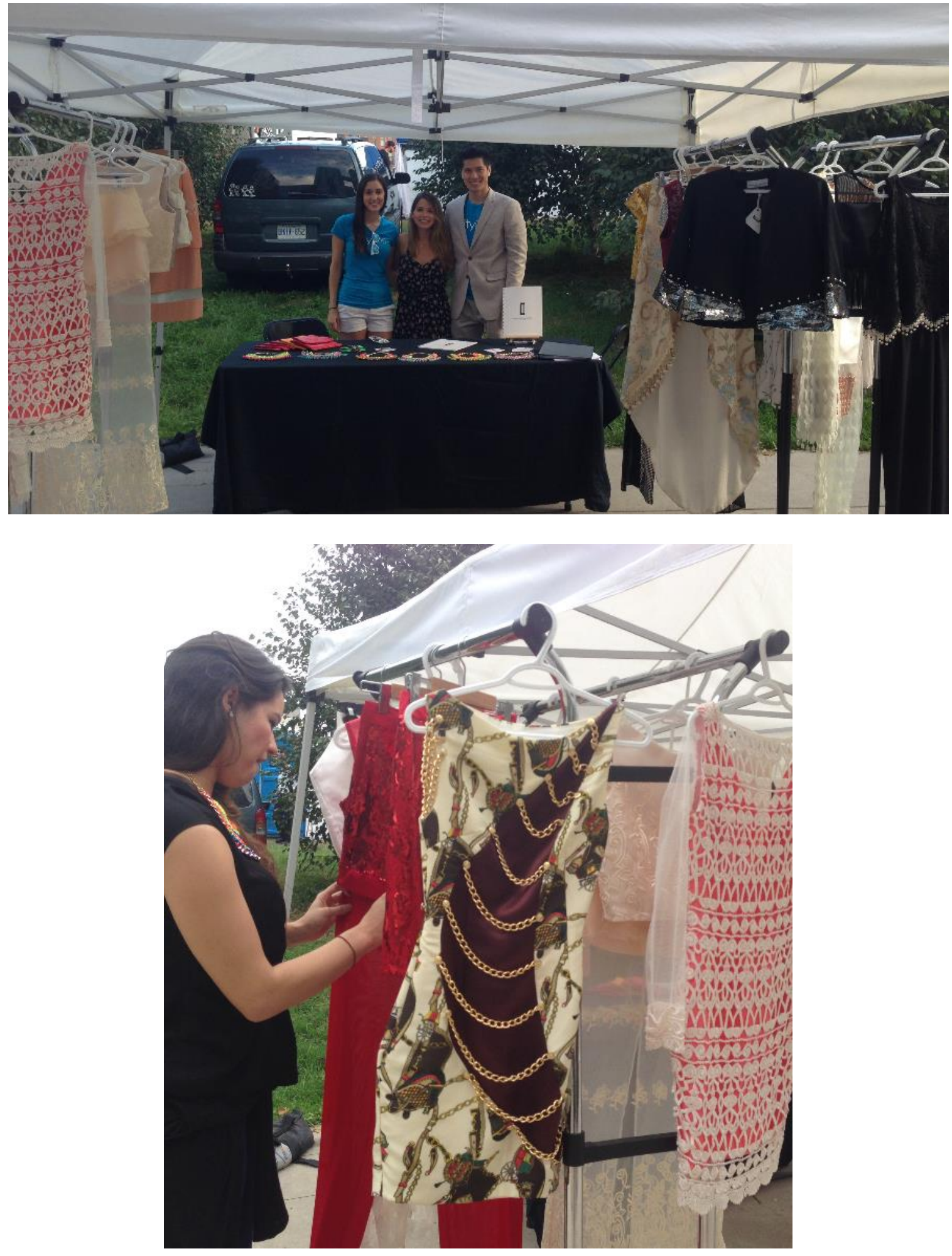

Figure 13.Cityfest Art Walk pictures of ConstanzaOquendo's stand. 


\section{Appendix 14: Latin Fashion Week Pre-launch Party}
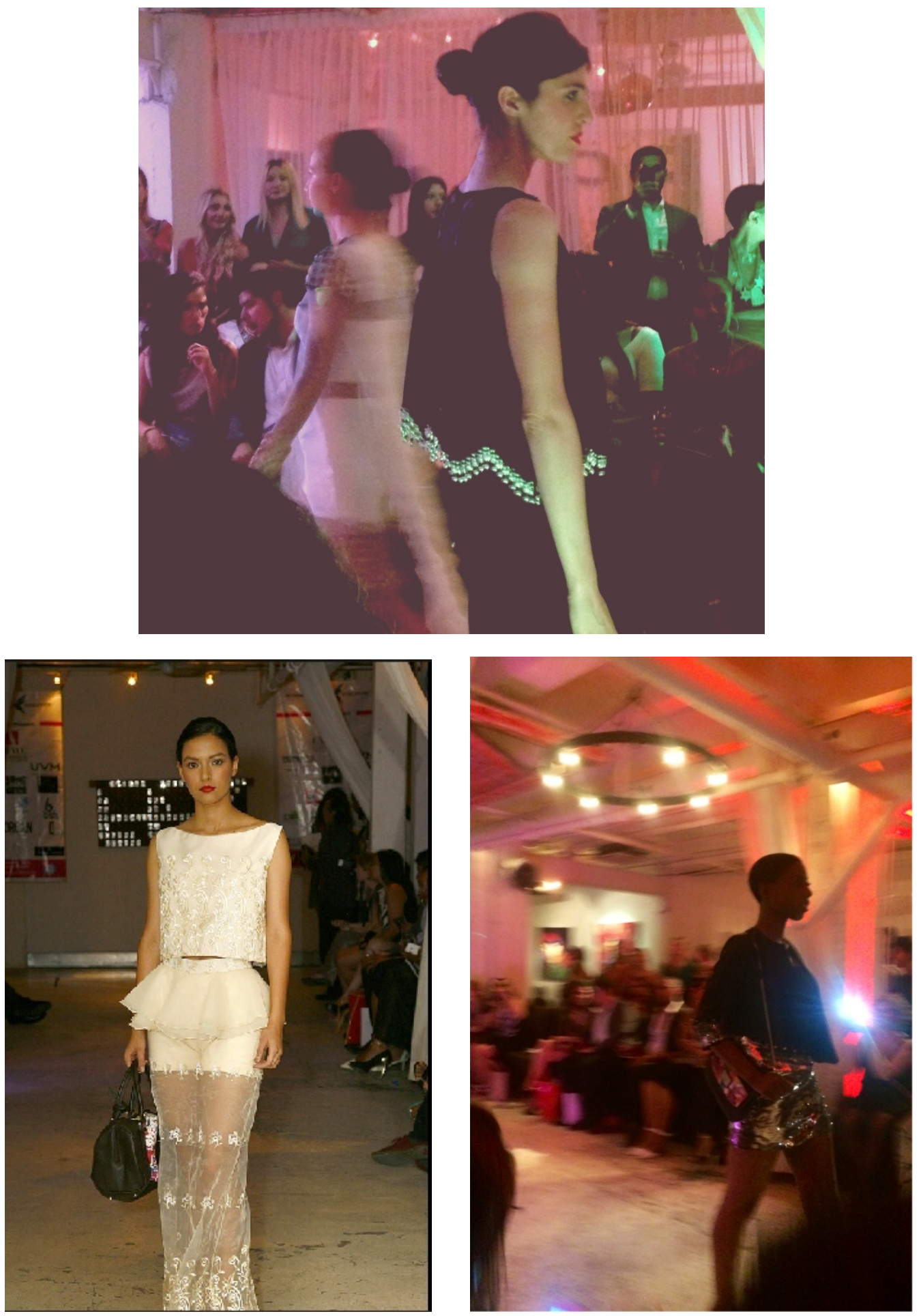

Figure 14. Latin fashion week pre-launch party. 
Appendix 15: Latin Fashion
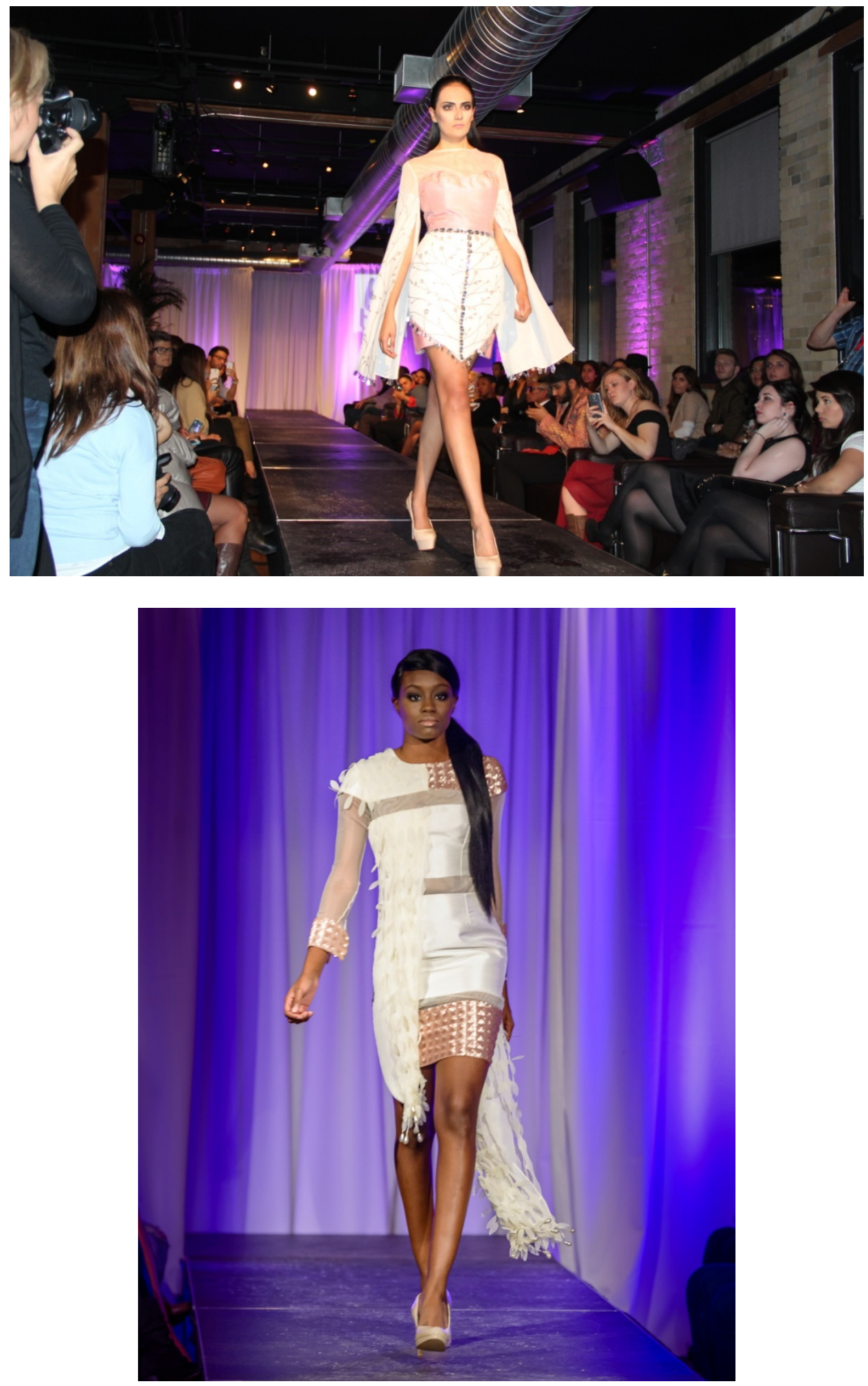

Figure 15. Latin fashion runway show. 


\section{Appendix 16: Media Exposure}

\section{MODA LATINA TUVO SU PASARELA EN TORONTO}

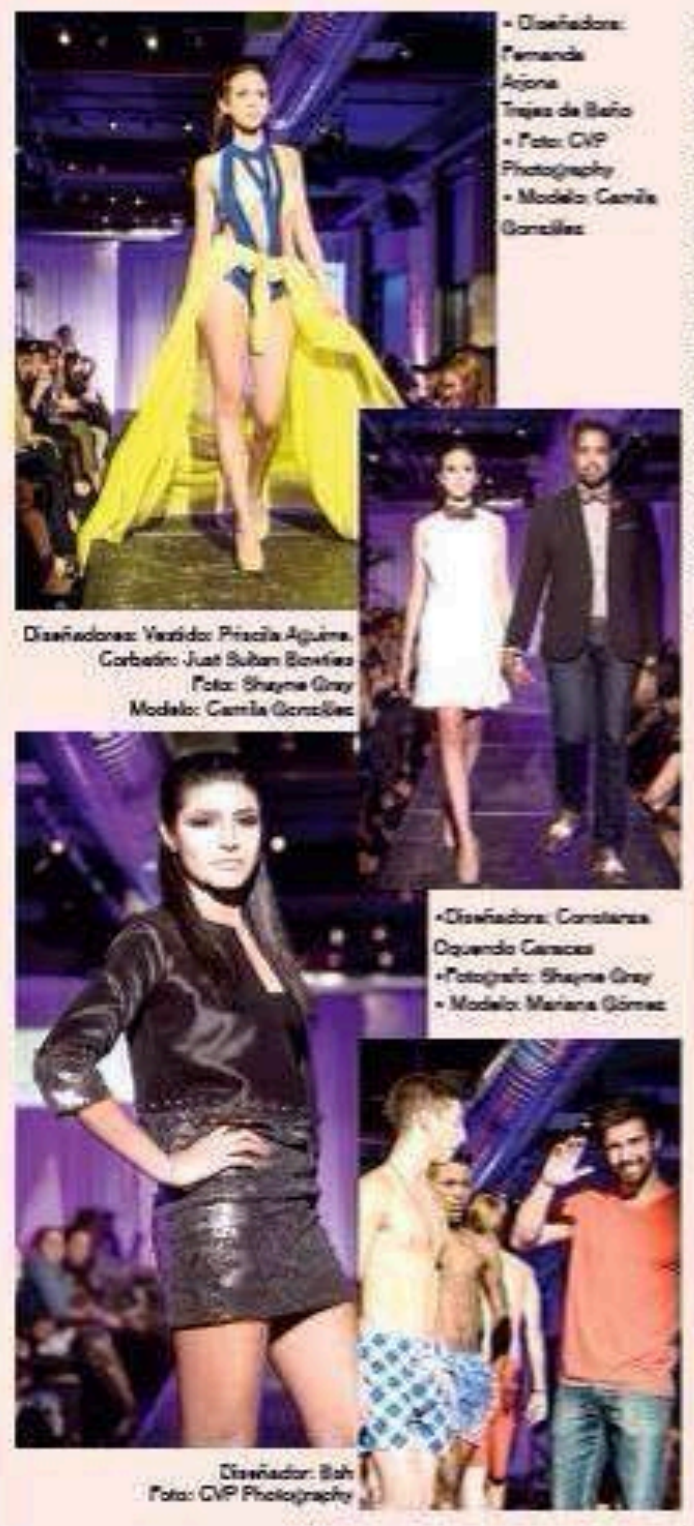

Con bollas modolos, inno- Los y ias modolos do orivadones disorios do crez- pen latinoamoricano tamtivos $y$ ormorgonto talontos bión tuvioron alli un lugar do cinco palsos so llowo ospocial pare mostrer sus a cabo reciontomento on capacidados.

Tononto il latin amorican parto do b rocaudado on Fashion Wook Canada. los diforontos dosfilos ha LAPWC, por sus ziglas on sido donado a 12 ong lo ingles, mostro la moipr do cal Act Toronto, que brind dachadoros tanto loca. servicios do apojo a porlos como intornacionaios, sones quo whon con Virl dandolo nuevamonto una sida.

pasarola y una posbilidad tuopo do habor sido creado mostrarso on Nortoz- do esto ovonto on ol 2013

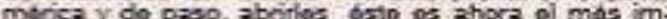
poribindados comproialog. portante do zu fipo on Ca Segan coments or organi- nadd, sogun lo comonts zador dal eventa, a mosi- Nidnios.

cano Hidector kontos, ontro Anowd so aprocian algua 24 yo ze do octubre pa- nas imagonps dol Latin sados osto evemto oxhibio Amorican Fashion Wook croacionos do 25 depta- LAFViC-. KAgradocomos dores do Canadb, Mboico, a Sivia Arroyavo por 54 Pord. Colombiay Brat. aporto parz estz notz).

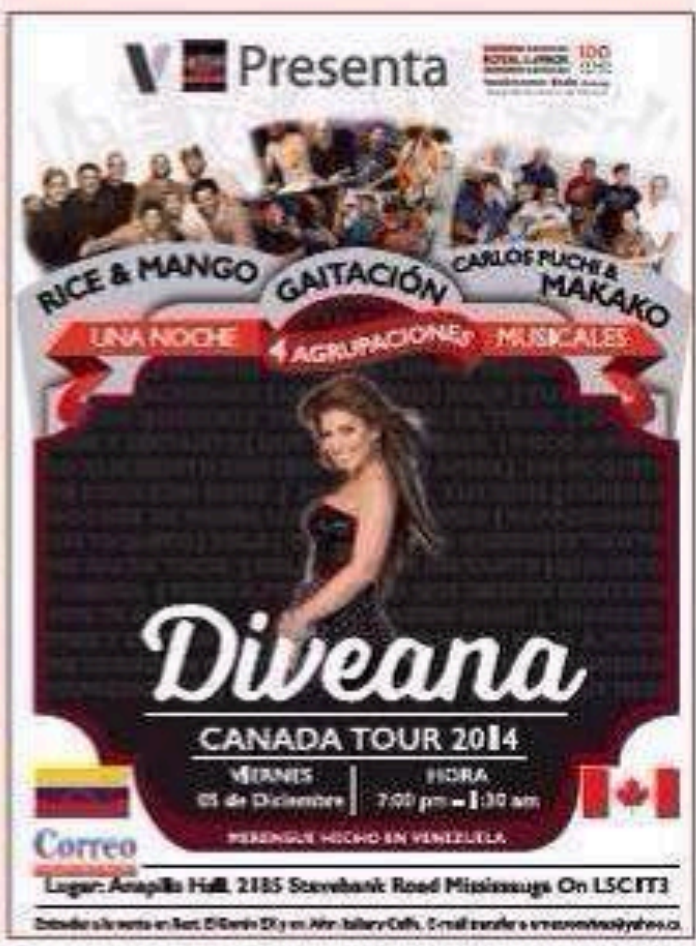

Figure 16.CorreoCanadiense paper. Latin American Fashion Week Canada was featured in the CorreoCanadiense paper, a local Latin American Newspaper in Toronto. 
FASHION'S FUTURE XPOSED
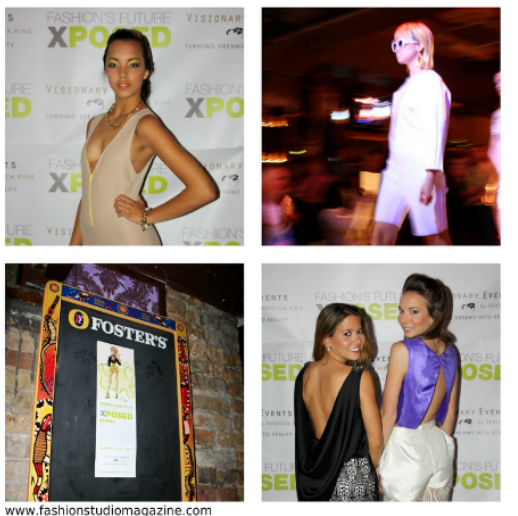

Photos by Eva Fydrych / Fashion Studio Magazine (Click to enlarge)

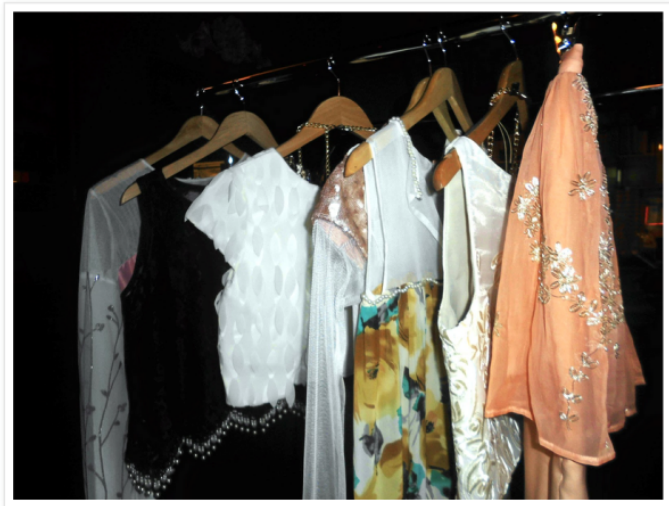

Designs by Constanza Oquendo (Venezuela)

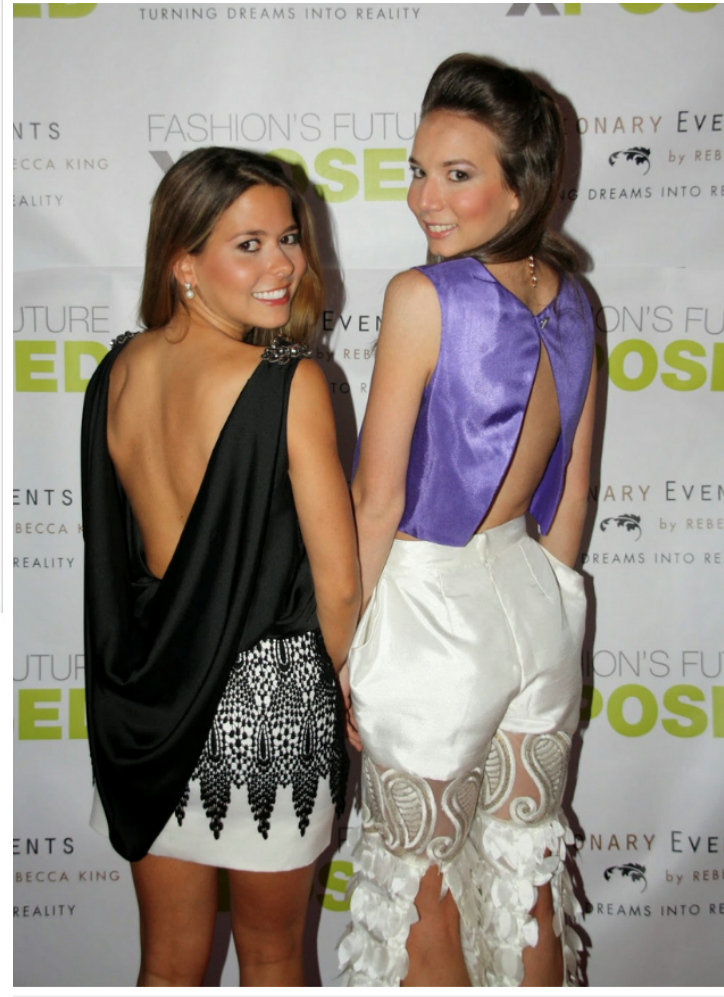

Designs by Constanza Oquendo (Photos by Eva Fydrych / Fashion Studio Magazine)

TORONTO - Yesterday night Fashion Studio Magazine had a pleasure to attend Xposed Fashion Show - an event showcasing emerging Canadian designers.

Organized by Visionary Events, the show took place at Toronto's iconic Brunswick House (481 Bloor Street West) and featured nine up-and-coming designers from across Ontario.

Apart from the runway show and the silent auction, the audience had a chance to get familiar with elegant designs by Constanza Oquendo (Venezuela) and watch the latest music videos by the Canadian singer and songwriter Vita Chambers.

Figure 17. Fashion Studio Magazine. Xposed and ConstanzaOquendo were featured in Fashion Studio Magazine. 


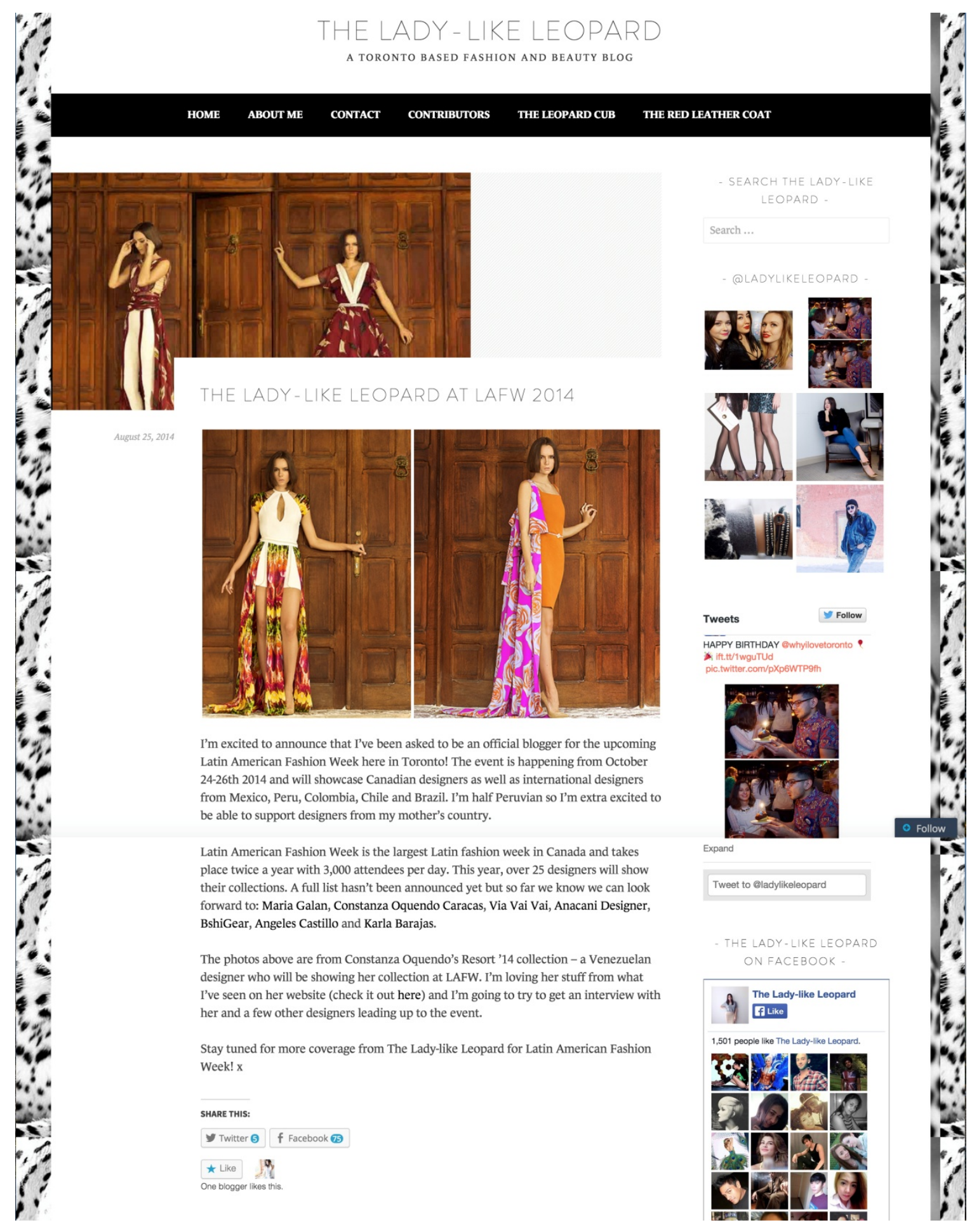

Figure 18. The Lady-Like Leopard. ConstanzaOquendo was featured in "The Lady-Like Leopard" online Blog. 


\section{Appendix 17:Questionnaire Results}

\section{Demographics}

\section{1) Gender}

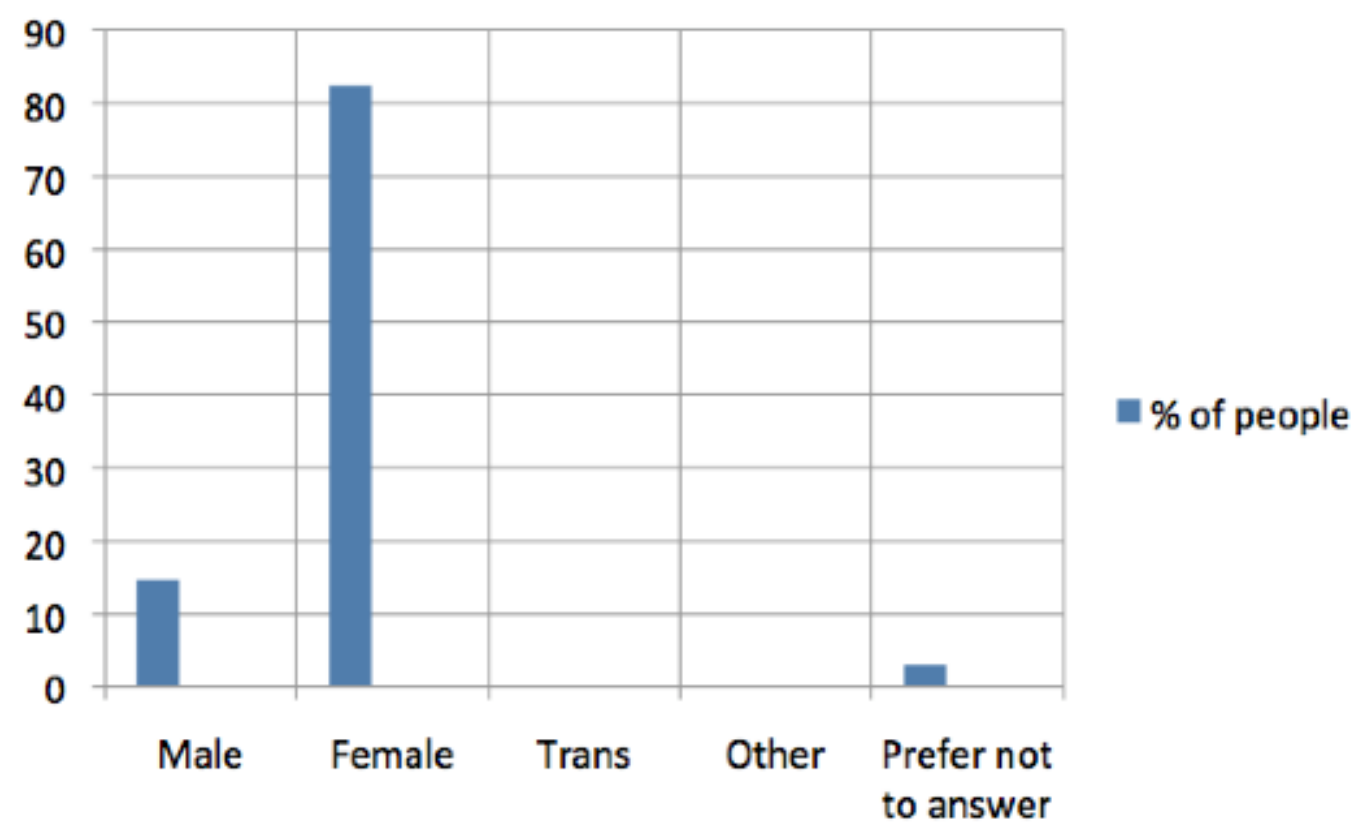

Figure 19. Gender. This figure shows the results obtained on question 1.1 of the questionnaire. 


\section{Demographics}

\section{2) Ethnicity Heritage (choose one)}

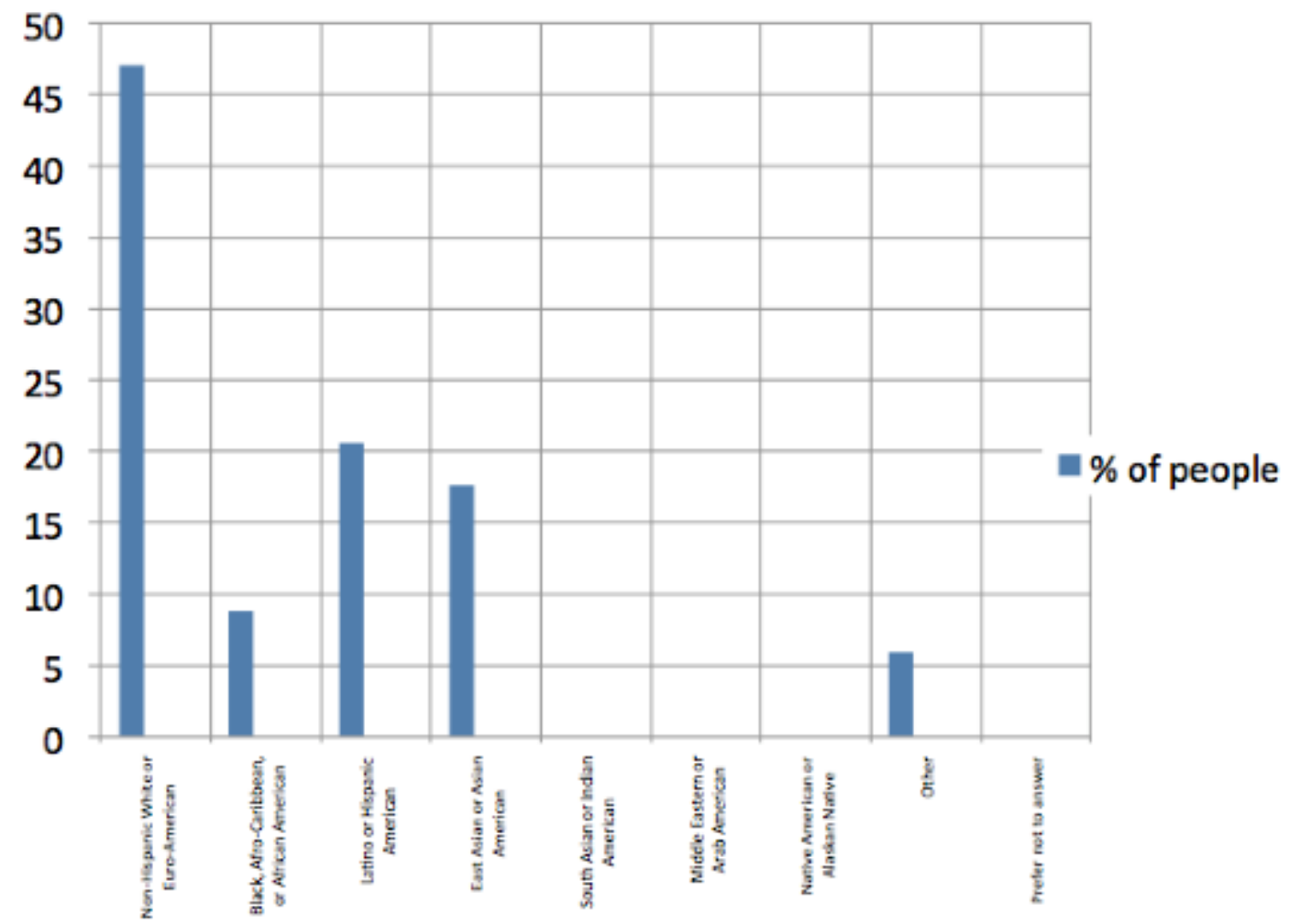

Figure 20. Ethnicity heritage. This figure shows the results obtained on question 1.2 of the questionnaire. 
Demographics

1.3) which culture do you identify yourself with? (choose one)

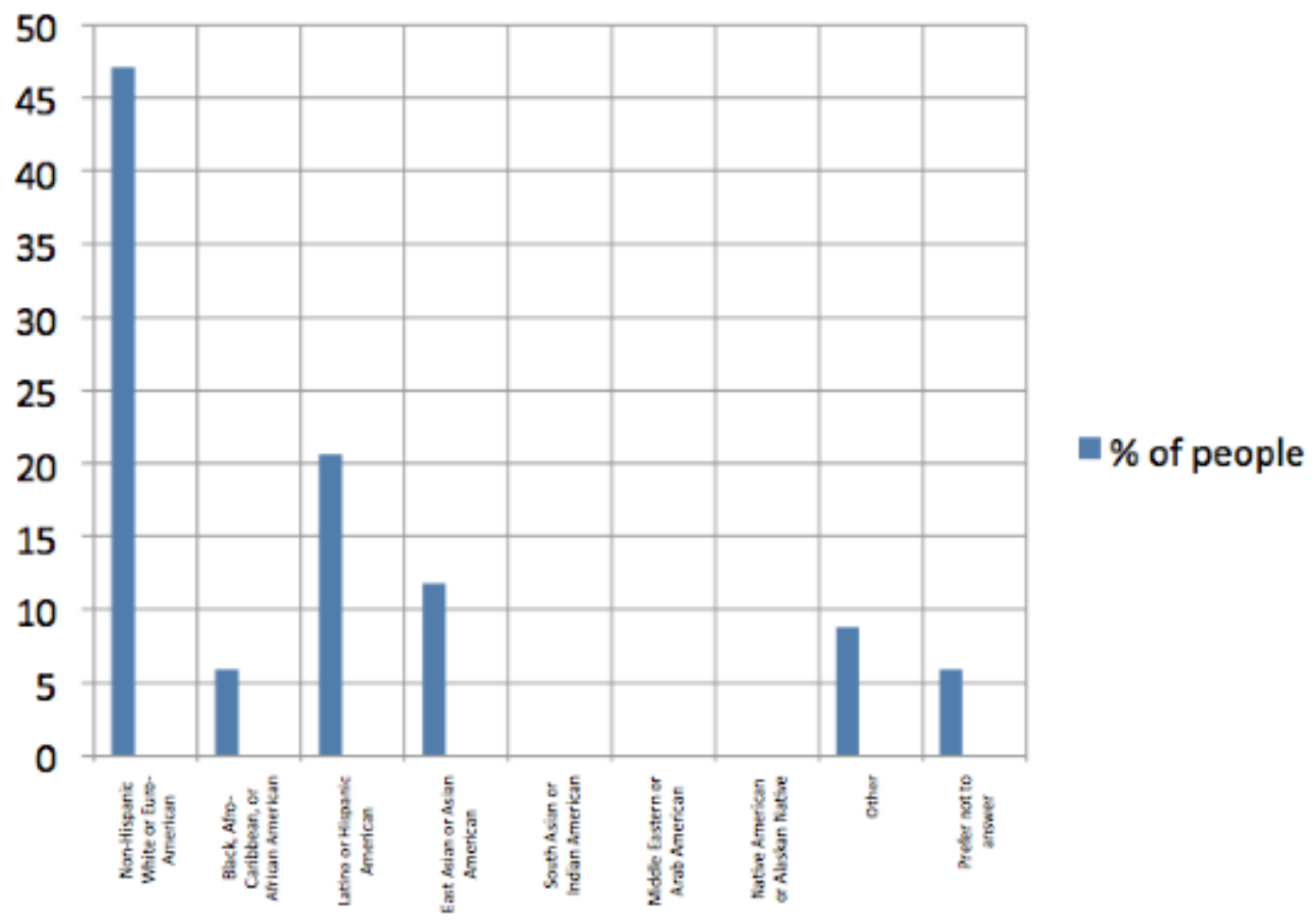

Figure 21. Culture identity. This figure shows the results obtained on question 1.3 of the questionnaire. 


\section{Demographics}

1.4) Age range

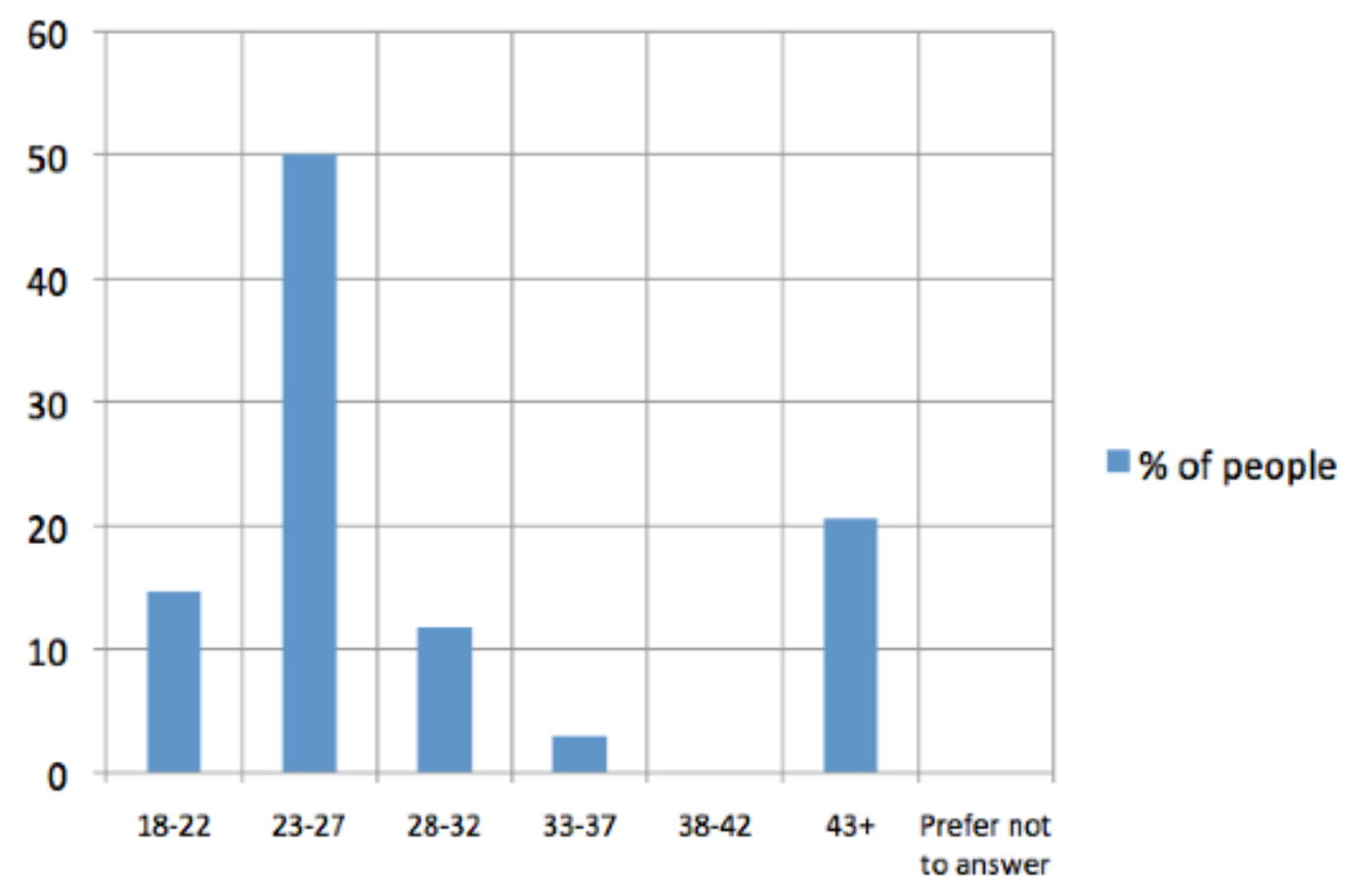

Figure 22. Age range. This figure shows the results obtained on question 1.4 of the questionnaire. 


\section{Demographics}

\section{5) Highest level of your education qualification}

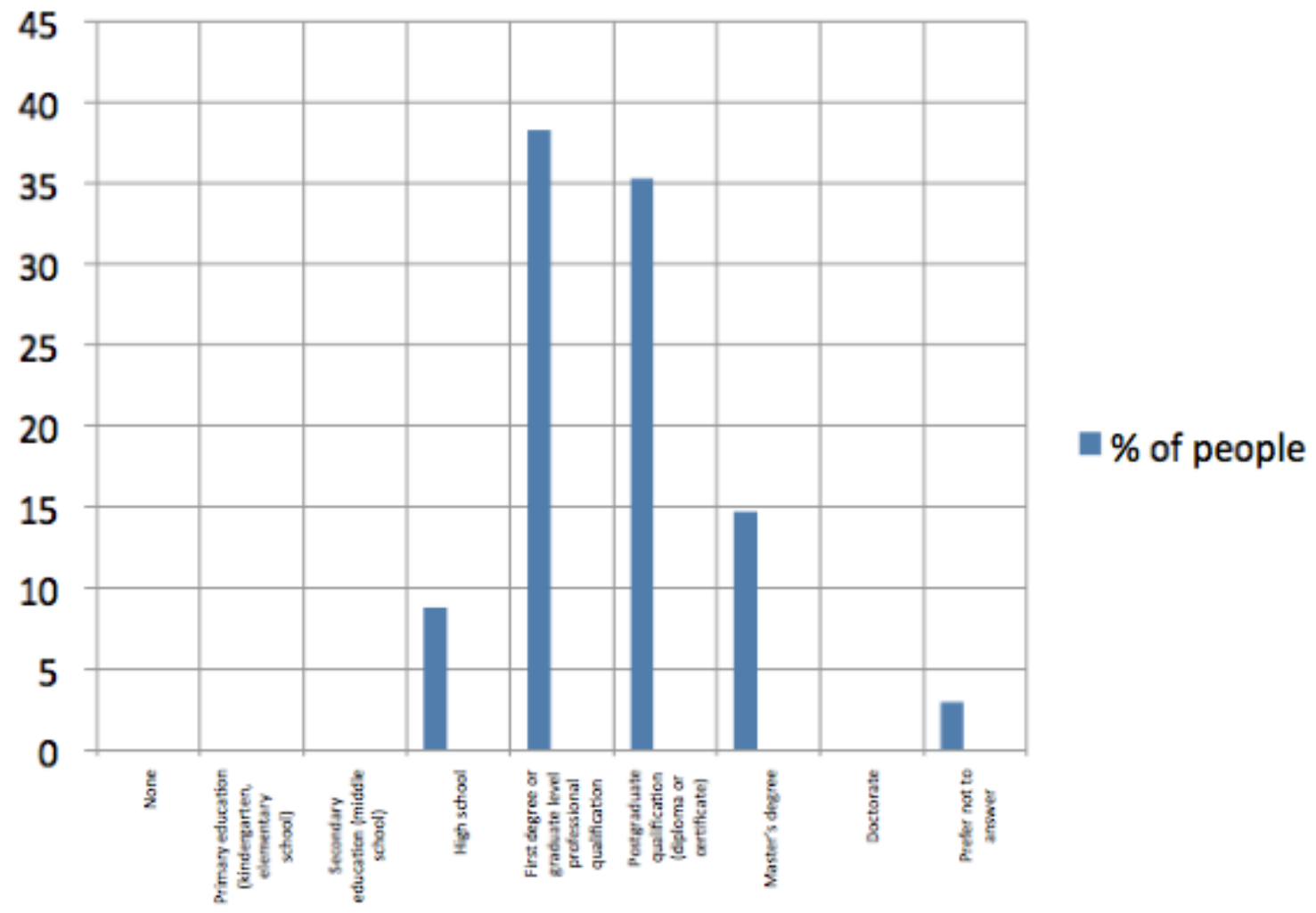

Figure 23. Education qualification. This figure shows the results obtained on question 1.5 of the questionnaire. 


\section{Demographics}

1.6) Monthly clothing expenditure (Choose one)

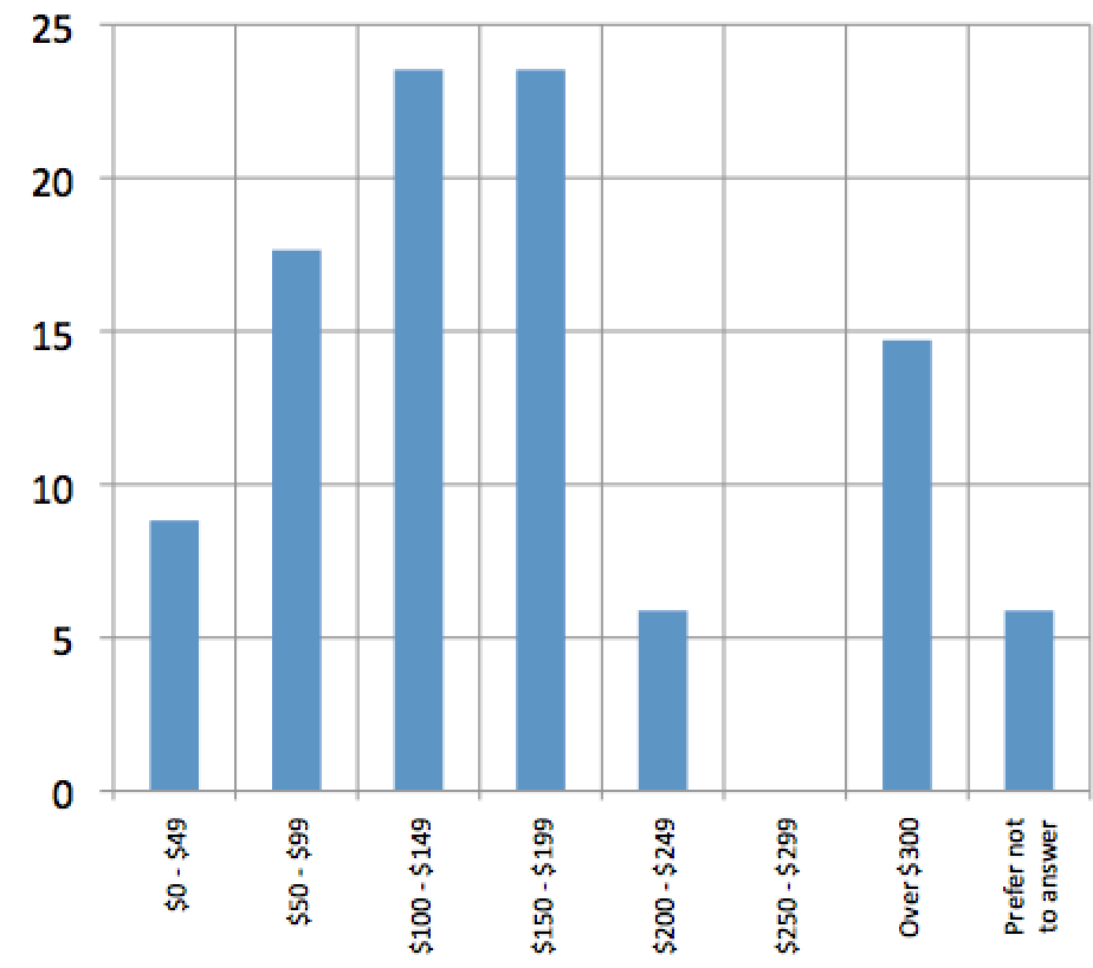

ॠ of people

Figure 24. Clothing expenditure. This figure shows the results obtained on question 1.6 of the questionnaire. 


\section{Personal Preferences}

\section{1) What color garments do your prefer? (Choose one)}
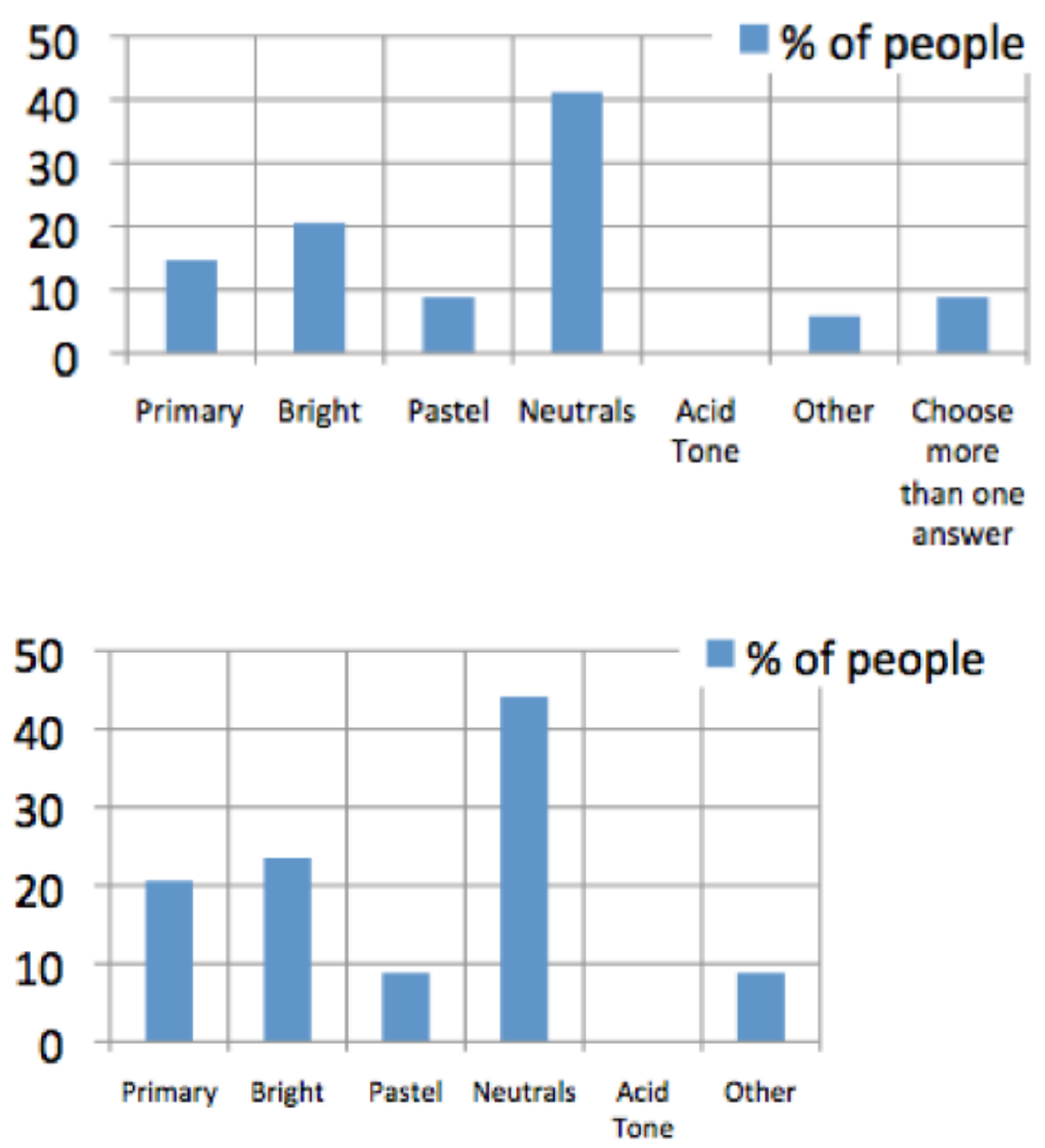

Figure 25. Color preference. This figure shows the results obtained on question 2.1 of the questionnaire. 


\section{Personal Preferences}

\section{2) What type of garment design do you prefer? (Choose one)}
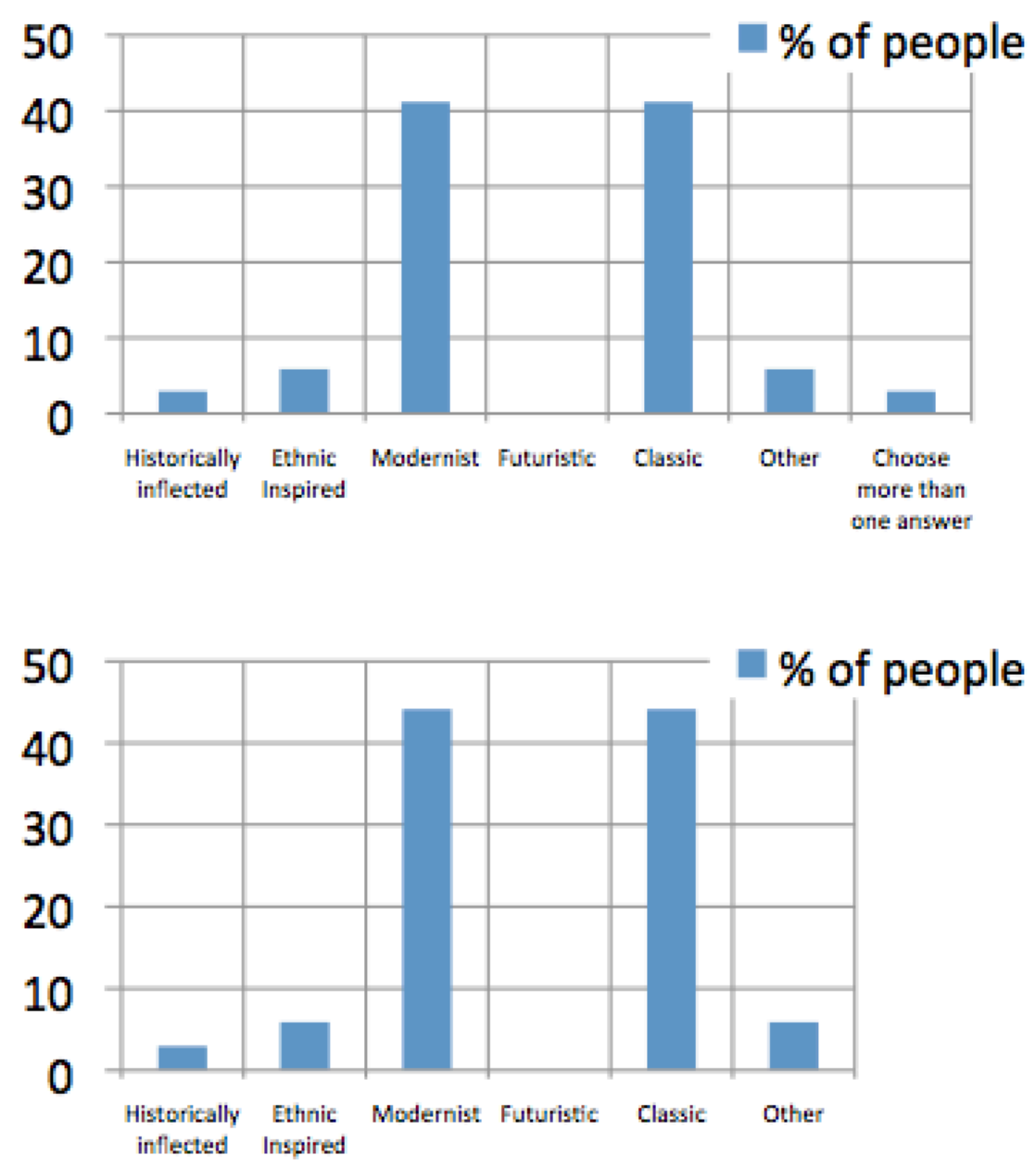

Figure 26. Garment design. This figure shows the results obtained on question 2.2 of the questionnaire. 


\section{Personal Preferences}

\section{3) Where do you go garment shopping for special evening events? (Choose one)}
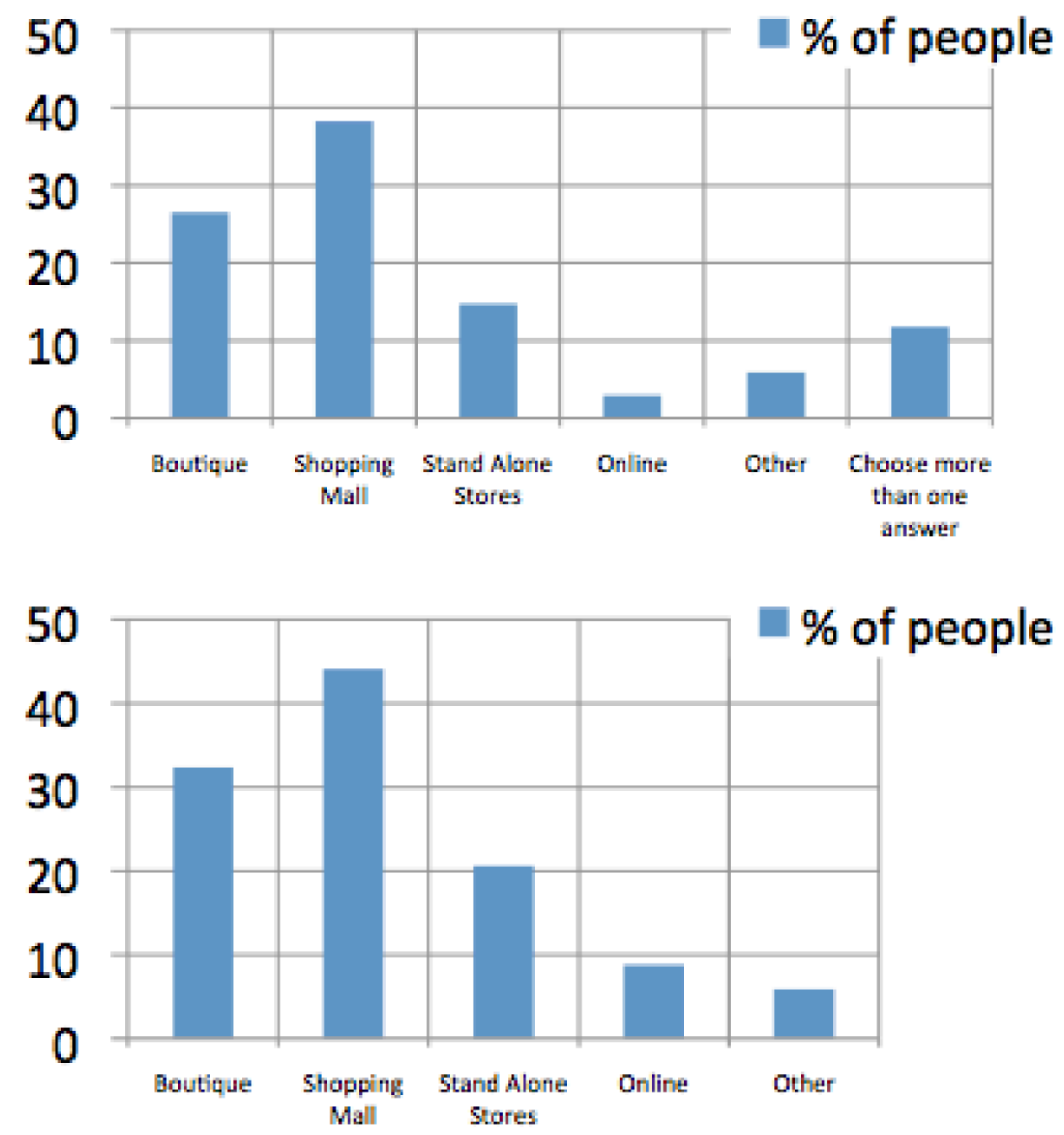

Figure 27. Eveningwear shopping. This figure shows the results obtained on question 2.3 of the questionnaire. 


\section{Personal Preferences}

\section{4) What are you looking for when you dress up? (Choose one)}
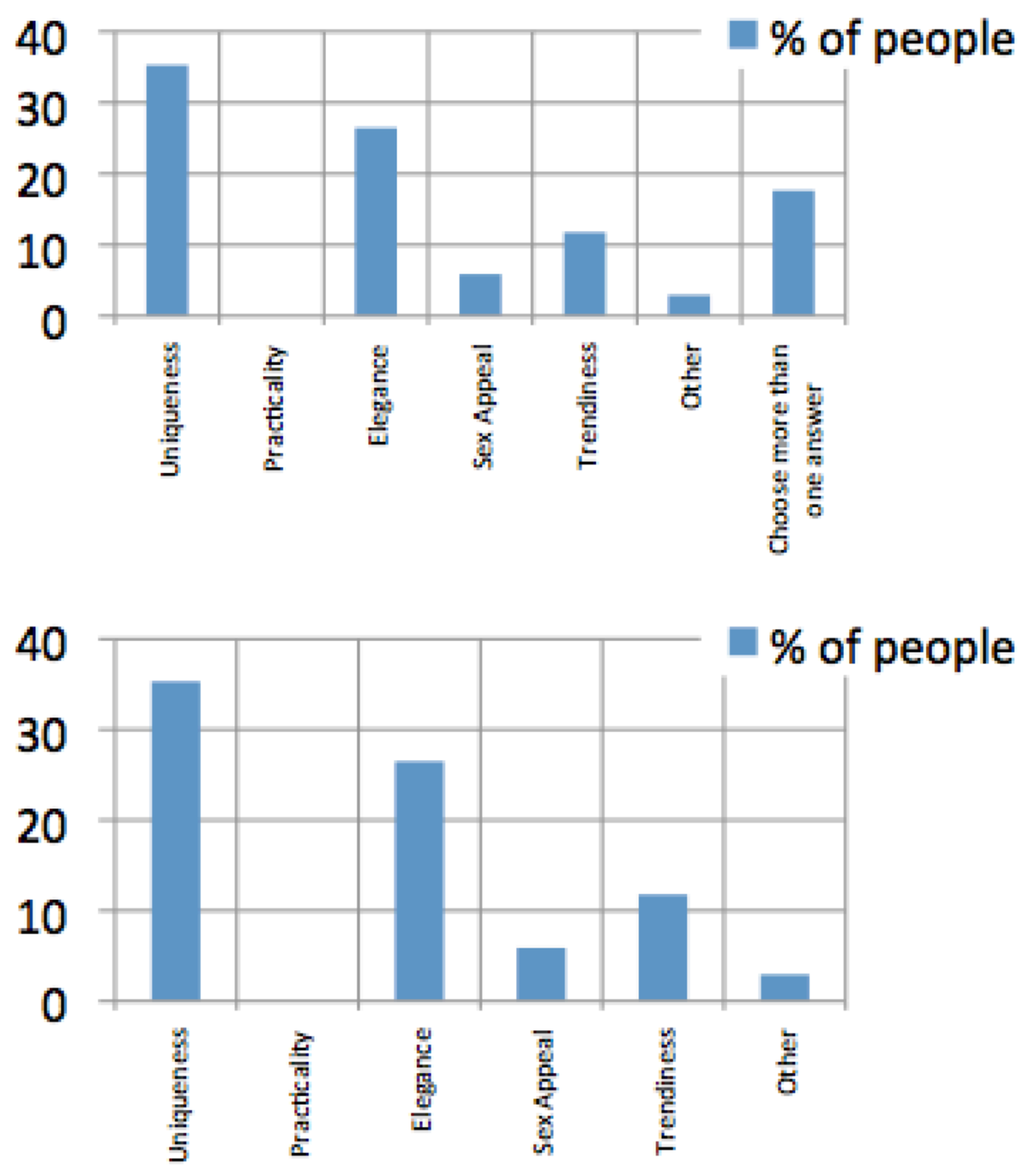

Figure 28. Dressing up. This figure shows the results obtained on question 2.4 of the questionnaire. 


\section{Personal Preferences}

\section{5) What makes you buy an evening garment? (Choose one)}
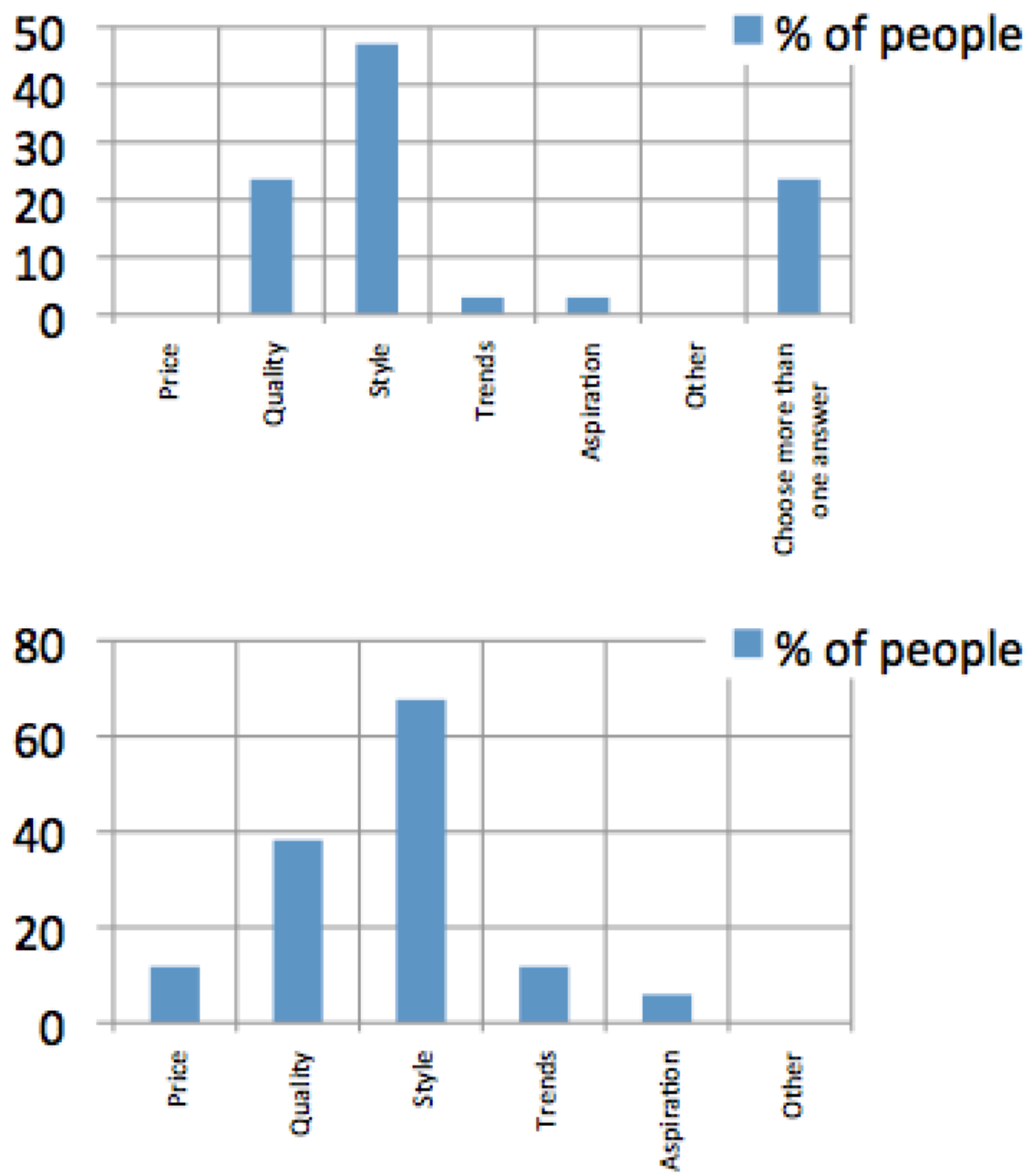

Figure 29. Buying eveningwear. This figure shows the results obtained on question 2.5 of the questionnaire. 
Product Information

3.1) List designers and brands that are in Toronto and are similar to Constanza Oquendo:

"I don't know any designer in Toronto that has pieces similar to

Constanza Oquendo"

"BCBGMAXAZRIA, Guess by Marciano"

"I can't think of any because her work is so unique"

"Not sure, similar to Zara"

"Aritzia, BCBG, Mendocino, Guess by Marciano, Bebe"

"Michael Costello"

"Nothing"

"Guess, Le Chateau"

"I don't know, I haven't been here a long time"

"Cannot define C.O. is awesome \& quite unique"

"Can't think of any"

"N/A"

"Can't think of any"

"BCBG, Guess by Marciano"

"None that I know of"

"This is too unique, I don't know any"

"Mikhael Kale"

"I have not seen designers with that style yet.

Unique yet sophisticated".

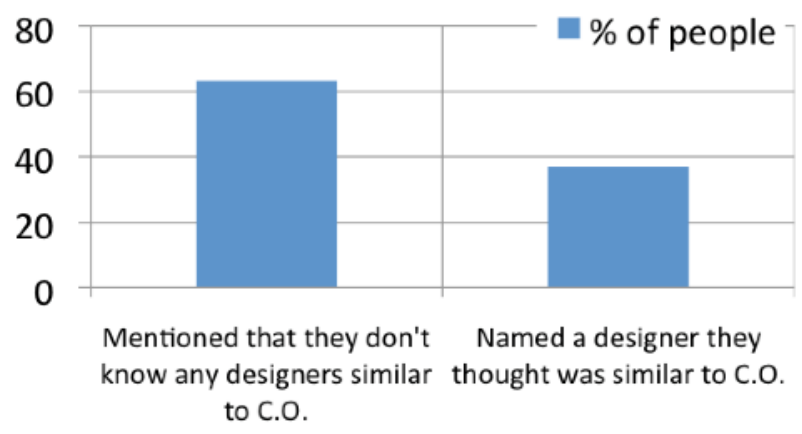

"No idea"

Figure 30. Similar designers to C.O. This figure shows the results obtained on question 3.1 of the questionnaire.

\section{Product Information}

3.2) Would you wear (C.O.) garments?

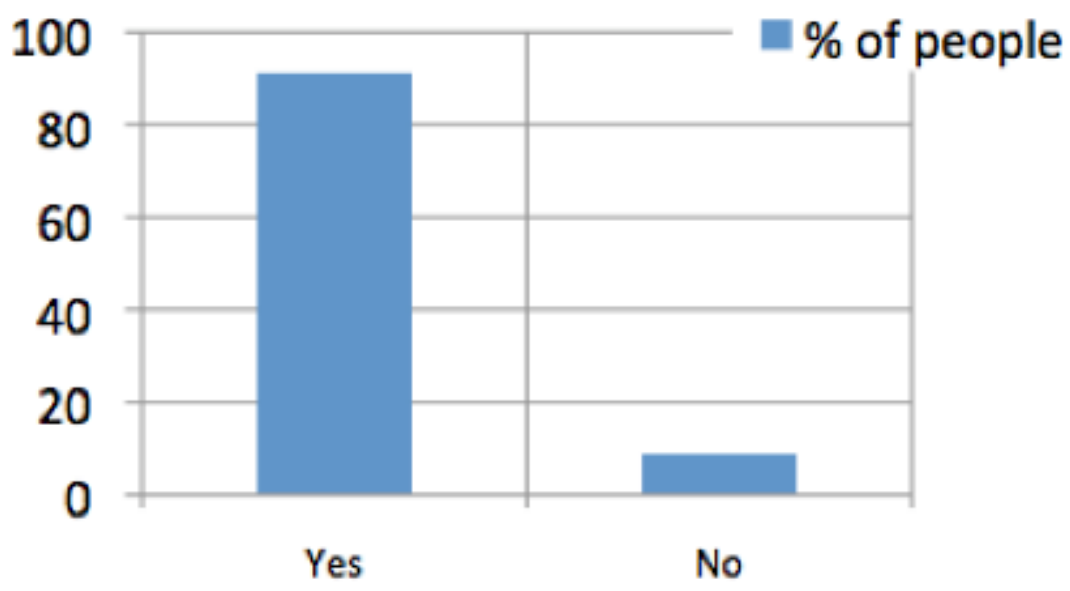

Figure 31. To wear C.O. This figure shows the results obtained on question 3.2 of the questionnaire. 


\section{Product Information \\ 3.3) Would you buy (C.O.) garments?}

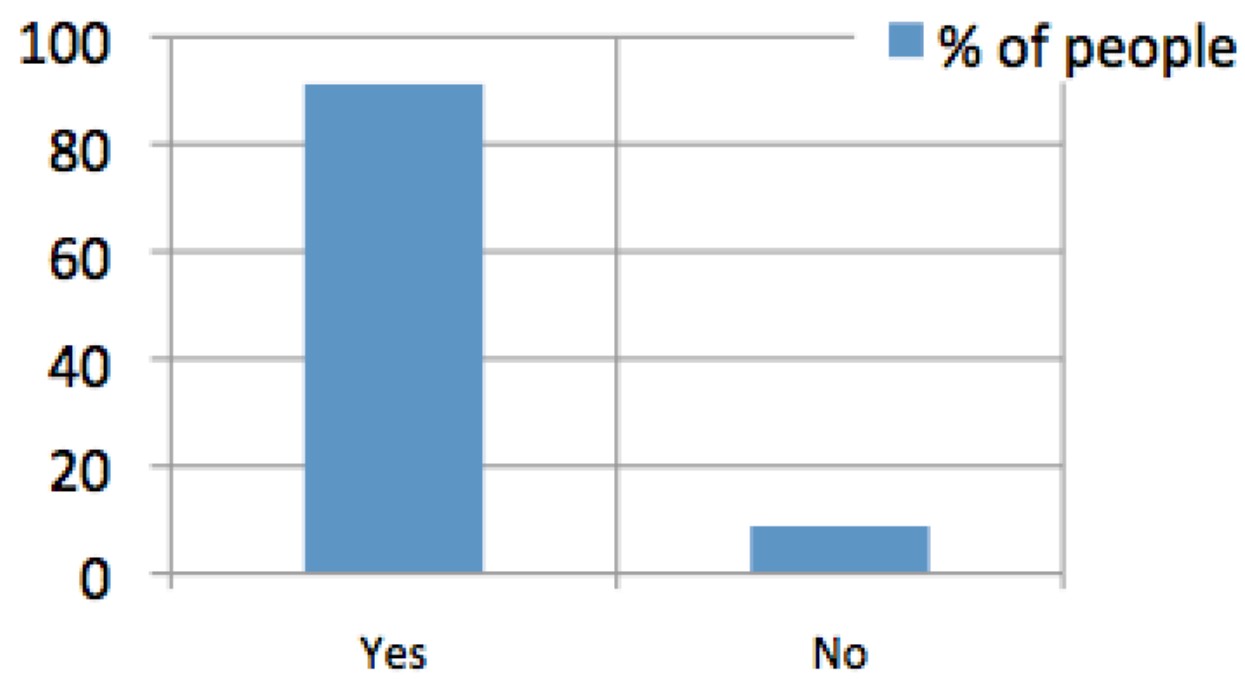

Figure 32. To buy C.O. This figure shows the results obtained on question 3.3 of the questionnaire. 


\section{Product Information}

\section{4) If your previous answer was yes, why would you buy them? (Choose one)}
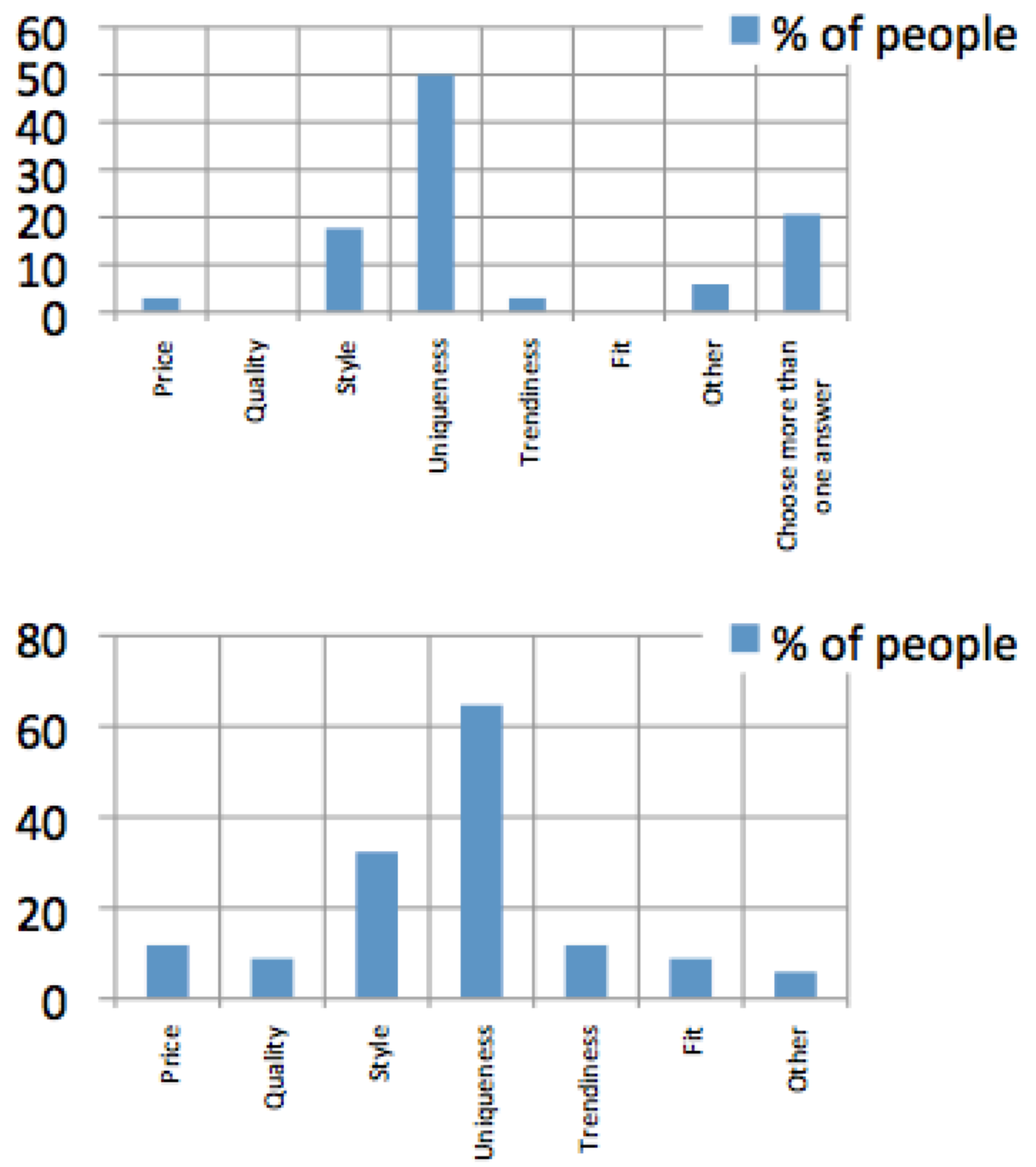

Figure 33. Reasons to buy C.O. This figure shows the results obtained on question 3.4 of the questionnaire. 


\section{5) If your previous answer was no please say why}

"Im not sure if I'd buy it or not generally, because there are only a few garments that fit my style out of all line"

"I would love to buy her garments, they are too high priced for me though"

"I am over 43 years ol, I am too old for these designs"

Figure 34. Reasons for not buying C.O. This figure shows the results obtained on question 3.5 of the questionnaire.

Product Information

3.6) How would you describe a customer of this brand?

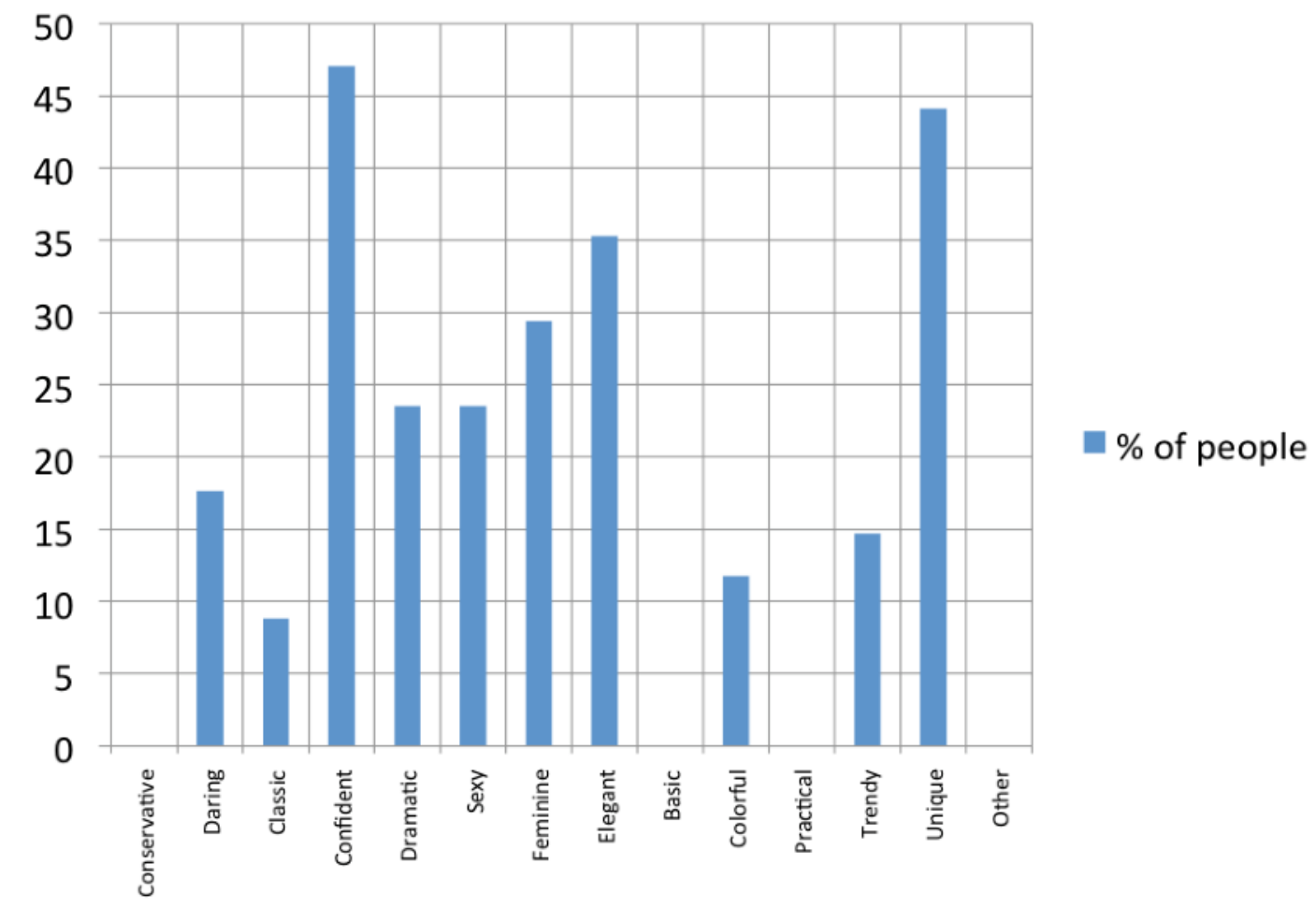

Figure 35. ConstanzaOquendo'scustomer description. This figure shows the results obtained on question 3.6 of the questionnaire. 


\section{Product Information}

3.7) Where in Toronto do you see these garments selling? (Choose one)
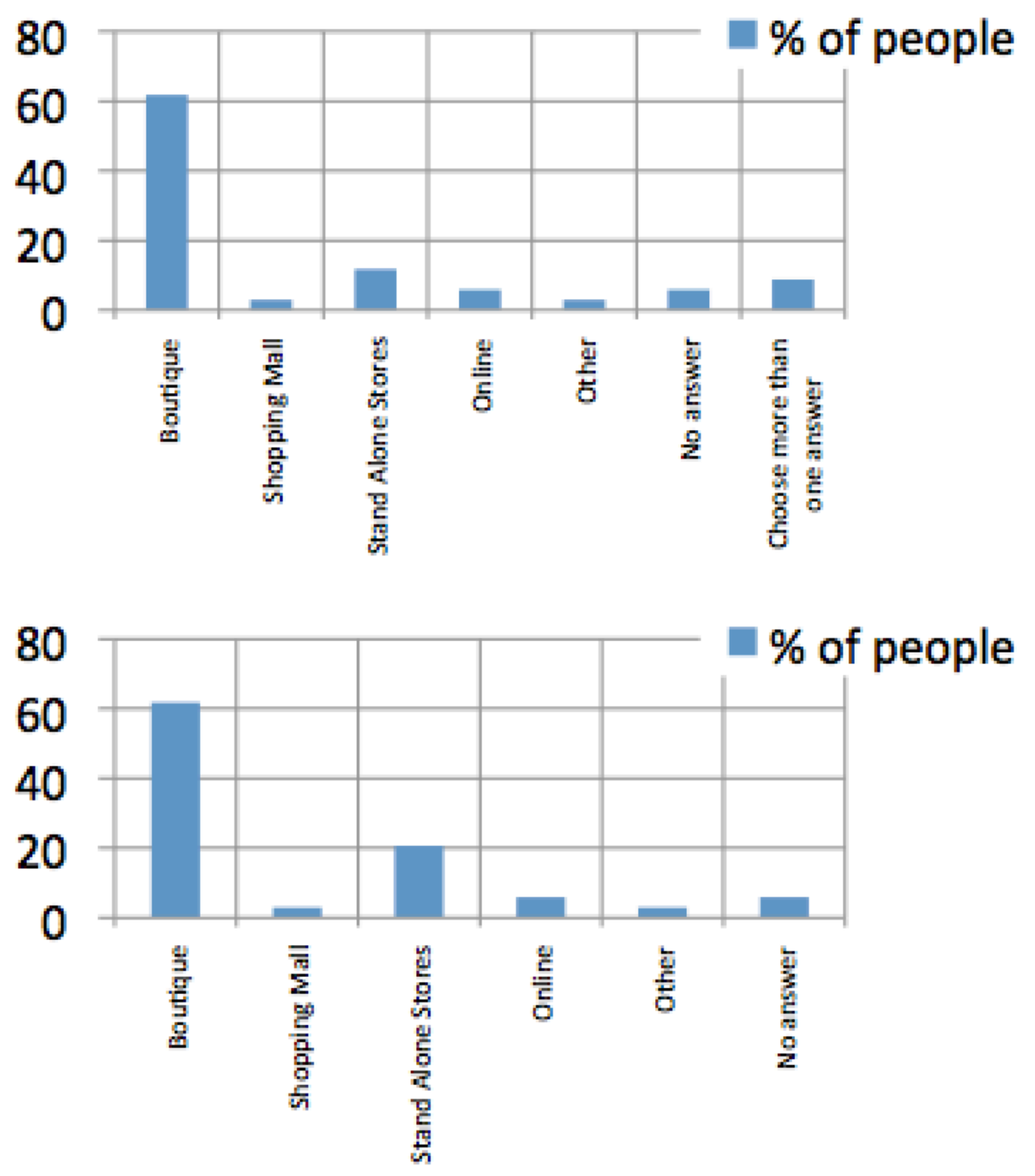

Figure 36. ConstanzaOquendo'sretailer. This figure shows the results obtained on question 3.7 of the questionnaire. 


\section{Product Information}

\section{8) If you believe they should be sold in}

boutiques, in what area in Toronto? (Choose one)
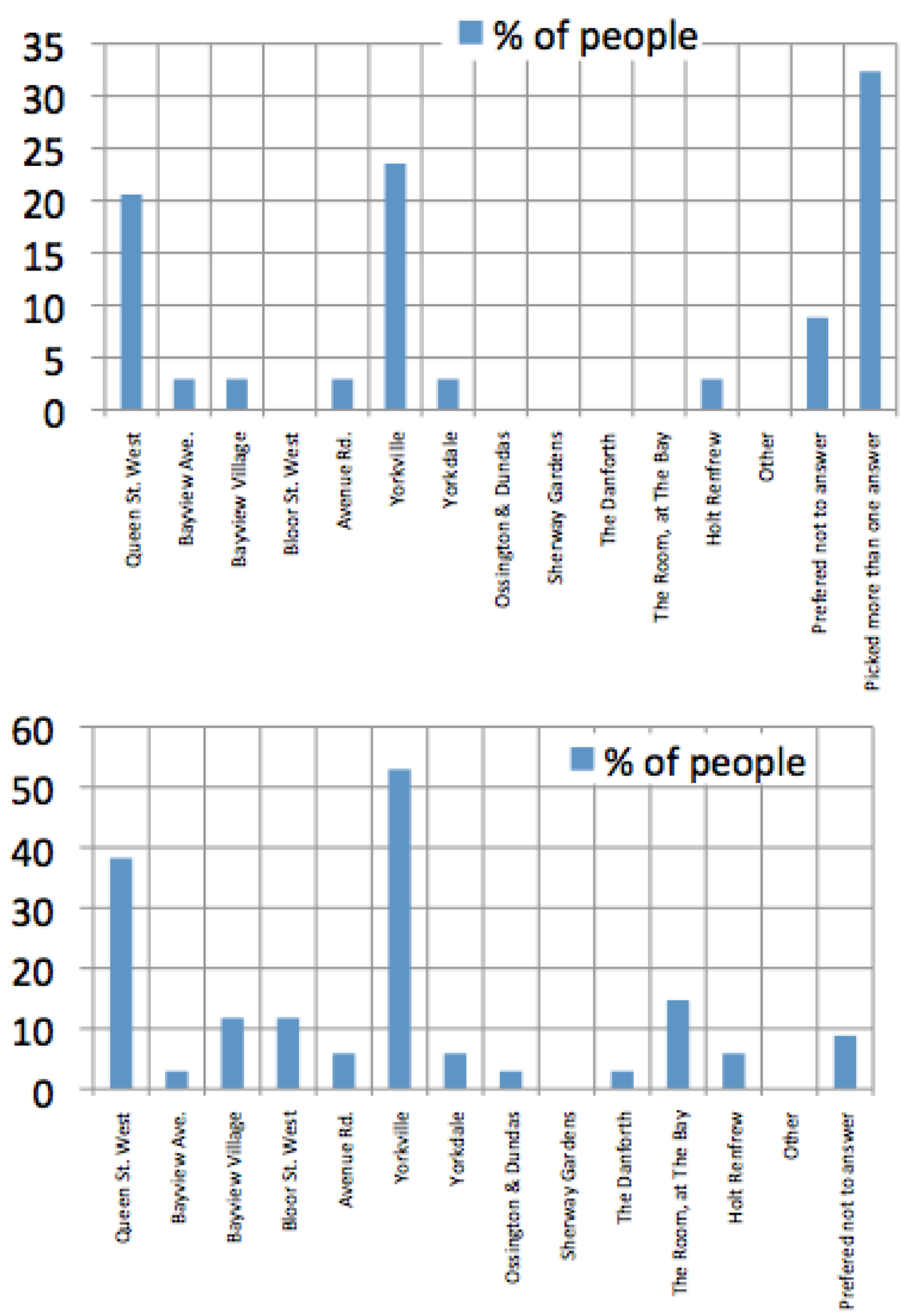

Figure 37. ConstanzaOquendo'sboutique location in Toronto. This figure shows the results obtained on question 3.7 of the questionnaire. 


\section{Product Information}

\section{9) What age range woman do you believe is the}

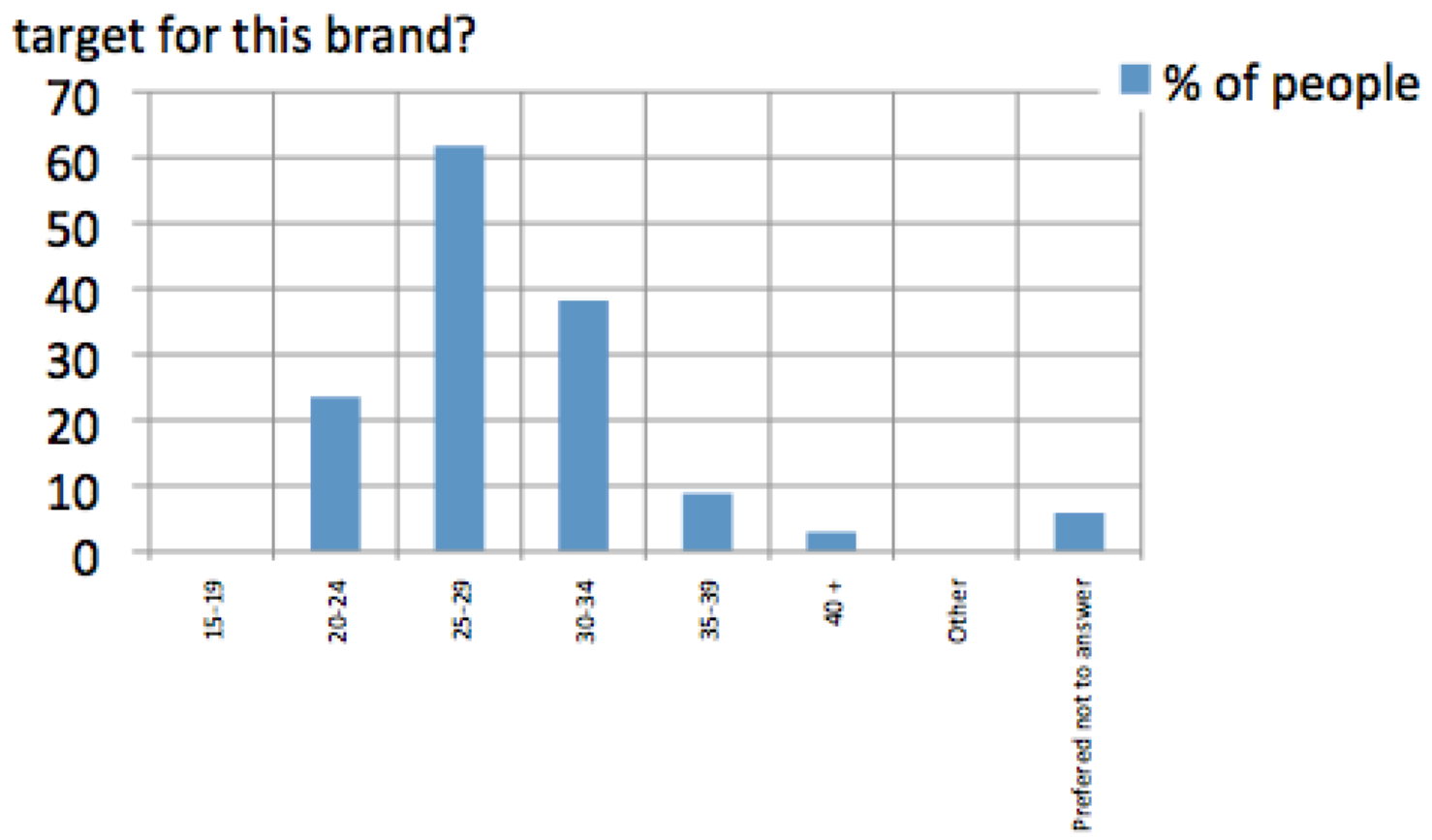

Figure 38. ConstanzaOquendo'starget age. This figure shows the results obtained on question 3.9 of the questionnaire. 


\section{References}

Arruda, M. C. (1997). Business ethics in Latin America. Journal of Business Ethics, 16(14), 1597-1603. doi:10.1023/A:1005823317019

Biography. (n.d.). Retrieved from http://www.constanzaoquendo.com

Brown, T. (2012, December 7). Here and there: Hispanic heritage in Toronto. Retrieved from http://heritagetoronto.org/here-and-there-hispanic-heritage-in-toronto/

Burns, N., \& Grove, S. K. (2010). Understanding nursing research: Building an evidence-based practice. Maryland Heights, MO: Elsevier Saunders.

City of Toronto. (2015). Toronto facts: Diversity. Retrieved from http://tiny.cc/aiaqxx

Cityfest Toronto. (2014). Community. Retrieved from http://cityfest.ca/2014/

Competition Bureau. (2000, September). Guide to the textile labelling and advertising regulations. Retrieved from http://www.competitionbureau.gc.ca/eic/site/cbbc.nsf/eng/01249.html

Competition Bureau. (2012, January 11). CA Identification Number. Retrievedfrom http://www.competitionbureau.gc.ca/eic/site/cb-bc.nsf/eng/h_02575.html

Competition Bureau. (2012, July 15). Textile labelling: Glossary. Retrieved from http://www.competitionbureau.gc.ca/eic/site/cb-bc.nsf/eng/01537.html

Conill. (2012). The Hispanic influence on Americanculture (Conill white paper). Retrieved from http://conill.com/thinking

Critchell, S. (2002, March 12). Exploring Latin fashion in the real world. Los Angeles Times. Retrievedfrom http://articles.latimes.com/2002/mar/12/news/lv-latinfashion12 
Foreign Affairs, Trade and Development Canada. (2013, December 18). Canada's Free Trade Agreements.Retrieved from http://www.international.gc.ca/trade-agreements-accordscommerciaux/agr-acc/fta-ale.aspx?lang=eng

Ginieniewicz, J., \&Schugurensky, D. (Eds.).(2006).Ruptures, continuities and re-learning: The political participation of Latin Americans in Canada. Toronto, ON: Transformative Learning Centre, OISE/UT.

Girard, M., \&Smith, M. (2013). Working in a regulated occupation in Canada: An immigrantnative born comparison.Journal of International Migration and Integration, 14(2), 219244.doi:10.1007/s12134-012-0237-5

Grosse, R., \&Mesquita, L. F. (Eds.). (2007). Can Latin American firms compete?Oxford, UK:Oxford University Press.

Jabareen, Y. (2009). Building a conceptual framework: Philosophy, definitions, and procedure. International Journal of Qualitative Methods, 8(4). Retrieved from http://ejournals.library.ualberta.ca/index.php/IJQM/article/view/6118/5892

Kaitlin. (2012, December 7). Fiesta Hispanica: From vision to reality. Retrieved from http://heritagetoronto.org/fiesta-hispanica-from-vision-to-reality/

Klopper, H. (2008). The qualitative research proposal. Curationis, 31(4), 62-72.

Ko, E., \&Megehee, C. M. (2012). Fashion marketing of luxury brands: Recent research issues and contributions. Journal of Business Research, 65(10), 13951398.doi:10.1016/j.jbusres.2011.10.004

Lockhart, J. (2014, October 4). History of Latin America. Encyclopcedia Britannica. Retrieved from http://www.britannica.com/EBchecked/topic/331694/history-of-Latin-America 
Maddeaux, S. (2014, July 17). Show us the money! Now Toronto. Retrievedfrom https://nowtoronto.com/lifestyle/features/show-us-the-money/

Meléndez, M. (1995). La vestimentacomoretórica de poder y símbolo de producción cultural en la Américameridional: de Colón a El lazarillo de ciegoscaminantes. Revista de EstudiosHispánicos, 29, 411-439.

Miedema, G., \& Brown, T. (2012, December 7). Toronto's heritage of diversity. Retrieved from http://heritagetoronto.org/torontos-heritage-of-diversity/

Myers, M. (1999). Investigating information systems with ethnographic research. Communications of the AIS, 2(4es), Article 1.Retrieved from www.qual.auckland.ac.nz/Myers\%20CAIS\%20article.pdf

Networking Worldwide. (n.d.). Latin fashion week. Retrievedfrom http://latinfashionweek.ca/fashionweek/

Pancrazio, J. J. (2004). The logic of fetishism: AlejoCarpentier and the Cuban tradition. Lewisburg, PA: Bucknell University Press.

Posner, H. (2011). Marketing fashion. London, UK: Laurence King.

Root, R. A. (2000). Tailoring the nation: Fashion writing in nineteenth-century Argentina. Fashion Theory: The Journal of Dress, Body \& Culture, 4(1), 89117.doi:10.2752/136270400779572037

Root, R. A. (2005). The Latin American fashion reader. Oxford, UK: Berg.

Ruiz, W. (2013, December 16). Latin Americans. The Canadian Encyclopedia. Retrieved from http://www.thecanadianencyclopedia.ca/en/article/latin-americans/ 
Schugurensky, D., \&Ginieniewicz, J. (2007, July 15). The Latin American community in Canada: Some challenges ahead. diálogos.Retrieved from http://dialogos.ca/2007/07/thelatin-american-community-in-canada-some-challenges-ahead/

Statistics Canada. (2007, August 16). The Latin American community in Canada. Retrieved from http://www.statcan.gc.ca/pub/89-621-x/89-621-x2007008-eng.htm\#1

Statistics Canada. (2014, February 26). Annual population estimates by census metropolitan area, July 1, 2013. Retrieved from http://www.statcan.gc.ca/dailyquotidien/140226/t140226b001-eng.htm

Tsalikis, J., Seaton, B., \& Shepherd, P. L. (2014). Business ethics index: Latin America. Journal of Business Ethics, 119(2), 209-218. doi:10.1007/s10551-012-1587-9

Valladares, M. (2013, June 12). Latin women's influence on fashion.eHow. Retrieved from http://www.ehow.com/info_12283097_latin-womens-influence-fashion.html

Veronis, L. (2010).Immigrant participation in the transnational era: Latin Americans' experiences with collective organising in Toronto. Journal of International Migration and Integration,11(2), 173-192.doi:10.1007/s12134-010-0133-9

White, R. M. (2002, January 17). Latin fashion comes to the museum at FIT. New York Amsterdam News, 93(3), p. 19.

Xposed Fashion Show. (n.d.). Fashion forward. Retrieved from http://www.xposedfashionshow.ca/

Youth Employment Services. (2013, January 1). Passion for fashion. Retrieved from http://www.yes.on.ca/passionforfashion/ 